\title{
Suzuki Coupling of Protected Aryl Diazonium lons: Expanding the Knowledge of Triazabutadiene Compatible Reactions
}

Abigail J. Shepard, Julia A. Townsend, Christopher Foley, Christopher Hulme ${ }^{1}$, Michael T. Marty ${ }^{2}$, John C. Jewett ${ }^{2 *}$

${ }^{1}$ Department of Pharmacology and Toxicology, University of Arizona, Tucson, Arizona 85721, United States

${ }^{2}$ Department of Chemistry and Biochemistry, University of Arizona, Tucson, Arizona, 85721 United States

`Email. jjewett@email.arizona.edu

\section{Supporting Information}

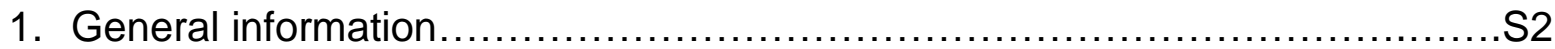

2. Synthetic procedures and compound characterization.......................... 3

3. Biochemical experiments and mass spectrometry ................................ 12

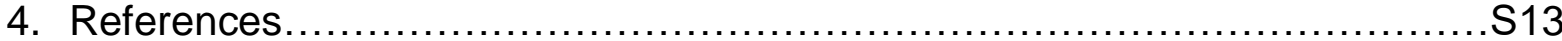

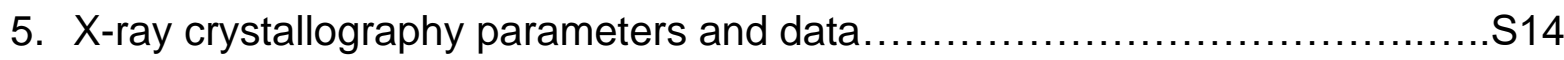

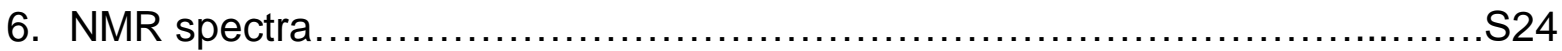




\section{General information}

Potassium tert-butoxide, tripotassium phosphate, phenylboronic acid, pyridine-4ylboronic acid, 4-aminophenylboronic acid hydrochloride, (4(methoxycarbonyl)phenyl)boronic acid, (4-((tert-butoxycarbonyl)amino)phenyl)boronic acid, $m$-tolylboronic acid, thiophen-2-ylboronic acid, benzo[d][1,3]dioxol-5-ylboronic acid, 1-methyl-4-(4,4,5,5-tetramethyl-1,3,2-dioxaborolan-2-yl)-1H-pyrazole, $p$-cresol, and listed solvents were purchased from commercial suppliers and used without further purification. The catalyst [1,1'-Bis(diphenylphosphino)ferrocene]dichloropalladium(II) complex with acetone, Pd 13.0-15.0\% used for Suzuki coupling was purchased from Alfa Aesar.

Decomposition and melting temperature were measured using a Stanford Research Systems OptiMelt MPA100 Melting Point Apparatus, as reported as $T_{d}=$ decomposition temperature and $T_{m}=$ melting temperature of decomposed triazabutadiene. NMR spectroscopy was performed on a Bruker AVIII-400 NMR Spectrometer or Bruker DRX500 , as specified. The residual solvent peaks for reference solvents in ${ }^{1} \mathrm{H}$ and ${ }^{13} \mathrm{C}$ NMR spectra were as follows: $7.26 \mathrm{ppm}$ and $77.05 \mathrm{ppm}$ for $\mathrm{CDCl}_{3}, 2.50$ for DMSO-d6. The spectra coupling is reported in hertz, chemical shifts are reported in ppm, and the abbreviations for multiplicities are reported as $s=$ singlet, $d=$ doublet, $t=$ triplet, $q=$ quartet, $\mathrm{p}=$ pentet, and $\mathrm{m}=$ multiplet. IR was recorded on a Thermo Fisher Scientific Nicolet IS50R FT-IR spectrometer which was equipped with an MCT-A detector, along with a germanium spectratech thunderdome ATR accessory. Signals for IR data are reported as $\mathrm{w}=$ weak, $\mathrm{br}=$ broad, and $\mathrm{s}=$ strong. High resolution mass spectra were recorded using a Bruker Solaris FT-ICR. The single crystal XRD measurements were performed at the XRD facility in the Department of Chemistry and Biochemistry of the University of Arizona, on a Bruker Kappa Apex II X-ray diffractometer. The molybdenum Ka X-ray source was used, and the measurement temperature was $100 \mathrm{~K}$. Native mass spectrometry was performed using a Q-Exactive HF quadrupole-mass spectrometer with Ultra-High Mass Range modifications (Thermo Fisher Scientific). 


\section{Synthetic procedures and compound characterization}

(E)-2-((4-bromophenyl)triaz-2-en-1-ylidene)-1,3-dimesityl-2,3-dihydro-1H-imidazole (1)

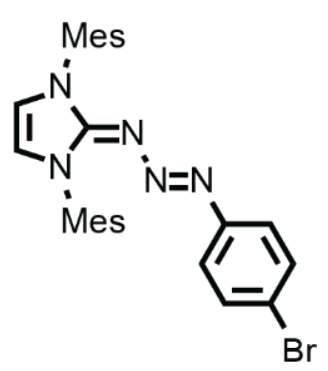

To a flame dried flask under argon charged with 1,3-dimesityl-1Himidazol-3-ium chloride ${ }^{1}$ ( $250 \mathrm{mg}, 0.73 \mathrm{mmol}, 1$ equiv) dissolved in a $1: 5$ mixture of dry acetonitrile:dry tetrahydrofuran $(18 \mathrm{~mL})$ was added 1-azido-4-bromobenzene ${ }^{2}$ (160 mg, $0.81 \mathrm{mmol}, 1.1$ equiv).

Potassium tert-butoxide ( $100 \mathrm{mg}, 0.92 \mathrm{mmol}, 1.25$ equiv) was added in one portion and the reaction was left to stir for 45 minutes at room temperature. Upon completion, the reaction mixture was filtered, and the solvent was removed under reduced pressure. The resulting solid was purified by flash chromatography on silica, using a $0-25 \%$ acetone/hexane gradient affording the target product as a yellow solid $\left(290 \mathrm{mg}, 79 \%, \mathrm{R}_{\mathrm{f}}=0.3 \mathrm{in} 25 \%\right.$

acetone/hexane on silica plate). Crystals suitable for $x$-ray diffraction were grown using the vapor diffusion method, with dichloromethane being the solvent and hexane the precipitant. Chambers were left undisturbed for five days at room temperature. Melting Point $\mathrm{T}_{\mathrm{d}}=188^{\circ} \mathrm{C}$ as determined by a color change from yellow solid to brown solid, $\mathrm{Tm}$ $=238^{\circ} \mathrm{C}$ as determined by melting of the brown solid. ${ }^{1} \mathrm{H} \mathrm{NMR}\left(400 \mathrm{MHz}, \mathrm{CDCl}_{3}\right) \delta$ $7.11(\mathrm{~d}, J=8.7 \mathrm{~Hz}, 2 \mathrm{H}), 6.99(\mathrm{~s}, 4 \mathrm{H}), 6.58(\mathrm{~s}, 2 \mathrm{H}), 6.41(\mathrm{~d}, \mathrm{~J}=8.7 \mathrm{~Hz}, 2 \mathrm{H}), 2.37(\mathrm{~s}, 6 \mathrm{H})$, $2.16(\mathrm{~s}, 12 \mathrm{H}) .{ }^{13} \mathrm{C} \mathrm{NMR}\left(100 \mathrm{MHz}, \mathrm{CDCl}_{3}\right) \delta 151.7,150.6,138.9,135.1,134.2,131.2$, 129.5, 123.0, 118.7, 117.1, 21.2, 18.1. IR (ATR) 1530 (m), 1492 (w), 1477 (w), 1364 $(\mathrm{m}), 1255(\mathrm{~s}), 1197(\mathrm{w}), 1178(\mathrm{~m}), 1156(\mathrm{~m}), 872(\mathrm{~m}), 732(\mathrm{~m})$. HRMS (ESI) m/z: [M+H] Calculated for $\mathrm{C}_{27} \mathrm{H}_{28} \mathrm{BrN} 5 \mathrm{H}$ 502.1607; Found 502.1601.

(Z)-2-((E)-(4-bromophenyl)triaz-2-en-1-ylidene)-1-mesityl-3-methyl-2,3-dihydro-1Himidazole (5)

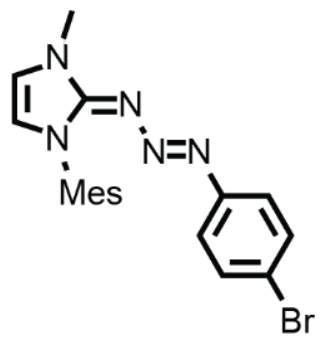

To a flame dried flask under argon charged with 1-mesityl-3-methyl$1 \mathrm{H}$-imidazol-3-ium iodide ${ }^{3}$ ( $250 \mathrm{mg}, 0.73 \mathrm{mmol}, 1$ equiv) dissolved in dry tetrahydrofuran $(20 \mathrm{~mL})$ was added 1-azido-4-bromobenzene ${ }^{2}$ (195 mg, $0.99 \mathrm{mmol}, 1.3$ equiv). Potassium tert-butoxide (100 mg, $0.92 \mathrm{mmol}, 1.25$ equiv) was added in one portion and the reaction was left to stir for two hours at room temperature. Upon completion, the reaction mixture was filtered, and the solvent was removed under reduced pressure. The resulting yellow oil was purified by flash chromatography on silica, using a $0-40 \%$ acetone/dichloromethane gradient affording the target product as a crystalline brown solid ( $252 \mathrm{mg}, 83 \%, \mathrm{R}_{\mathrm{f}}=0.3$ in $20 \%$ acetone/dichloromethane on silica plate). Crystals suitable for $\mathrm{x}$-ray diffraction were grown using the vapor diffusion method, with dichloromethane being the solvent and hexane the precipitant. Chambers were left undisturbed for five days at room temperature. Melting Point $T_{d}=162^{\circ} \mathrm{C}$ as determined by a color change from yellow solid to brown solid, $\mathrm{T}_{\mathrm{m}}=191^{\circ} \mathrm{C}$ as determined by melting of the brown solid. ${ }^{1} \mathrm{H}$ NMR $\left(400 \mathrm{MHz}, \mathrm{CDCl}_{3}\right) \delta 7.15(\mathrm{~d}, \mathrm{~J}=8.7$ $\mathrm{Hz}, 2 \mathrm{H}), 6.98(\mathrm{~s}, 2 \mathrm{H}), 6.70(\mathrm{~d}, \mathrm{~J}=2.4 \mathrm{~Hz}, 1 \mathrm{H}), 6.53-6.46(\mathrm{~m}, 2 \mathrm{H}), 6.34(\mathrm{~d}, \mathrm{~J}=2.4 \mathrm{~Hz}$, 
1H), $3.67(\mathrm{~s}, 3 \mathrm{H}), 2.40(\mathrm{~s}, 3 \mathrm{H}), 2.03(\mathrm{~s}, 6 \mathrm{H}) .{ }^{13} \mathrm{C} \mathrm{NMR}\left(100 \mathrm{MHz}, \mathrm{CDCl}_{3}\right) \delta$ 151.7, 150.7, 138.4, 135.9, 134.6, 131.2, 129.3, 122.9, 118.7, 116.7, 116.6, 33.4, 21.2, 18.1. IR (ATR) $1545(\mathrm{~s}), 1477(\mathrm{~m}), 1407(\mathrm{~m}), 1371(\mathrm{~s}), 1331(\mathrm{~m}), 1293(\mathrm{w}), 1262(\mathrm{~m}), 1181$ (m), 1153 (s), 832 (w), 738 (w). HRMS (ESI) m/z: [M+H] Calculated for $\mathrm{C}_{19} \mathrm{H}_{20} \mathrm{BrN}_{5} \mathrm{H}$ 398.0981; Found 398.0976.

(E)-2-((E)-(4-bromophenyl)triaz-2-en-1-ylidene)-1-(tert-butyl)-3-methyl-2,3-dihydro1H-imidazole (6)

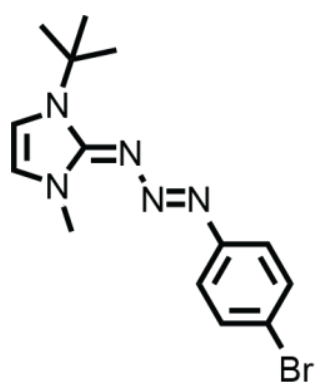

To a flame dried flask under argon charged with 1-(tert-butyl)-3methyl-1H-imidazol-3-ium iodide ${ }^{4}$ ( $266 \mathrm{mg}, 1 \mathrm{mmol}, 1$ equiv) dissolved in dry tetrahydrofuran $(17 \mathrm{~mL})$ was added 1-azido-4bromobenzene $^{2}$ (145 mg, $1.2 \mathrm{mmol}, 1.2$ equiv). Potassium tertbutoxide (145 mg, $1.3 \mathrm{mmol}, 1.3$ equiv) was added in one portion and the reaction was left to stir for two hours at room temperature. Upon completion, the reaction mixture was filtered, and the solvent was removed under reduced pressure. The resulting yellow oil was purified by flash chromatography on basic alumina, using a $0-3 \%$ methanol/dichloromethane gradient affording the target product as a yellow oil $(267 \mathrm{mg}$, $79 \%, R_{f}=0.3$ in $1 \%$ methanol/dichloromethane on basic alumina plate). Crystals suitable for x-ray diffraction were grown using the vapor diffusion method, with acetone being the solvent and hexane the precipitant. Chambers were left undisturbed for five days at room temperature. Melting Point $T_{d}=128^{\circ} \mathrm{C}$ as determined by a color change from yellow solid to brown solid, $\mathrm{T}_{\mathrm{m}}=139^{\circ} \mathrm{C}$ as determined by melting of the brown solid. ${ }^{1} \mathrm{H}$ NMR $\left(400 \mathrm{MHz}, \mathrm{CDCl}_{3}\right) \delta 7.49-7.32(\mathrm{~m}, 4 \mathrm{H}), 6.73(\mathrm{~s}, 1 \mathrm{H}), 6.39(\mathrm{~s}, 1 \mathrm{H}), 3.77$ (s, 3H), $1.70(\mathrm{~s}, 9 \mathrm{H}) . \quad(400 \mathrm{MHz}$, DMSO-d6) $\delta 7.49-7.43(\mathrm{~d}, 2 \mathrm{H}), 7.32-7.26$ (d, 2H), $7.12(\mathrm{~d}, \mathrm{~J}=2.6 \mathrm{~Hz}, 1 \mathrm{H}), 6.96(\mathrm{~d}, \mathrm{~J}=2.5 \mathrm{~Hz}, 1 \mathrm{H}), 3.73(\mathrm{~s}, 3 \mathrm{H}), 1.62(\mathrm{~s}, 9 \mathrm{H}) .{ }^{13} \mathrm{C}$ NMR $\left(100 \mathrm{MHz}, \mathrm{CDCl}_{3}\right) \delta 152.6,151.8,131.7,122.4,117.9,117.0,112.3,58.6,39.1,30.2$, 28.9. IR (ATR) $1527(\mathrm{~s}), 1478(\mathrm{~m}), 1408(\mathrm{~m}), 1361(\mathrm{~s}), 1281(\mathrm{w}), 1244(\mathrm{~s}), 1189(\mathrm{~s})$, 1153 (s), 833 (w). HRMS (ESI) m/z: [M+H] Calculated for $\mathrm{C}_{14} \mathrm{H}_{18} \mathrm{BrN}_{5} \mathrm{H} 336.0825$; Found 336.0817.

\section{General procedure A for Suzuki coupling}

To a flask loaded with 1, 5, or $\mathbf{6}$ (30 mg, 1 equiv), boronic acid (1.25 equiv), tripotassium phosphate (2.5 equiv), and [1,1'-Bis(diphenylphosphino)ferrocene]dichloropalladium(II) (0.11 equiv) was added $1 \mathrm{~mL}$ of a solution of dioxane:water (5:1). The set up was degassed with argon for 5 minutes, then heated to $95^{\circ} \mathrm{C}$ using an oil bath while maintaining an inert atmosphere with an argon balloon for one hour. Upon completion, the reaction mixture was diluted with dichloromethane and passed through a celite pad and further rinsed with dichloromethane. The product was purified using gravity column chromatography. 


\section{General procedure B for Suzuki coupling}

To a flask loaded with 1 (30 mg, 1 equiv), pinacol ester (1.25 equiv), tripotassium phosphate (2.5 equiv), and [1,1'-Bis(diphenylphosphino)ferrocene]dichloropalladium(II) (0.11 equiv) was added $1 \mathrm{~mL}$ of a solution of dioxane:water (5:1). The set up was degassed with argon for 5 minutes, then heated to $95^{\circ} \mathrm{C}$ using an oil bath while maintaining an inert atmosphere with an argon balloon for one hour. Upon completion, the reaction mixture was diluted with dichloromethane, passed through a celite pad and further rinsed with dichloromethane. The product was purified using gravity column chromatography.

\section{General procedure $\mathbf{C}$ for Suzuki coupling}

To a flask loaded with 5 or 6 (30 mg, 1 equiv), boronic acid (1.25 equiv), tripotassium phosphate (4.5 equiv), and [ $1,1^{\prime}$-Bis(diphenylphosphino)ferrocene]dichloropalladium(II) (0.11 equiv) was added $1 \mathrm{~mL}$ of a solution of dioxane:water (5:1). The set up was degassed with argon for 5 minutes, then heated to $95^{\circ} \mathrm{C}$ using an oil bath while maintaining an inert atmosphere with an argon balloon for one hour. Upon completion, the reaction mixture was diluted with dichloromethane, passed through a celite pad and further rinsed with dichloromethane. The product was purified using gravity column chromatography.

\section{A note on the purification of products using general procedures A-C for Suzuki coupling}

Suzuki coupled products $\mathbf{4 a - i}, \mathbf{7 a - b}$, and $\mathbf{8} \mathbf{a}-\mathbf{b}$ experience extensive degradation when subjected to silica and neutral alumina as the solid phase for column chromatography as made evident by TLC conditions, and the authors of this paper suggest the use of basic alumina for this class of compounds. The use of flash chromatography is also an unsuitable means for purification, and the authors of this paper suggest the use of gravity chromatography for flow rate control.

(E)-2-([1,1'-biphenyl]-4-yltriaz-2-en-1-ylidene)-1,3-dimesityl-2,3-dihydro-1Himidazole (4a)

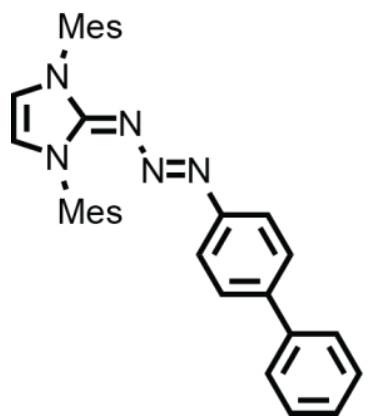

Starting with phenylboronic acid, following general procedure $\mathbf{A}$. Purified using gradient column chromatography on basic alumina, from $0-1 \%$ methanol/dichloromethane. Isolated product as a brown oil (27 mg, 90\%). Crystals suitable for x-ray diffraction were grown using the vapor diffusion method, with a 4:1 mixture of diethyl ether:methanol being the solvent and hexane the precipitant. Chambers were left undisturbed for five days at room temperature. ${ }^{1} \mathrm{H}$ NMR $\left(400 \mathrm{MHz}, \mathrm{CDCl}_{3}\right) \delta 7.55-7.51(\mathrm{~m}, 2 \mathrm{H})$, 7.40 (t, J=7.6 Hz, 2H), 7.30 (d, J= $7.4 \mathrm{~Hz}, 1 \mathrm{H}$ ), 7.26 (s, 2H), 7.01 (s, 4H), 6.65 (d, J=8.5 $\mathrm{Hz}, 2 \mathrm{H}), 6.58(\mathrm{~s}, 2 \mathrm{H}), 2.39(\mathrm{~s}, 6 \mathrm{H}), 2.20(\mathrm{~s}, 12 \mathrm{H}) .{ }^{13} \mathrm{C} \mathrm{NMR}\left(100 \mathrm{MHz}, \mathrm{CDCl}_{3}\right) \delta 151.7$, $150.8,141.3,138.7,138.2,135.2,134.3,129.4,128.7,126.9,121.8,117.0,21.2,18.1$. 
IR (ATR) 1533 (s), 1483 (w), 1415 (w), 1372 (s), 1254 (w), 1199 (w)m 1174 (m), 1152 (s), 1104 (w), 845 (w), $767(w), 734(m), 698(m)$. HRMS (ESI) m/z: [M+H] Calculated for $\mathrm{C}_{33} \mathrm{H}_{33} \mathrm{~N}_{5} \mathrm{H}$ 500.2815; Found 500.2804.

Starting with phenylboronic acid, following general procedure A, using $5 \mathrm{~mol} \%$ catalyst (2.7 mg, 0.05 equiv.). Purified using gradient column chromatography on basic alumina, from $0-1 \%$ methanol/dichloromethane. Isolated product as a brown oil (24 mg, $80 \%$ ). Compound characterization was with agreeance with the aforementioned spectra.

Starting with phenylboronic acid, following general procedure $\mathbf{A}$, using $1 \mathrm{~mol} \%$ catalyst ( $0.5 \mathrm{mg}, 0.01$ equiv.). Purified using gradient column chromatography on basic alumina, from $0-1 \%$ methanol/dichloromethane. Isolated product as a brown oil ( $28 \mathrm{mg}$, $93 \%$ ). Compound characterization was with agreeance with the aforementioned spectra.

(E)-2-((4-(benzo[d][1,3]dioxol-5-yl)phenyl)triaz-2-en-1-ylidene)-1,3-dimesityl-2,3dihydro-1H-imidazole (4b)

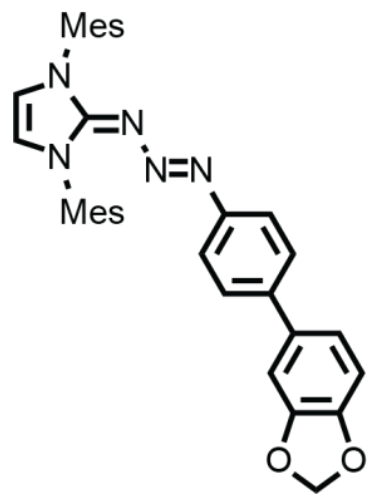

Starting with benzo[d][1,3]dioxol-5-ylboronic acid, following general procedure A. Purified using gradient column chromatography on basic alumina, from $0-1 \%$ methanol/dichloromethane. Isolated product as a brown oil $(24 \mathrm{mg}, 75 \%)$. ${ }^{1} \mathrm{H}$ NMR $\left(400 \mathrm{MHz}, \mathrm{CDCl}_{3}\right) \delta$ $7.18(\mathrm{~d}, J=8.6 \mathrm{~Hz}, 2 \mathrm{H}), 7.03-6.97(\mathrm{~m}, 6 \mathrm{H}), 6.85$ (d, $J=7.9 \mathrm{~Hz}$, $1 \mathrm{H}), 6.61(\mathrm{~d}, \mathrm{~J}=8.5 \mathrm{~Hz}, 2 \mathrm{H}), 6.58(\mathrm{~s}, 2 \mathrm{H}), 5.98(\mathrm{~s}, 2 \mathrm{H}), 2.38(\mathrm{~s}$, $6 \mathrm{H}), 2.19(\mathrm{~s}, 12 \mathrm{H}) .{ }^{13} \mathrm{C} \mathrm{NMR}\left(100 \mathrm{MHz}, \mathrm{CDCl}_{3}\right) \delta 151.7,150.5$, $148.1,146.8,138.7,138.0,135.8,135.2,134.3,129.4,126.6$, $121.8,120.3,117.0,108.6,107.4,101.1,21.2,18.1$. IR (ATR) $1534(\mathrm{~s}), 1478(\mathrm{~s}), 1442(\mathrm{w}), 1376(\mathrm{~s}), 1250(\mathrm{~m}), 1221(\mathrm{~m}), 1198$ (w), 1173 (s), 1104 (w) 1038 (w), 843 (w), 810 (w), 733 (w). HRMS (ESI) m/z: [M+H] Calculated for $\mathrm{C}_{34} \mathrm{H}_{33} \mathrm{~N}_{5} \mathrm{O}_{2} \mathrm{H}$ 544.2713; Found 544.2699.

Methyl (E)-4'-((1,3-dimesityl-1,3-dihydro-2H-imidazol-2-ylidene)triaz-1-en-1-yl)[1,1'-biphenyl]-4-carboxylate (4c)

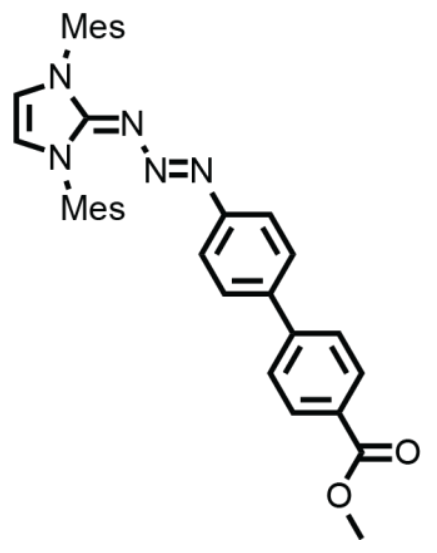

Starting with (4-(methoxycarbonyl)phenyl)boronic acid, following general procedure $\mathbf{A}$. Purified using gradient column chromatography on basic alumina, from $0-1 \%$ methanol/dichloromethane. Isolated product as a brown oil (28 mg, 85\%). ${ }^{1} \mathrm{H}$ NMR $\left(400 \mathrm{MHz}, \mathrm{CDCl}_{3}\right) \delta 8.08-8.04(\mathrm{~m}, 2 \mathrm{H})$, 7.59 (d, J= 8.4 Hz, 2H), 7.30 (d, J=8.5 Hz, 2H), $7.01(\mathrm{~s}, 4 \mathrm{H})$, $6.66(\mathrm{~d}, \mathrm{~J}=8.6 \mathrm{~Hz}, 2 \mathrm{H}), 6.60(\mathrm{~s}, 2 \mathrm{H}), 3.93(\mathrm{~s}, 3 \mathrm{H}), 2.38(\mathrm{~s}, 6 \mathrm{H})$, $2.19(\mathrm{~s}, 12 \mathrm{H}) .{ }^{13} \mathrm{C}$ NMR $\left(100 \mathrm{MHz}, \mathrm{CDCl}_{3}\right) \delta 167.2,151.7$, 151.6, 145.7, 138.8, 136.7, 135.2, 134.2, 130.1, 129.5, 128.4, 127.1, 126.6, 122.0, 117.1, 21.2, 18.1. IR (ATR) 1718 (s), 1529 (s), 1490 (w), $1428(w), 1372(\mathrm{~s}), 1280(\mathrm{~s}), 1255$ (m), 1175 (s), 
1152 (s), 1110 (m), 775 (w), 732 (w). HRMS (ESI) m/z: [M+H] Calculated for $\mathrm{C}_{35} \mathrm{H}_{35} \mathrm{~N}_{5} \mathrm{O}_{2} \mathrm{H}$ 558.2870; Found 558.2855.

Tert-butyl (E)-(4'-((1,3-dimesityl-1,3-dihydro-2H-imidazol-2-ylidene)triaz-1-en-1-yl)[1,1'-biphenyl]-4-yl)carbamate (4d)

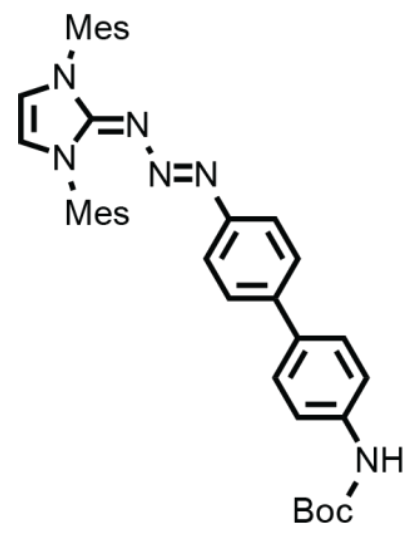

Starting with (4-((tert-butoxycarbonyl)amino)phenyl)boronic acid, following general procedure $\mathbf{A}$. Purified using gradient column chromatography on basic alumina, from $0-1 \%$ methanol/dichloromethane. Isolated as a brown oil $(28 \mathrm{mg}$, 76\%). ${ }^{1} \mathrm{H}$ NMR $\left(400 \mathrm{MHz}, \mathrm{CDCl}_{3}\right) \delta 7.45$ (d, J=8.6 Hz, 2H), 7.39 (d, J=8.5 Hz, 2H), $7.25-7.20(\mathrm{~m}, 2 \mathrm{H}), 7.00(\mathrm{~s}, 4 \mathrm{H}), 6.62(\mathrm{~d}, \mathrm{~J}=$ $8.5 \mathrm{~Hz}, 2 \mathrm{H}), 6.57(\mathrm{~s}, 2 \mathrm{H}), 2.37(\mathrm{~s}, 6 \mathrm{H}), 2.18(\mathrm{~s}, 12 \mathrm{H}), 1.54(\mathrm{~s}$, 9H). ${ }^{13} \mathrm{C}$ NMR $\left(100 \mathrm{MHz}, \mathrm{CDCl}_{3}\right) \delta 152.9,151.7,150.6,138.7$, $137.7,137.3,136.0,135.2,134.3,129.4,127.3,126.5,121.8$, 118.9, 116.9, 28.5, 21.2, 18.1. IR (ATR) $1715(\mathrm{w}), 1531$ (s), $1491(\mathrm{~m}), 1426(\mathrm{w}), 1376(\mathrm{~m}), 1304(\mathrm{w}), 1154(\mathrm{~s}), 1104(\mathrm{w}), 1055$

(w), $829(\mathrm{~m}), 738(\mathrm{~m}), 692(\mathrm{w})$. HRMS (ESI) m/z: $[\mathrm{M}+\mathrm{H}]$ Calculated for $\mathrm{C}_{38} \mathrm{H}_{42} \mathrm{~N}_{6} \mathrm{O}_{2} \mathrm{H}$ 615.3448; Found 615.3433.

(E)-1,3-dimesityl-2-((3'-methoxy-[1,1'-biphenyl]-4-yl)triaz-2-en-1-ylidene)-2,3dihydro-1H-imidazole (4e)

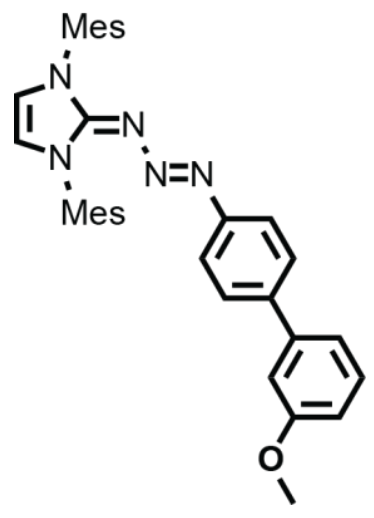

Starting with (3-methoxyphenyl)boronic acid, following general procedure A. Purified using gradient column chromatography on basic alumina, from $0-1 \%$ methanol/dichloromethane. Isolated as a brown oil $(26 \mathrm{mg}, 81 \%)$. ${ }^{1} \mathrm{H}$ NMR $\left(400 \mathrm{MHz}, \mathrm{CDCl}_{3}\right) \delta 7.31$ (d, J= $8.0 \mathrm{~Hz}, 1 \mathrm{H}), 7.26(\mathrm{~s}, 2 \mathrm{H}), 7.14-7.10(\mathrm{~m}, 1 \mathrm{H}), 7.07(\mathrm{t}, J=2.1 \mathrm{~Hz}$, $1 \mathrm{H}), 7.01$ (s, 4H), 6.85 (dd, J=8.0, $2.5 \mathrm{~Hz}, 1 \mathrm{H}), 6.64(\mathrm{~d}, J=8.5 \mathrm{~Hz}$, $2 \mathrm{H}), 6.58(\mathrm{~s}, 2 \mathrm{H}), 3.86(\mathrm{~s}, 3 \mathrm{H}), 2.38(\mathrm{~s}, 6 \mathrm{H}), 2.19(\mathrm{~s}, 12 \mathrm{H}) .{ }^{13} \mathrm{C}$ NMR $\left(100 \mathrm{MHz}, \mathrm{CDCl}_{3}\right) \delta 159.9,151.7,151.0,142.9,138.7,138.0$, 135.2, 134.3, 129.7, 129.4, 126.9, 121.8, 119.5, 117.0, 112.6, 112.3, 55.4, 21.2, 18.1. IR (ATR) 1533 (s), $1491(\mathrm{w}), 1461$ (w), 1375 (s), 1295 (w), 1199 (w), $1173(\mathrm{~m}), 1152$ (s), 1104 (w), 841 (w), 736 (w). HRMS (ESI) $\mathrm{m} / \mathrm{z}:[\mathrm{M}+\mathrm{H}]$ Calculated for $\mathrm{C}_{34} \mathrm{H}_{35} \mathrm{~N}_{5} \mathrm{OH} 530.2921$; Found 530.2958. 
(E)-1,3-dimesityl-2-((3'-methyl-[1,1'-biphenyl]-4-yl)triaz-2-en-1-ylidene)-2,3-dihydro1H-imidazole (4f)

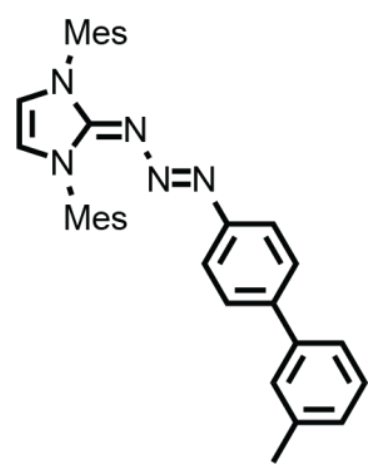

Starting with $\mathrm{m}$-tolylboronic acid, following general procedure $\mathbf{A}$. Isolated as a brown oil (27 mg, 87\%). Purified using gradient column chromatography on basic alumina, from $0-1 \%$ methanol/dichloromethane. ${ }^{1} \mathrm{H}$ NMR $\left(400 \mathrm{MHz}, \mathrm{CDCl}_{3}\right) \delta 7.33$ (dd, $J=7.4,1.6 \mathrm{~Hz}, 2 \mathrm{H}), 7.31-7.28(\mathrm{~m}, 1 \mathrm{H}), 7.26(\mathrm{~s}, 2 \mathrm{H}), 7.12(\mathrm{~d}, \mathrm{~J}=$ $7.1 \mathrm{~Hz}, 1 \mathrm{H}), 7.01(\mathrm{~s}, 4 \mathrm{H}), 6.66-6.62(\mathrm{~m}, 2 \mathrm{H}), 6.58(\mathrm{~s}, 2 \mathrm{H}), 2.41(\mathrm{~s}$, $3 \mathrm{H}), 2.38(\mathrm{~s}, 6 \mathrm{H}), 2.19(\mathrm{~s}, 12 \mathrm{H}) .{ }^{13} \mathrm{C}$ NMR $\left(100 \mathrm{MHz}, \mathrm{CDCl}_{3}\right) \delta$ 151.8, 150.8, 141.3, 138.7, 138.4, 138.2, 134.3, 129.4, 128.6, 127.7, 127.6, 126.9, 124.0, 121.8, 117.0, 21.7, 21.2, 18.1. IR (ATR) 1534 (s), 1491 (w), 1403 (w), 1375 (s), 1254 (w), 1199 (w), 1173 (m), $1152(\mathrm{~s})$, 1103 (w), $844(w), 786(w), 734(m), 699$ (w). HRMS (ESI) m/z: [M+H] Calculated for $\mathrm{C}_{34} \mathrm{H}_{35} \mathrm{~N}_{5} \mathrm{H}$ 514.2971; Found 514.2958.

(E)-4-(4-((1,3-dimesityl-1,3-dihydro-2H-imidazol-2-ylidene)triaz-1-en-1yl)phenyl)pyridine $(\mathbf{4 g})$

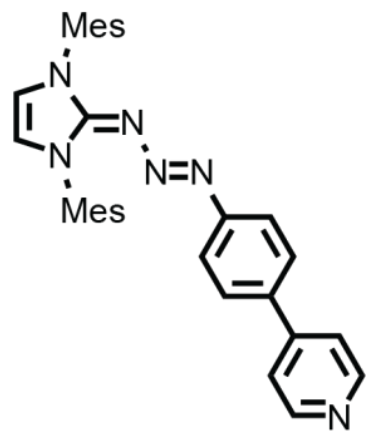

Starting with pyridin-4-ylboronic acid, following general procedure A. Purified using gradient column chromatography on basic alumina, from $0-1 \%$ methanol/dichloromethane. Isolated product as a brown oil (19 mg, 63\%). ${ }^{1} \mathrm{H}$ NMR $\left(400 \mathrm{MHz}, \mathrm{CDCl}_{3}\right) \delta 8.61-$ $8.56(\mathrm{~m}, 2 \mathrm{H}), 7.44-7.41(\mathrm{~m}, 2 \mathrm{H}), 7.31(\mathrm{~d}, \mathrm{~J}=8.6 \mathrm{~Hz}, 2 \mathrm{H}), 7.01(\mathrm{~s}$, $4 \mathrm{H}), 6.66(\mathrm{~d}, \mathrm{~J}=8.6 \mathrm{~Hz}, 2 \mathrm{H}), 6.61(\mathrm{~s}, 2 \mathrm{H}), 2.38(\mathrm{~s}, 6 \mathrm{H}), 2.18(\mathrm{~s}$, 12H). ${ }^{13} \mathrm{C}$ NMR $\left(100 \mathrm{MHz}, \mathrm{CDCl}_{3}\right) \delta 152.4,151.7,150.2,148.3$, 138.8, 135.1, 134.6, 134.2, 129.5, 126.8, 122.0, 121.2, 117.2, 77.5, 77.2, 76.8, 21.2, 18.1. IR (ATR) $1533(\mathrm{~m}), 1478(\mathrm{w}), 1377(\mathrm{~m})$, $1306(\mathrm{w}), 1250(\mathrm{~m}), 1199(\mathrm{~m}), 1176(\mathrm{~m}), 1154(\mathrm{~m}), 1105(\mathrm{w}), 1038(\mathrm{~m}), 810(\mathrm{w})$. HRMS (ESI) $\mathrm{m} / \mathrm{z}:[\mathrm{M}+\mathrm{H}]$ Calculated for $\mathrm{C}_{32} \mathrm{H}_{32} \mathrm{~N}_{6} \mathrm{H}$ 501.2767; Found 501.2755.

(E)-1,3-dimesityl-2-((4-(thiophen-2-yl)phenyl)triaz-2-en-1-ylidene)-2,3-dihydro-1Himidazole (4h)

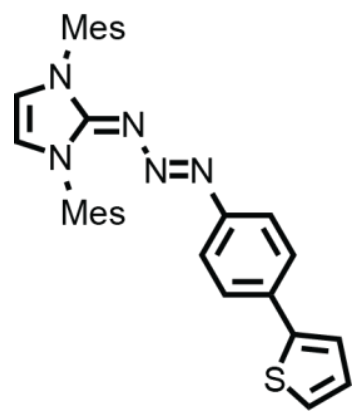

Starting with thiophen-2-ylboronic acid, following general procedure

A. Purified using gradient column chromatography on basic alumina, from $0-1 \%$ methanol/dichloromethane. Isolated as a brown oil (23 mg, 77\%). ' $1 \mathrm{H}$ NMR $\left(400 \mathrm{MHz}, \mathrm{CDCl}_{3}\right) \delta 7.30(\mathrm{~m}, 5 \mathrm{H})$, $7.02(\mathrm{~s}, 4 \mathrm{H}), 6.66-6.54(\mathrm{~m}, 4 \mathrm{H}), 2.39(\mathrm{~d}, \mathrm{~J}=5.3 \mathrm{~Hz}, 6 \mathrm{H}), 2.20$ (s, 12H). ${ }^{13} \mathrm{C}$ NMR $\left(100 \mathrm{MHz}, \mathrm{CDCl}_{3}\right) \delta 151.69,150.60,142.53$, $138.71,135.18,134.28,133.02,129.42,126.36,126.24,126.00$ $121.81,119.41,116.98,77.48,77.16,76.84,21.22,18.10$. IR (ATR) $2923(w), 1531(\mathrm{~s}), 1493(\mathrm{~m}), 1429(\mathrm{~m}), 1381(\mathrm{~s}), 1304(\mathrm{w}), 1253(\mathrm{w}), 1174(\mathrm{~m})$, 
$1153(\mathrm{~m}), 1087$ (w), 844 (w), 781 (w). HRMS (ESI) m/z: [M+H] Calculated for $\mathrm{C}_{31} \mathrm{H}_{31} \mathrm{~N}_{5} \mathrm{SH}$ 506.2379; Found 506.2366.

(E)-4-(4-((1,3-dimesityl-1,3-dihydro-2H-imidazol-2-ylidene)triaz-1-en-1-yl)phenyl)-1methyl-1H-pyrazole (4i)

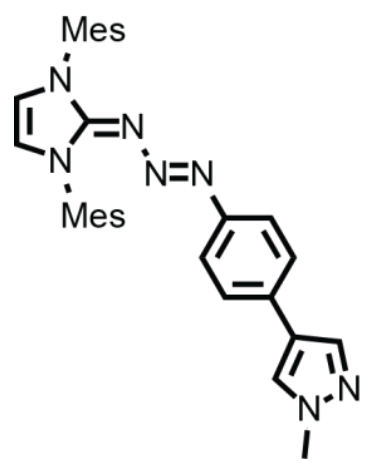

Starting with 1-methyl-4-(4,4,5,5-tetramethyl-1,3,2-dioxaborolan-2yl)-1H-pyrazole, following general procedure B. Purified using gradient column chromatography on basic alumina, from $0-1 \%$ methanol/dichloromethane. Isolated as a brown oil $(25 \mathrm{mg}, 83 \%)$.

${ }^{1} \mathrm{H}$ NMR $\left(400 \mathrm{MHz}, \mathrm{CDCl}_{3}\right) \delta 7.66(\mathrm{~s}, 1 \mathrm{H}), 7.50(\mathrm{~s}, 1 \mathrm{H}), 7.14-7.09$ $(\mathrm{m}, 2 \mathrm{H}), 7.00(\mathrm{~s}, 4 \mathrm{H}), 6.57(\mathrm{~s}, 4 \mathrm{H}), 3.91(\mathrm{~s}, 3 \mathrm{H}), 2.37(\mathrm{~s}, 6 \mathrm{H}), 2.17$ $(\mathrm{s}, 12 \mathrm{H}) .{ }^{13} \mathrm{C}$ NMR $\left(100 \mathrm{MHz}, \mathrm{CDCl}_{3}\right) \delta 151.7,150.0,138.7,136.7$, 135.2, 134.3, 129.8, 129.4, 126.6, 125.3, 123.5, 121.9, 116.9, 39.2, 21.2, 18.1. IR (ATR) $1532(\mathrm{~s}), 1492(\mathrm{w}), 1434(\mathrm{w}), 1385(\mathrm{~m}), 1254$

(w), $1174(m), 1123(m), 1101(w), 954(w), 840(w)$. HRMS (ESI) m/z: [M+H] Calculated for $\mathrm{C}_{31} \mathrm{H}_{33} \mathrm{~N}_{7} \mathrm{H}$ 504.2876; Found 504.286.

(Z)-2-((E)-[1,1'-biphenyl]-4-yltriaz-2-en-1-ylidene)-1-mesityl-3-methyl-2,3-dihydro1H-imidazole (7a)

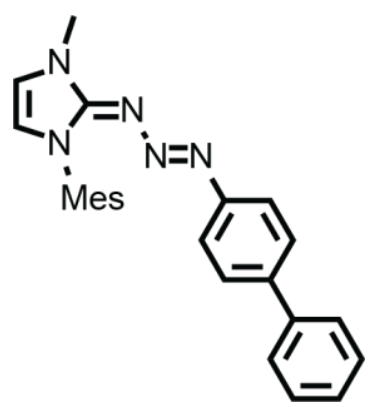

Starting with phenylboronic acid, following general procedure $\mathbf{A}$. Purified using gradient column chromatography on basic alumina, from $0-1 \%$ methanol/dichloromethane. Isolated product as a brown oil (20 mg, 67\%). Crystals suitable for x-ray diffraction were grown using the vapor diffusion method, with a methanol being the solvent and hexane the precipitant. Chambers were left undisturbed for five days at room temperature. ${ }^{1} \mathrm{H}$ NMR $(400 \mathrm{MHz}$, $\mathrm{CDCl} 3) \delta 7.55-7.52(\mathrm{~m}, 2 \mathrm{H}), 7.40(\mathrm{t}, \mathrm{J}=7.7 \mathrm{~Hz}, 2 \mathrm{H}), 7.32-7.28$

(m, 3H), $7.01(\mathrm{~s}, 2 \mathrm{H}), 6.74(\mathrm{~d}, J=8.5 \mathrm{~Hz}, 2 \mathrm{H}), 6.68(\mathrm{~d}, J=2.4 \mathrm{~Hz}, 1 \mathrm{H}), 6.33(\mathrm{~d}, J=2.4$ $\mathrm{Hz}, 1 \mathrm{H}), 3.68(\mathrm{~s}, 3 \mathrm{H}), 2.41$ (s, 3H), 2.07 (s, 6H). ${ }^{13} \mathrm{C} \mathrm{NMR} \mathrm{(100} \mathrm{MHz,} \mathrm{CDCl} 3$ ) $\delta 141.3$, 138.4, 138.3, 136.0, 134.7, 131.2, 129.4, 128.8, 127.0, 126.9, 122.9, 121.8, 116.6, 116.5, 33.4, 21.2, 18.1. IR (ATR) $1532(\mathrm{~s}), 1492(\mathrm{w}), 1434(\mathrm{w}), 1385(\mathrm{~m}), 1254(\mathrm{w})$, $1174(\mathrm{~m}), 1123(\mathrm{~m}), 1101(\mathrm{w}), 954(\mathrm{w}), 840(\mathrm{w})$. HRMS (ESI) m/z: [M+H] Calculated for $\mathrm{C}_{25} \mathrm{H}_{25} \mathrm{~N}_{5} \mathrm{H}$ 396.2189; Found 396.2185. 
4'-((E)-((Z)-1-mesityl-3-methyl-1,3-dihydro-2H-imidazol-2-ylidene)triaz-1-en-1-yl)[1,1'-biphenyl]-4-amine (7b)

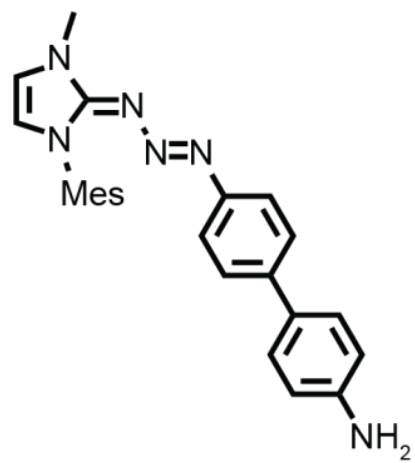

Starting with 4-aminophenyl boronic acid hydrochloride, following general procedure $\mathbf{C}$. Purified using gradient column chromatography on basic alumina, from $0-1 \%$ methanol/dichloromethane. Isolated product as a brown oil (22 $\mathrm{mg}, 85 \%)$. ${ }^{1} \mathrm{H}$ NMR $\left(400 \mathrm{MHz}, \mathrm{CDCl}_{3}\right) \delta 7.35(\mathrm{~d}, \mathrm{~J}=8.0 \mathrm{~Hz}, 2 \mathrm{H})$, $7.24(\mathrm{~d}, \mathrm{~J}=9.2 \mathrm{~Hz}, 2 \mathrm{H}), 7.00(\mathrm{~s}, 2 \mathrm{H}), 6.81-6.63(\mathrm{~m}, 5 \mathrm{H}), 6.33$ $(\mathrm{s}, 1 \mathrm{H}), 3.68(\mathrm{~s}, 3 \mathrm{H}), 2.41(\mathrm{~s}, 3 \mathrm{H}), 2.06(\mathrm{~s}, 6 \mathrm{H}) .{ }^{13} \mathrm{C}$ NMR $(100$ $\left.\mathrm{MHz}, \mathrm{CDCl}_{3}\right) \delta 151.7,149.9,145.6,138.4,138.3,136.0,134.7$, $131.7,129.3,128.7,128.1,127.8,126.5,126.2,121.7,116.6$, 116.4, 115.5, 33.4, 21.2, 18.1. IR (ATR) 3325 (br), 1611 (m), 1547 (s), 1489 (s), 1379 $(\mathrm{m}), 1300(\mathrm{w}), 1262(\mathrm{~m}), 1180(\mathrm{~m}), 1158(\mathrm{~m}), 830(\mathrm{w})$. HRMS (ESI) m/z: [M+H] Calculated for $\mathrm{C}_{25} \mathrm{H}_{26} \mathrm{~N}_{6} \mathrm{H}$ 411.2298; Found 411.2299.

(E)-2-((E)-[1,1'-biphenyl]-4-yltriaz-2-en-1-ylidene)-1-(tert-butyl)-3-methyl-2,3dihydro-1H-imidazole (8a)

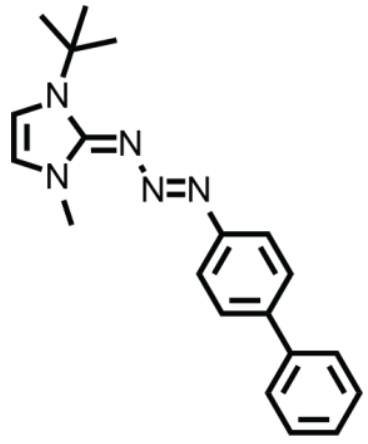

Starting with phenylboronic acid, following general procedure $\mathbf{A}$. Purified using gradient column chromatography on basic alumina, from $0-1 \%$ methanol/dichloromethane. Isolated product as a brown oil (18 mg, 60\%). ${ }^{1} \mathrm{H}$ NMR $\left(400 \mathrm{MHz}, \mathrm{CDCl}_{3}\right) \delta 7.64-7.54$ $(\mathrm{m}, 6 \mathrm{H}), 7.42(\mathrm{t}, \mathrm{J}=7.7 \mathrm{~Hz}, 2 \mathrm{H}), 7.33-7.27(\mathrm{t}, 1 \mathrm{H}), 6.73(\mathrm{~d}, \mathrm{~J}=2.6$ $\mathrm{Hz}, 1 \mathrm{H}), 6.39(\mathrm{~d}, \mathrm{~J}=2.6 \mathrm{~Hz}, 1 \mathrm{H}), 3.83(\mathrm{~s}, 3 \mathrm{H}), 1.72(\mathrm{~s}, 9 \mathrm{H})$. (400 $\mathrm{MHz}, \mathrm{DMSO}-\mathrm{d} 6) \delta 7.64$ (dd, J = 14.7, $7.8 \mathrm{~Hz}, 3 \mathrm{H}), 7.44$ (dq, J = 8.9, 3.6, 3.0 Hz, 4H), $7.34-7.26(\mathrm{~m}, 1 \mathrm{H}), 7.10(\mathrm{~d}, \mathrm{~J}=2.9 \mathrm{~Hz}, 1 \mathrm{H})$, $6.94(\mathrm{~d}, \mathrm{~J}=2.6 \mathrm{~Hz}, 1 \mathrm{H}), 3.74(\mathrm{~d}, \mathrm{~J}=19.4 \mathrm{~Hz}, 3 \mathrm{H}), 1.62(\mathrm{~d}, \mathrm{~J}=7.2$ $\mathrm{Hz}, 9 \mathrm{H}) .{ }^{13} \mathrm{C}$ NMR $\left(100 \mathrm{MHz}, \mathrm{CDCl}_{3}\right) \delta 152.8,151.9,141.2,137.8,128.8,127.5,126.9$, 121.3, 117.0, 112.3, 58.4, 39.3, 29.0. IR (ATR) 1531 (s), $1482(\mathrm{w}), 1412(\mathrm{w}), 1372(\mathrm{~m})$, 1280 (s), 1244 (w), 1193 (w), 1153 (s), 845 (w), 767 (w). HRMS (ESI) m/z: [M+H] Calculated for $\mathrm{C}_{20} \mathrm{H}_{23} \mathrm{~N}_{5} \mathrm{H}$ 334.2032; Found 334.2024.

4'-((E)-((E)-1-(tert-butyl)-3-methyl-1,3-dihydro-2H-imidazol-2-ylidene)triaz-1-en-1yl)-[1,1'-biphenyl]-4-amine (8b)

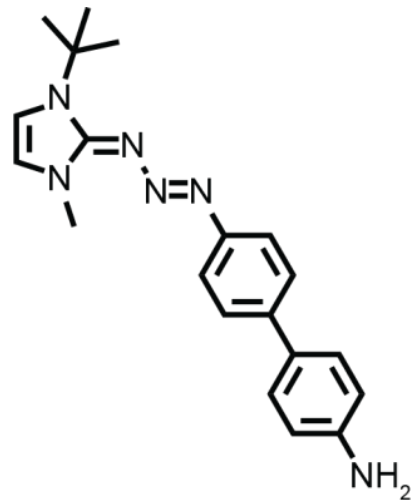

Starting with 4-aminophenyl boronic acid hydrochloride, following general procedure $\mathbf{C}$. Purified using gradient column chromatography on basic alumina, from $0-1 \%$ methanol/dichloromethane. Isolated products as a brown oil (18 mg, 56\%). ${ }^{1} \mathrm{H}$ NMR $\left(400 \mathrm{MHz}, \mathrm{CDCl}_{3}\right) \delta 7.60-7.37(\mathrm{~m}, 6 \mathrm{H})$, $6.77-6.70(\mathrm{~m}, 5 \mathrm{H}), 6.37(\mathrm{~d}, \mathrm{~J}=2.6 \mathrm{~Hz}, 1 \mathrm{H}), 3.82(\mathrm{~s}, 3 \mathrm{H}), 1.72$ (s, 9H). ${ }^{13} \mathrm{C} \mathrm{NMR}\left(100 \mathrm{MHz}, \mathrm{CDCl}_{3}\right) \delta 152.8,150.9,141.3$, 137.9, 128.8, 127.7, 126.7, 126.3, 121.2, 116.9, 112.2, 58.5, 39.3, 29.0. IR (ATR) 3365 (br), 1612 (m), 1527 (s), 1411 (w), 
$1373(\mathrm{~m}), 1243$ (w), 1193 (s), 1157 (s), 824 (m), 765 (w), 735 (m). HRMS (ESI) m/z: $[\mathrm{M}+\mathrm{H}]$ Calculated for $\mathrm{C}_{20} \mathrm{H}_{24} \mathrm{~N}_{6} \mathrm{H} 349.2141$; Found 349.2139.

(E)-2-([1,1'-biphenyl]-4-yldiazenyl)-4-methylphenol (9)

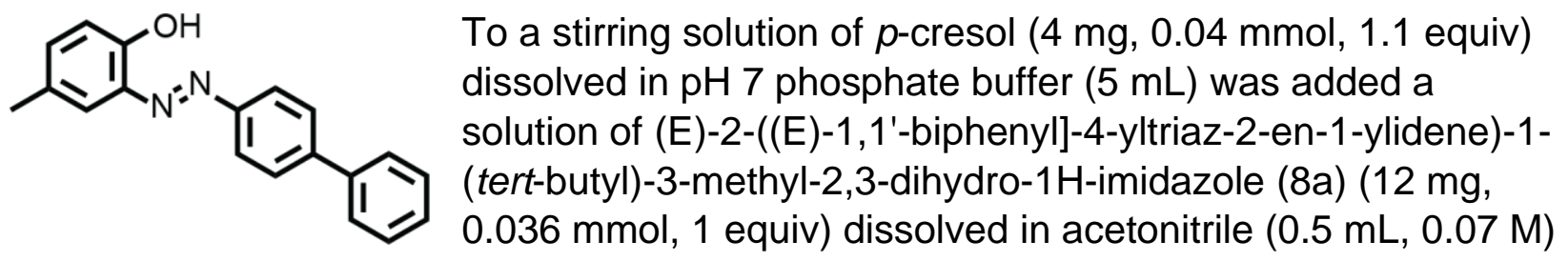
dropwise. The reaction was left to stir for 4 hours under an argon atmosphere. Upon completion, the mixture was diluted with $15 \mathrm{~mL}$ of water and washed with dichloromethane $(2 \times 20 \mathrm{~mL})$. The organic layers were pooled and washed with brine (2 $x 40 \mathrm{~mL}$ ), dried over sodium sulfate, and the solvent was removed under reduced pressure. The product was purified by flash chromatography on silica gel, with a gradient run from $0-25 \%$ acetone/hexane. The fractions containing the target product were collected and the solvent was removed under reduced pressure. The resulting oil was washed with acetonitrile, filtered, and the solvent was removed under reduced pressure. The orange solid was washed with acetonitrile, filtered, and the solvent was removed under reduced pressure affording the target product as an orange solid $(6 \mathrm{mg}$, $60 \%, \mathrm{R}_{\mathrm{f}}=0.4$ in $100 \%$ hexane on silica plate). ${ }^{1} \mathrm{H}$ NMR $\left(400 \mathrm{MHz}, \mathrm{CDCl}_{3}\right) \delta 12.75$ (s, $1 \mathrm{H}), 7.98-7.90(\mathrm{~m}, 2 \mathrm{H}), 7.78-7.72(\mathrm{~m}, 3 \mathrm{H}), 7.67(\mathrm{dd}, \mathrm{J}=7.4,1.8 \mathrm{~Hz}, 2 \mathrm{H}), 7.48(\mathrm{t}, \mathrm{J}=$ $7.5 \mathrm{~Hz}, 2 \mathrm{H}), 7.40(\mathrm{t}, \mathrm{J}=7.3 \mathrm{~Hz}, 1 \mathrm{H}), 7.17(\mathrm{dd}, \mathrm{J}=8.3,2.3 \mathrm{~Hz}, 1 \mathrm{H}), 6.95(\mathrm{~d}, \mathrm{~J}=8.4 \mathrm{~Hz}$, $1 \mathrm{H}), 2.41(\mathrm{~s}, 3 \mathrm{H}) .{ }^{13} \mathrm{C}$ NMR $\left(100 \mathrm{MHz}, \mathrm{CDCl}_{3}\right) \delta 150.70,149.92,143.96,140.12$, 137.34, 134.40, 133.09, 129.38, 129.09, 128.17, 127.31, 122.83, 118.01, 77.48, 77.16, 76.84, 20.48. IR (ATR) 3453 (br), 2979 (w), 1265 (m), 840 (w), 780 (w), 757 (w), 739 (s), 713 (w), 689 (w). HRMS (ESI) m/z: [M+H] Calculated for $\mathrm{C}_{19} \mathrm{H}_{16} \mathrm{~N}_{2} \mathrm{OH} 289.1342$; Found 289.1334. 


\section{Protein labeling and native mass spectrometry}

\section{Protein expression and purification}

Membrane scaffold protein MSP1D1T2(-) was expressed and purified as previously described. ${ }^{5}$

\section{Protein labeling and native mass spectrometry analysis}

A stock solution of $\mathbf{8 a}(30 \mathrm{mM})$ was prepared prior to protein loading. To an eppendorf containing pH 9 borate buffer $(163.3 \mu \mathrm{L}, 100 \mathrm{mM})$ was added MSP1D1T2(-) $(33.33 \mu \mathrm{L}$, $150 \mu \mathrm{M}$ in $0.2 \mathrm{M}$ ammonium acetate) followed by $3.33 \mu \mathrm{L}$ of stock $8 \mathrm{a}$, bringing the total volume to $200 \mu \mathrm{L}$ and diluting the final protein concentration to $25 \mu \mathrm{M}$. The protein mixture was left to incubate for 28 hours at room temperature. Protein samples were buffer exchanged twice into $0.2 \mathrm{M}$ ammonium acetate $(\mathrm{pH} 6.8)$ to a final concentration of $50 \mu \mathrm{M}$. The samples were analyzed using $1100 \mathrm{~V}$ of spray voltage, $50 \mathrm{~V}$ source voltage, $50 \mathrm{~V}$ collision energy, and the trapping gas was set to 3 . The $\mathrm{m} / \mathrm{z}$ range for all samples was 1,500-15,000 and a resolution setting of 15,000. Data was analyzed using UniDec. ${ }^{6}$
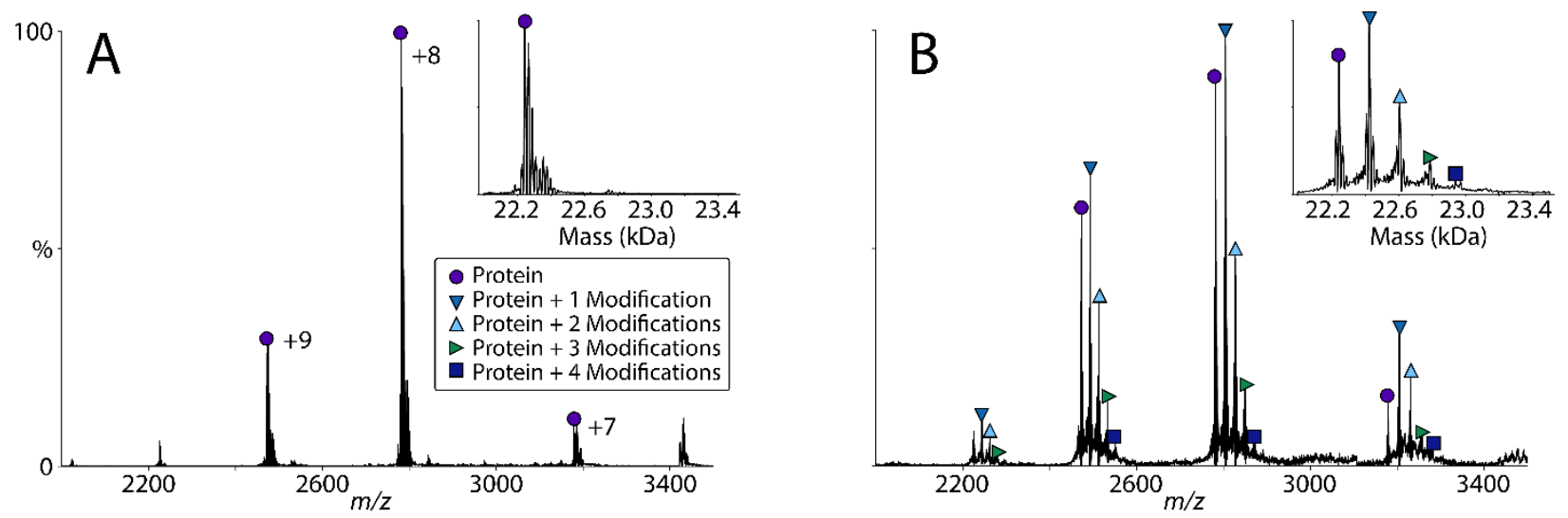

Figure S1. (A) Native mass spectrum of protein MSP1D1T2(-) shows the monomeric protein (purple circle) with no modifications. (B) Following chemical modification, new peaks are seen at with $1 \times 181 \mathrm{Da}$ (blue down triangle), $2 \times 181 \mathrm{Da}$ (light blue up triangle), $3 \times 181 \mathrm{Da}$ (green right triangle), and $4 \times 181$ Da modifications (dark blue square). Insets show the deconvolved mass distribution for the corresponding mass spectra. 


\section{References}

(1) Hintermann, L. Expedient Syntheses of the N-Heterocyclic Carbene Precursor Imidazolium Salts IPr. HCl, IMes. $\mathrm{HCl}$ and IXy. HCl. Beilstein J. Org. Chem. 2007, 3, 2-6.

(2) Kwok, S. W.; Fotsing, J. R.; Fraser, R. J.; Rodionov, V. O.; Fokin, V. V. TransitionMetal-Free Catalytic Synthesis of 1,5-Diaryl-1,2,3-Triazoles. Org. Lett. 2010, 12 (19), 4217-4219.

(3) Kaliner, M.; Strassner, T. Tunable Aryl Alkyl lonic Liquids with Weakly Coordinating Bulky Borate Anion. Tetrahedron Lett. 2016, 57 (31), 3453-3456.

(4) Levens, A.; An, F.; Breugst, M.; Mayr, H.; Lupton, D. W. Influence of the NSubstituents on the Nucleophilicity and Lewis Basicity of N-Heterocyclic Carbenes. Org. Lett. 2016, 18 (15), 3566-3569.

(5) Reid, D. J.; Keener, J. E.; Wheeler, A. P.; Zambrano, D. E.; Diesing, J. M.; Reinhardt-Szyba, M.; Makarov, A.; Marty, M. T. Engineering Nanodisc Scaffold Proteins for Native Mass Spectrometry. Anal. Chem. 2017, 89 (21), 1118911192.

(6) Marty, M. T.; Baldwin, A. J.; Marklund, E. G.; Hochberg, G. K. A.; Benesch, J. L. P.; Robinson, C. V. Bayesian Deconvolution of Mass and lon Mobility Spectra: From Binary Interactions to Polydisperse Ensembles. Anal. Chem. 2015, 87 (8), 4370-4376. 


\section{$\underline{X-r a y}$ crystallography data parameters}

Table S1. Parameters for crystallographic data of (E)-2-((4-bromophenyl)triaz-2-en-1ylidene)-1,3-dimesityl-2,3-dihydro-1H-imidazole (1).

Empirical formula

Formula weight

Temperature $[\mathrm{K}]$

Crystal system

Space group

a $[\AA]$

$\mathrm{b}[\AA]$

c $[\AA]$

$\alpha\left[^{\circ}\right]$

$\beta\left[^{\circ}\right]$

$\left.Y{ }^{\circ}\right]$

Volume $\left[\AA^{3}\right]$

Z

$\rho_{\text {calc }}\left[\mathrm{g} / \mathrm{cm}^{3}\right]$

$\mu\left[\mathrm{mm}^{-1}\right]$

$\mathrm{F}(000)$

Crystal size $\left[\mathrm{mm}^{3}\right]$

Radiation

$2 \Theta$ range for data collection $\left[{ }^{\circ}\right]$

Index ranges

Reflections collected

Independent reflections

Data/restraints/parameters

Goodness-of-fit on $\mathrm{F}^{2}$

Final $R$ indexes, $I>2 \sigma[l]$

Final $R$ indexes, all data

peak/hole [e $\AA^{-3}$ ]

CCDC Number
$\mathrm{C}_{27} \mathrm{H}_{28} \mathrm{BrN}_{5}$

502.45

100

monoclinic

$\mathrm{C} 2 / \mathrm{c}$

15.2959(15)

12.5153(13)

28.502(3)

90

101.975(4)

90

5337.6(9)

8

1.251

1.563

2080.0

$0.29 \times 0.18 \times 0.08$

$\operatorname{MoK\alpha }(\lambda=0.71073)$

2.922 to 50.698

$-18 \leq h \leq 17,-13 \leq k \leq 15,-33 \leq \mathrm{I} \leq 34$

25802

$4895\left[R_{\text {int }}=0.0833, R_{\text {sigma }}=0.0717\right]$

$4895 / 1 / 304$

1.023

$\mathrm{R}_{1}=0.0418, \mathrm{wR}_{2}=0.0939$

$\mathrm{R}_{1}=0.0641, \mathrm{wR}_{2}=0.1042$

$0.80 /-0.31$

2042944 


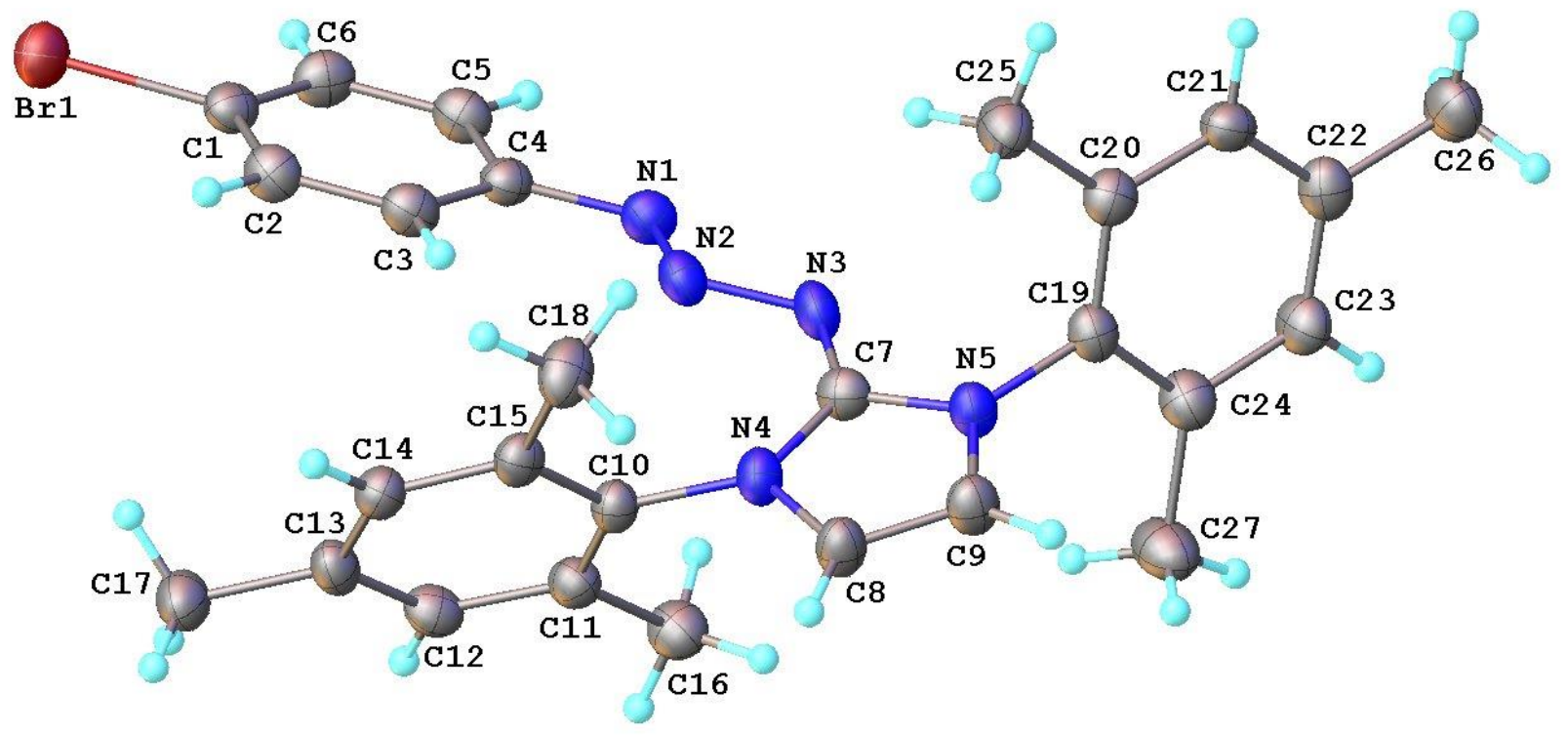

Figure S2. Molecular structure of 1.

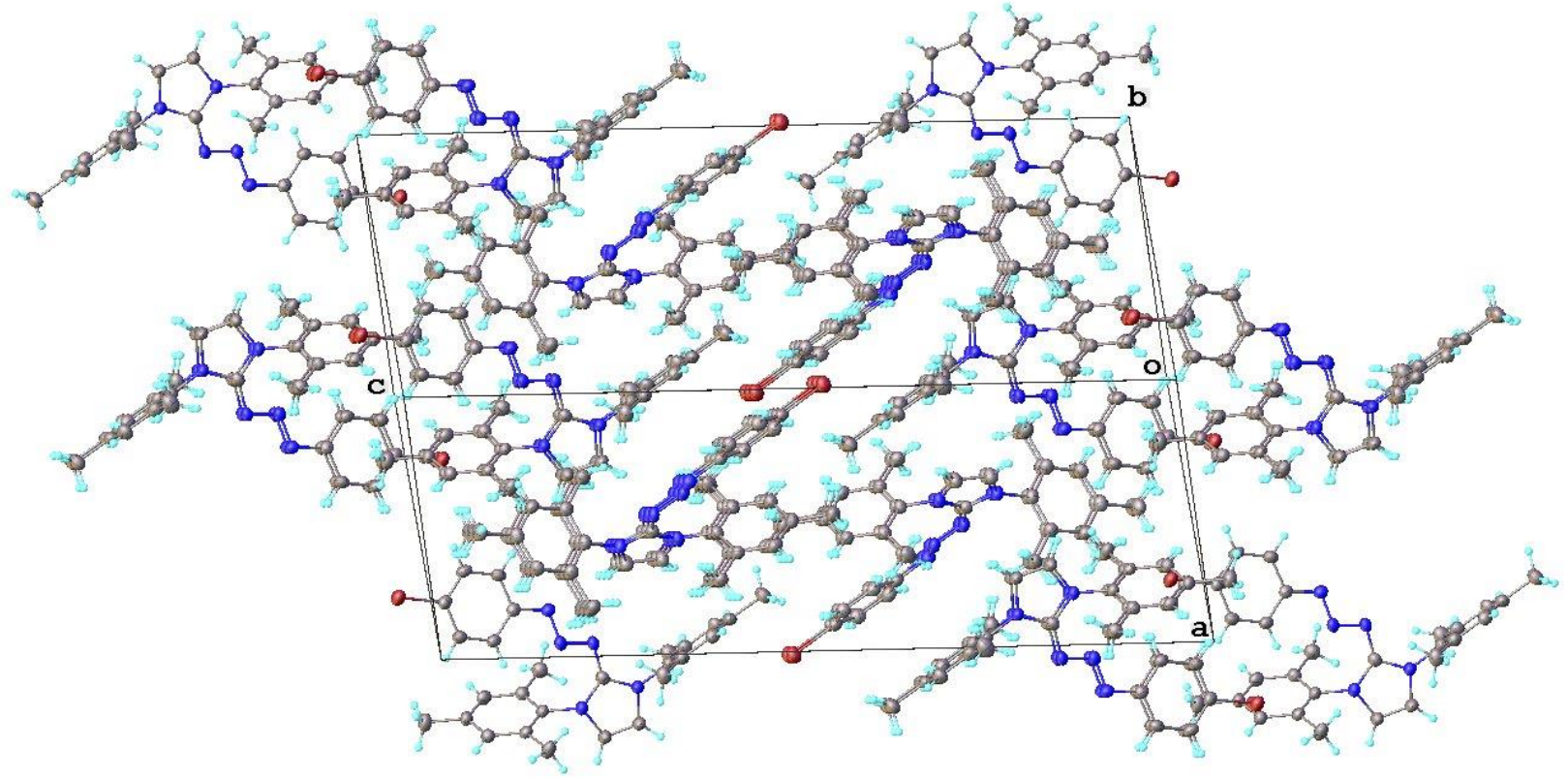

Figure S3. Unit cell of 1 and packing, showing eight molecules per unit cell and one molecule per asymmetric unit. The displacement ellipsoids are at $50 \%$ probability level; the hydrogen atoms at carbons are at predicted positions. 
Table S2. Parameters for crystallographic data of (Z)-2-((E)-(4-bromophenyl)triaz-2-en1-ylidene)-1-mesityl-3-methyl-2,3-dihydro-1H-imidazole (5).

\begin{tabular}{|c|c|}
\hline Empirical formula & $\mathrm{C}_{27} \mathrm{H}_{28} \mathrm{BrN}_{5}$ \\
\hline Formula weight & 398.31 \\
\hline Temperature $[\mathrm{K}]$ & 100 \\
\hline Crystal system & monoclinic \\
\hline Space group & $\mathrm{P} 2_{1} / \mathrm{c}$ \\
\hline $\mathrm{a}[\AA]$ & $18.4799(9)$ \\
\hline$b[\AA ̊]$ & $10.5977(5)$ \\
\hline$c[\AA]$ & $9.7035(5)$ \\
\hline$\alpha\left[^{\circ}\right]$ & 90 \\
\hline$\beta\left[^{\circ}\right]$ & $93.198(2)$ \\
\hline $\mathrm{Y}\left[{ }^{\circ}\right]$ & 90 \\
\hline Volume $\left[\AA^{3}\right]$ & $1897.42(16)$ \\
\hline Z & 4 \\
\hline$\rho_{\text {calc }}\left[\mathrm{g} / \mathrm{cm}^{3}\right]$ & 1.394 \\
\hline$\mu\left[\mathrm{mm}^{-1}\right]$ & 2.177 \\
\hline$F(000)$ & 816.0 \\
\hline Crystal size $\left[\mathrm{mm}^{3}\right]$ & $0.26 \times 0.25 \times 0.05$ \\
\hline Radiation & $\operatorname{MoK} \alpha(\lambda=0.71073)$ \\
\hline $2 \Theta$ range for data collection $\left[^{\circ}\right]$ & 4.432 to 53.506 \\
\hline Index ranges & $-23 \leq h \leq 23,-13 \leq k \leq 13,-11 \leq \mathrm{I} \leq 12$ \\
\hline Reflections collected & 19113 \\
\hline Independent reflections & $4025\left[R_{\text {int }}=0.0307, R_{\text {sigma }}=0.0245\right]$ \\
\hline Data/restraints/parameters & $4025 / 0 / 230$ \\
\hline Goodness-of-fit on $\mathrm{F}^{2}$ & 1.030 \\
\hline Final $R$ indexes, $I>2 \sigma[l]$ & $\mathrm{R}_{1}=0.0360, w R_{2}=0.0870$ \\
\hline Final $R$ indexes, all data & $\mathrm{R}_{1}=0.0473, \mathrm{wR}_{2}=0.0922$ \\
\hline peak/hole $\left[\mathrm{e} \AA^{-3}\right]$ & $0.79 /-0.81$ \\
\hline CCDC Number & 2042946 \\
\hline
\end{tabular}




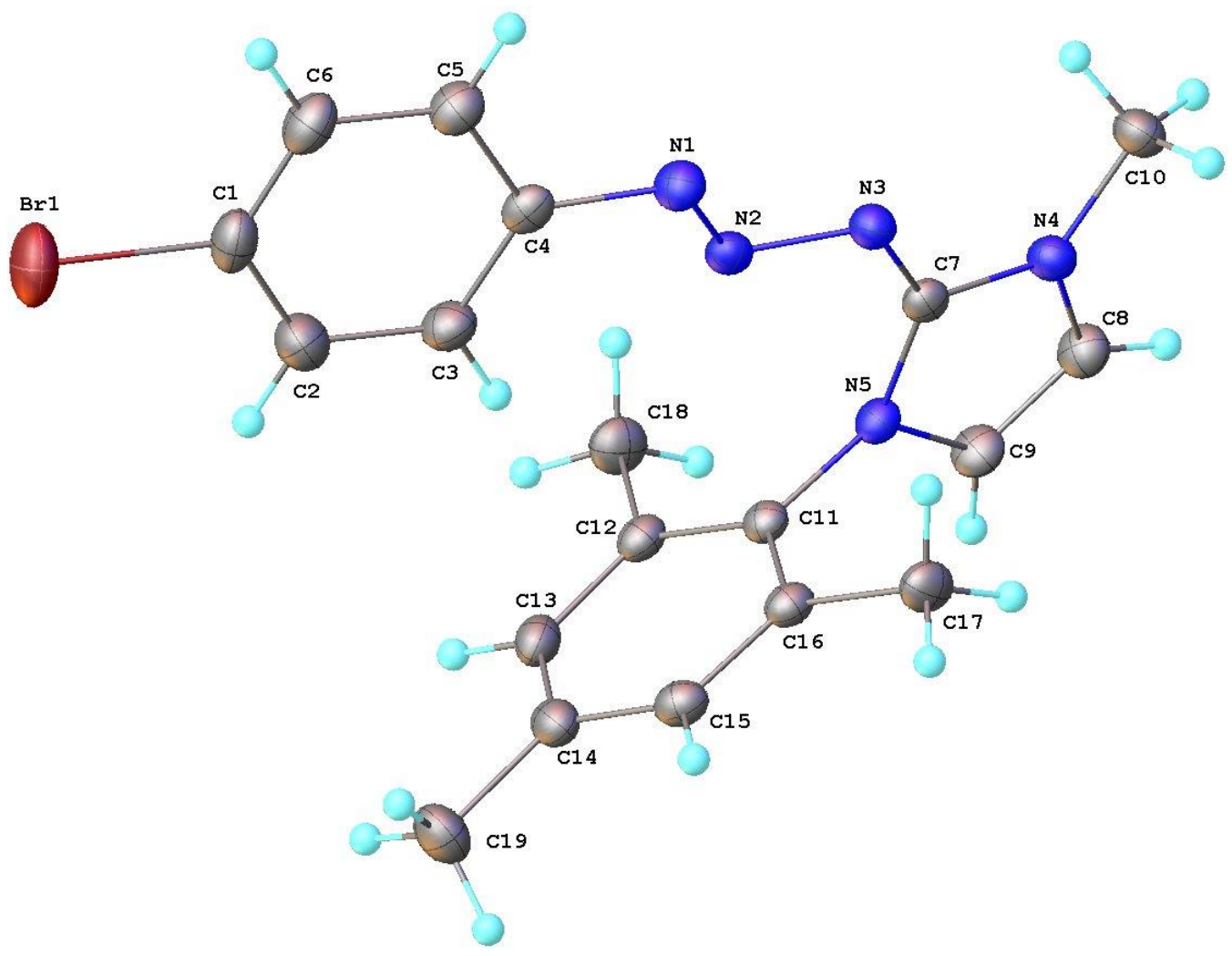

Figure S4. Molecular structure of 5.

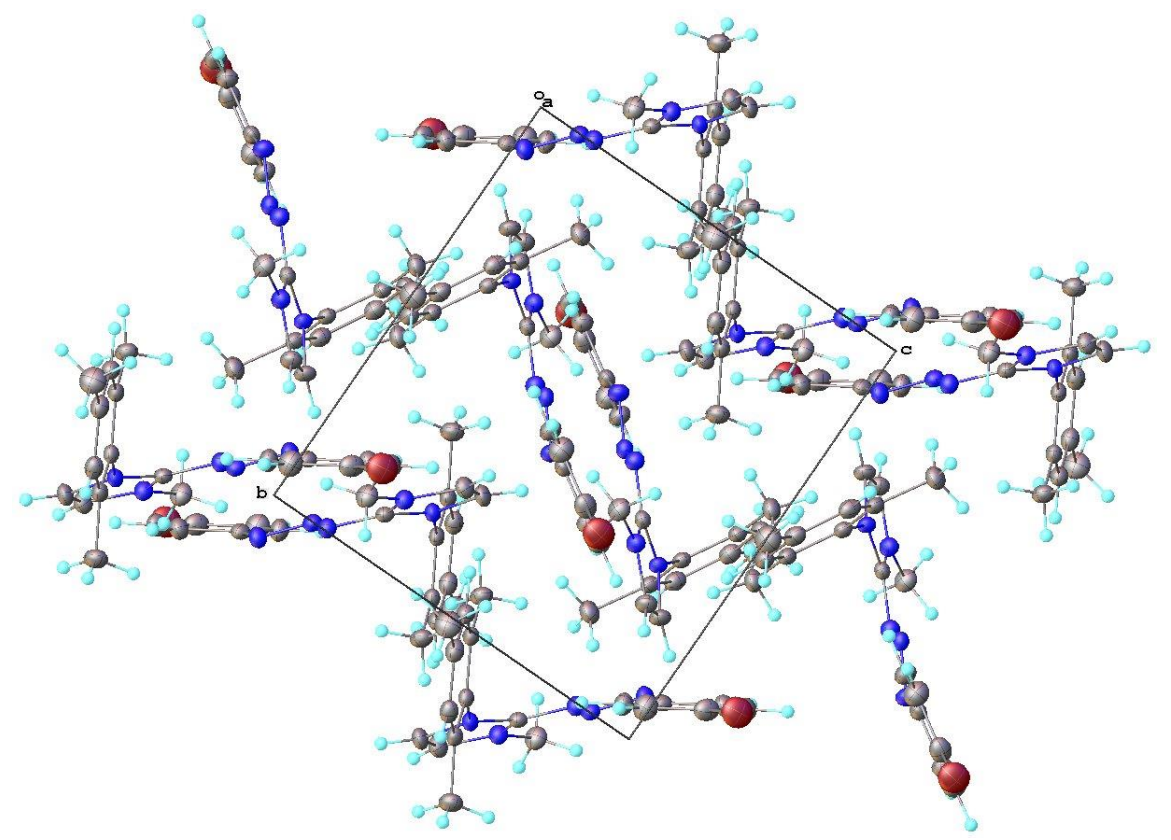

Figure S5. Unit cell of $\mathbf{5}$ and packing, showing four molecules per unit cell and one molecule per asymmetric unit. The displacement ellipsoids are at $50 \%$ probability level; the hydrogen atoms at carbons are at predicted positions. 
Table S3. Parameters for crystallographic data of $(E)-2-((E)-(4-b r o m o p h e n y l) t r i a z-2-e n-$ 1-ylidene)-1-(tert-butyl)-3-methyl-2,3-dihydro-1H-imidazole (6).

\begin{tabular}{|c|c|}
\hline Empirical formula & $\mathrm{C}_{14} \mathrm{H}_{18} \mathrm{BrN}_{5}$ \\
\hline Formula weight & 336.24 \\
\hline Temperature $[\mathrm{K}]$ & 100 \\
\hline Crystal system & monoclinic \\
\hline Space group & $\mathrm{P} 2{ }_{1} / \mathrm{C}$ \\
\hline $\mathrm{a}[\AA ̊]$ & $11.6851(7)$ \\
\hline $\mathrm{b}[\AA ̊]$ & $9.2723(4)$ \\
\hline$c[\AA ̊]$ & $14.2050(8)$ \\
\hline$\alpha\left[^{\circ}\right]$ & 90 \\
\hline$\beta\left[^{\circ}\right]$ & $99.344(2)$ \\
\hline $\mathrm{V}\left[{ }^{\circ}\right]$ & 90 \\
\hline Volume $\left[\AA^{3}\right]$ & 1518.66(14) \\
\hline Z & 4 \\
\hline$\rho_{\text {calc }}\left[\mathrm{g} / \mathrm{cm}^{3}\right]$ & 1.471 \\
\hline$\mu\left[\mathrm{mm}^{-1}\right]$ & 2.705 \\
\hline$F(000)$ & 688.0 \\
\hline Crystal size $\left[\mathrm{mm}^{3}\right]$ & $0.35 \times 0.23 \times 0.08$ \\
\hline Radiation & $\operatorname{MoKa}(\lambda=0.71073)$ \\
\hline $2 \Theta$ range for data collection $\left[{ }^{\circ}\right]$ & 3.532 to 52.04 \\
\hline Index ranges & $-14 \leq h \leq 14,-8 \leq k \leq 11,-17 \leq 1 \leq 17$ \\
\hline Reflections collected & 17244 \\
\hline Independent reflections & $2988\left[R_{\text {int }}=0.0261, R_{\text {sigma }}=0.0180\right]$ \\
\hline Data/restraints/parameters & $2988 / 0 / 185$ \\
\hline Goodness-of-fit on $\mathrm{F}^{2}$ & 1.027 \\
\hline Final $R$ indexes, $I>2 \sigma[l]$ & $\mathrm{R}_{1}=0.0210, \mathrm{wR}_{2}=0.0498$ \\
\hline Final $R$ indexes, all data & $\mathrm{R}_{1}=0.0257, \mathrm{wR}_{2}=0.0518$ \\
\hline peak/hole $\left[\mathrm{e} \AA^{-3}\right]$ & $0.29 /-0.30$ \\
\hline CCDC Number & 2042942 \\
\hline
\end{tabular}




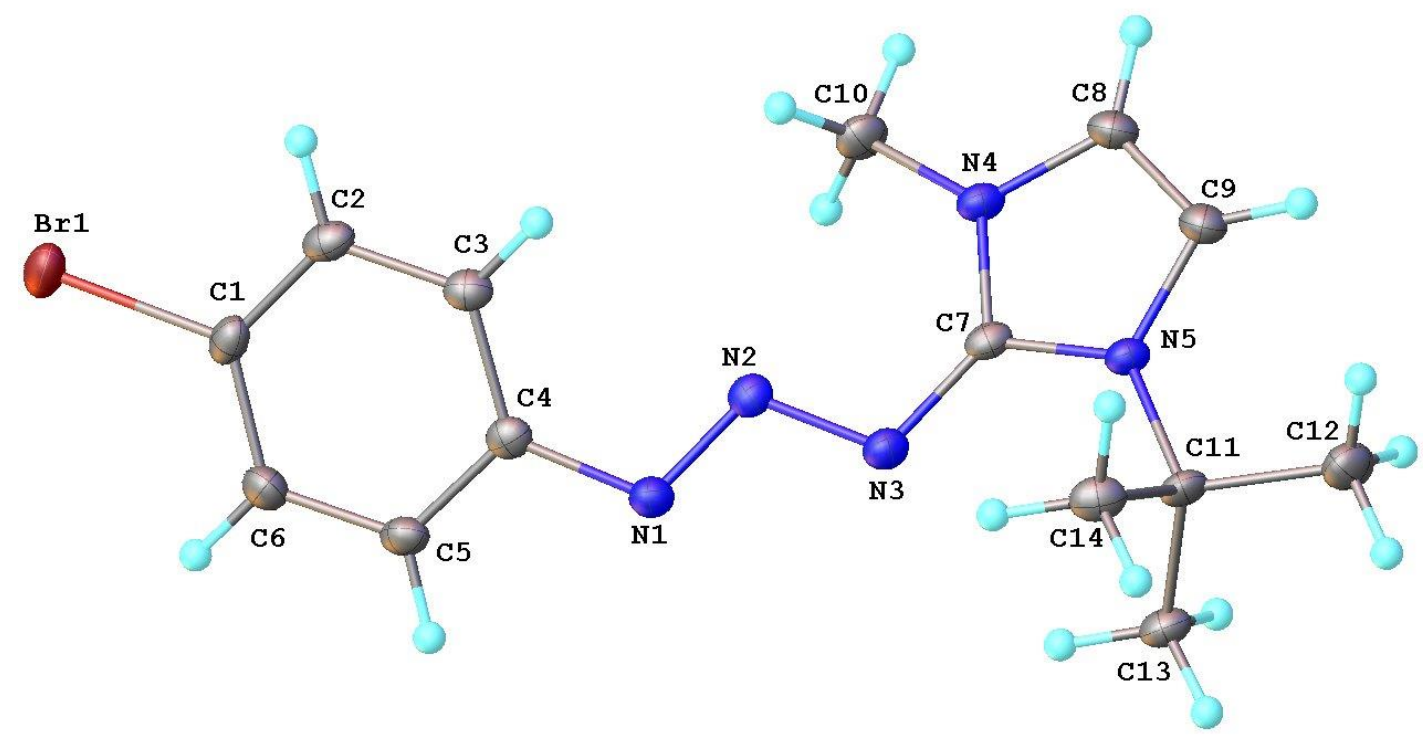

Figure S6. Molecular structure of 6.

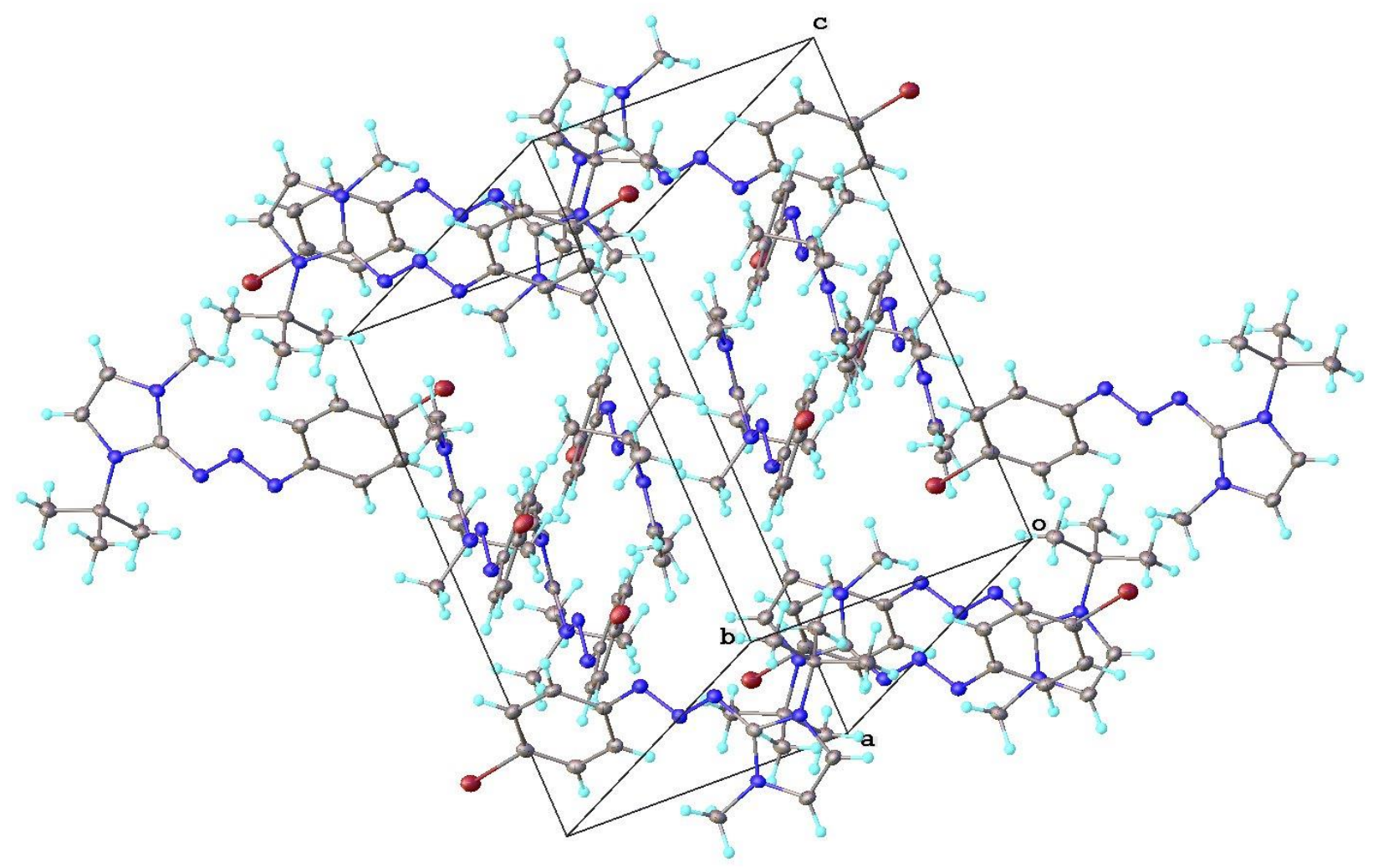

Figure S7. Unit cell of 6 and packing, showing four molecules per unit cell and one molecule per asymmetric unit. The displacement ellipsoids are at $50 \%$ probability level; the hydrogen atoms at carbons are at predicted positions. 
Table S4. Parameters for crystallographic data of (E)-2-([1,1'-biphenyl]-4-yltriaz-2-en-1ylidene)-1,3-dimesityl-2,3-dihydro-1H-imidazole (4a).

\begin{tabular}{|c|c|}
\hline Empirical formula & $\mathrm{C}_{33} \mathrm{H}_{33} \mathrm{~N}_{5}$ \\
\hline Formula weight & 499.64 \\
\hline Temperature $[\mathrm{K}]$ & 100 \\
\hline Crystal system & monoclinic \\
\hline Space group & $\mathrm{P} 2_{1} / \mathrm{n}$ \\
\hline $\mathrm{a}[\AA \AA]$ & $20.9160(17)$ \\
\hline$b[\AA]$ & $13.4543(12)$ \\
\hline$c[\AA ̊]$ & $21.9991(16)$ \\
\hline$\alpha\left[^{\circ}\right]$ & 90 \\
\hline$\beta\left[^{\circ}\right]$ & $114.118(4)$ \\
\hline $\mathrm{Y}\left[{ }^{\circ}\right]$ & 90 \\
\hline Volume $\left[\AA^{3}\right]$ & $5650.4(8)$ \\
\hline Z & 8 \\
\hline$\rho_{\text {calc }}\left[\mathrm{g} / \mathrm{cm}^{3}\right]$ & 1.175 \\
\hline$\mu\left[\mathrm{mm}^{-1}\right]$ & 0.071 \\
\hline$F(000)$ & 2128.0 \\
\hline Crystal size $\left[\mathrm{mm}^{3}\right]$ & $0.25 \times 0.25 \times 0.08$ \\
\hline Radiation & $\operatorname{MoKa}(\lambda=0.71073)$ \\
\hline $2 \Theta$ range for data collection $\left[^{\circ}\right]$ & 3.494 to 51.636 \\
\hline Index ranges & $-25 \leq h \leq 25,-16 \leq k \leq 16,-26 \leq \mathrm{I} \leq 19$ \\
\hline Reflections collected & 46913 \\
\hline Independent reflections & $10735\left[R_{\text {int }}=0.0556, R_{\text {sigma }}=0.0500\right]$ \\
\hline Data/restraints/parameters & $10735 / 3 / 738$ \\
\hline Goodness-of-fit on F² & 1.085 \\
\hline Final $R$ indexes, $I>2 \sigma[l]$ & $\mathrm{R}_{1}=0.0557, \mathrm{wR}_{2}=0.1530$ \\
\hline Final $R$ indexes, all data & $R_{1}=0.0918, w R_{2}=0.1773$ \\
\hline peak/hole $\left[\right.$ e $\left.\AA^{-3}\right]$ & $0.39 /-0.24$ \\
\hline CCDC Number & 2042943 \\
\hline
\end{tabular}




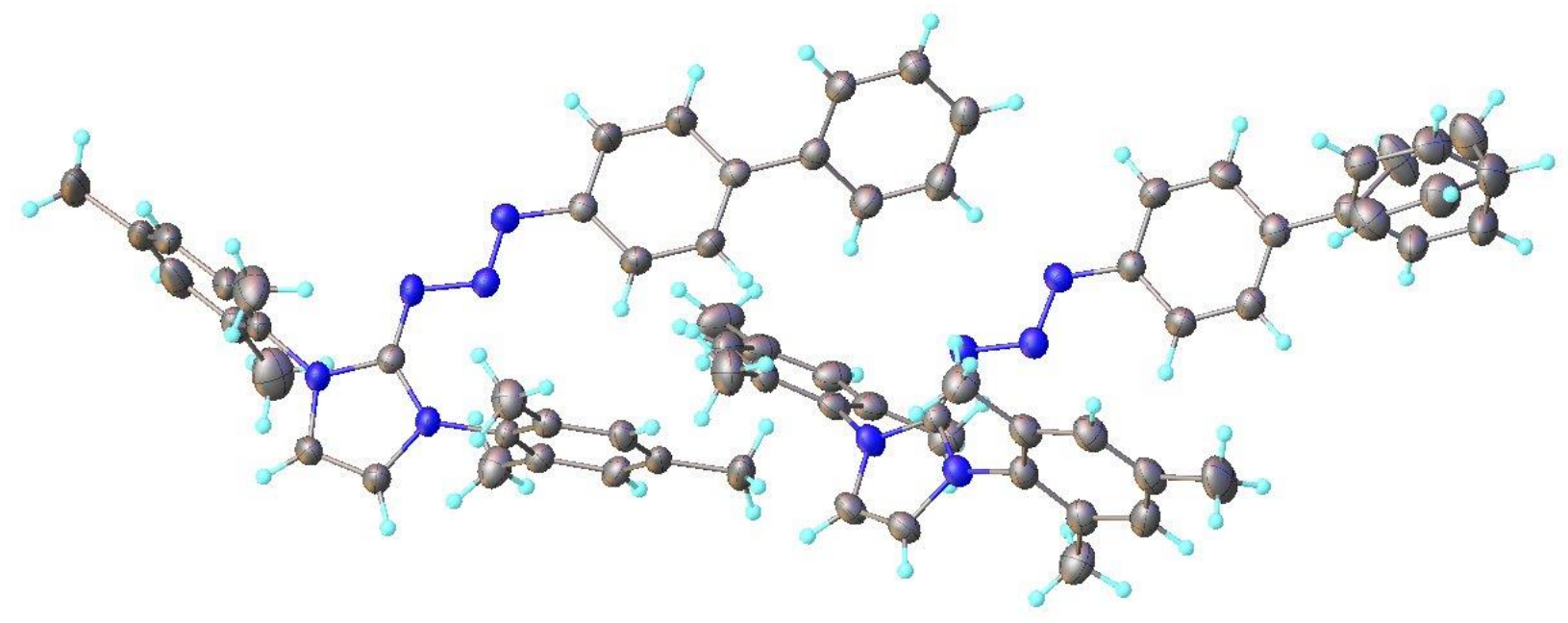

Figure S8. Molecular structure of $\mathbf{4 a}$, highlighting the two molecules per asymmetric unit.

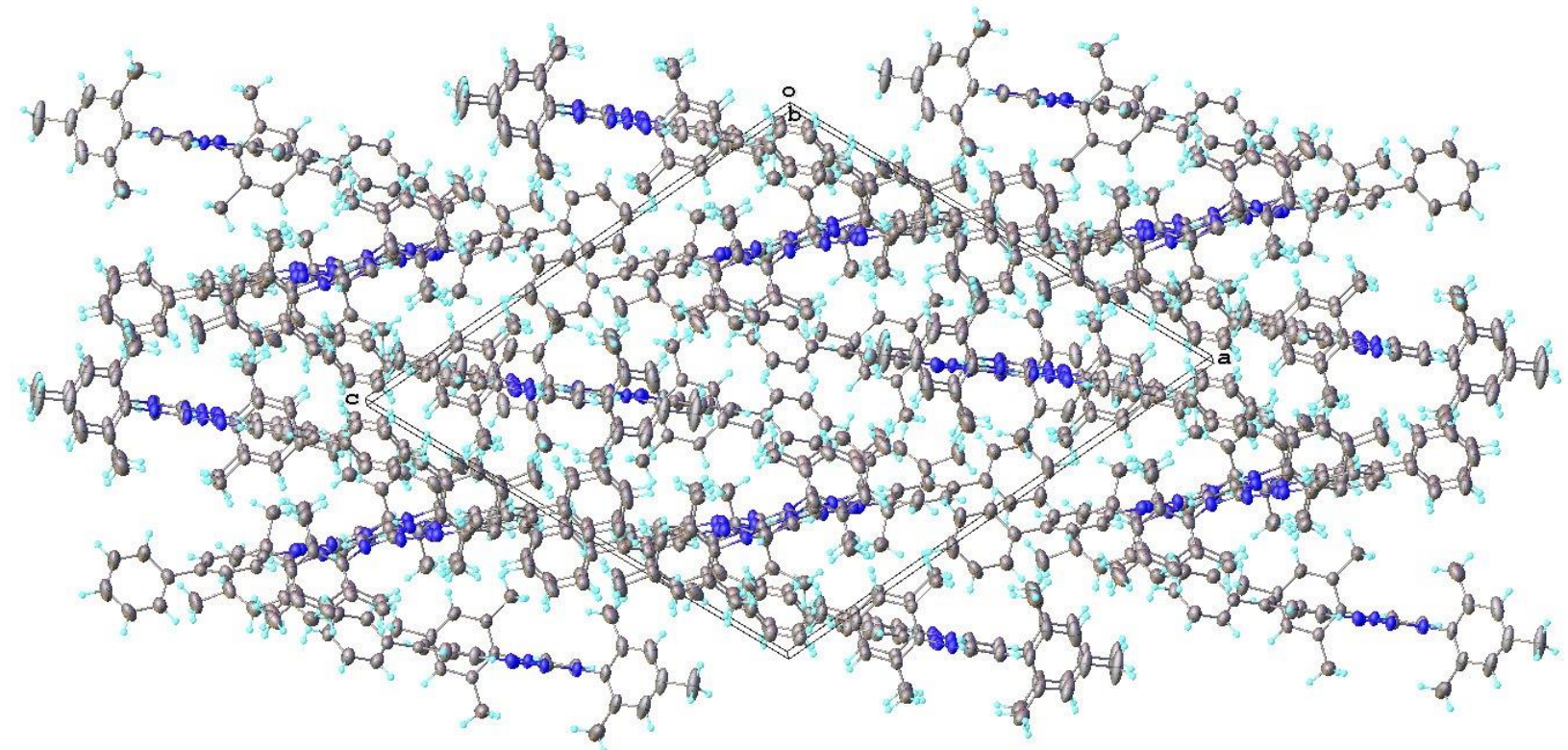

Figure S9. Unit cell of $\mathbf{4 a}$ and packing, showing eight molecules per unit cell and two molecules per asymmetric unit. The displacement ellipsoids are at $50 \%$ probability level; the hydrogen atoms at carbons are at predicted positions. 
Table S5. Parameters for crystallographic data of (Z)-2-((E)-[1,1'-biphenyl]-4-yltriaz-2en-1-ylidene)-1-mesityl-3-methyl-2,3-dihydro-1H-imidazole (7a).

\begin{tabular}{|c|c|}
\hline Empirical formula & $\mathrm{C}_{25} \mathrm{H}_{25} \mathrm{~N}_{5}$ \\
\hline Formula weight & 395.50 \\
\hline Temperature $[\mathrm{K}]$ & 100 \\
\hline Crystal system & monoclinic \\
\hline Space group & $21 / \mathrm{c}$ \\
\hline $\mathrm{a}[\AA]$ & $8.5299(14)$ \\
\hline $\mathrm{b}[\AA \AA]$ & $8.7061(17)$ \\
\hline$c[\AA]$ & $29.435(5)$ \\
\hline$\alpha\left[^{\circ}\right]$ & 90 \\
\hline$\beta\left[^{\circ}\right]$ & $95.800(9)$ \\
\hline $\mathrm{Y}\left[^{\circ}\right]$ & 90 \\
\hline Volume $\left[\AA^{3}\right]$ & $2174.7(7)$ \\
\hline Z & 4 \\
\hline$\rho_{\text {calc }}\left[\mathrm{g} / \mathrm{cm}^{3}\right]$ & 1.208 \\
\hline$\mu\left[\mathrm{mm}^{-1}\right]$ & 0.074 \\
\hline$F(000)$ & 840.0 \\
\hline Crystal size $\left[\mathrm{mm}^{3}\right]$ & $0.2 \times 0.1 \times 0.06$ \\
\hline Radiation & $\operatorname{MoKa}(\lambda=0.71073)$ \\
\hline $2 \Theta$ range for data collection $\left[^{\circ}\right]$ & 2.782 to 50.198 \\
\hline Index ranges & $-10 \leq h \leq 10,-8 \leq k \leq 10,-35 \leq 1 \leq 34$ \\
\hline Reflections collected & 13555 \\
\hline Independent reflections & $3834\left[R_{\text {int }}=0.1032, R_{\text {sigma }}=0.1100\right]$ \\
\hline Data/restraints/parameters & $3834 / 2 / 275$ \\
\hline Goodness-of-fit on $F^{2}$ & 1.054 \\
\hline Final $R$ indexes, $I>2 \sigma[I]$ & $\mathrm{R}_{1}=0.0989, \mathrm{wR}_{2}=0.2287$ \\
\hline Final $R$ indexes, all data & $\mathrm{R}_{1}=0.1596, \mathrm{wR}_{2}=0.2597$ \\
\hline peak/hole $\left[\mathrm{e} \AA^{-3}\right]$ & $0.82 /-0.34$ \\
\hline CCDC Number & 2042945 \\
\hline
\end{tabular}




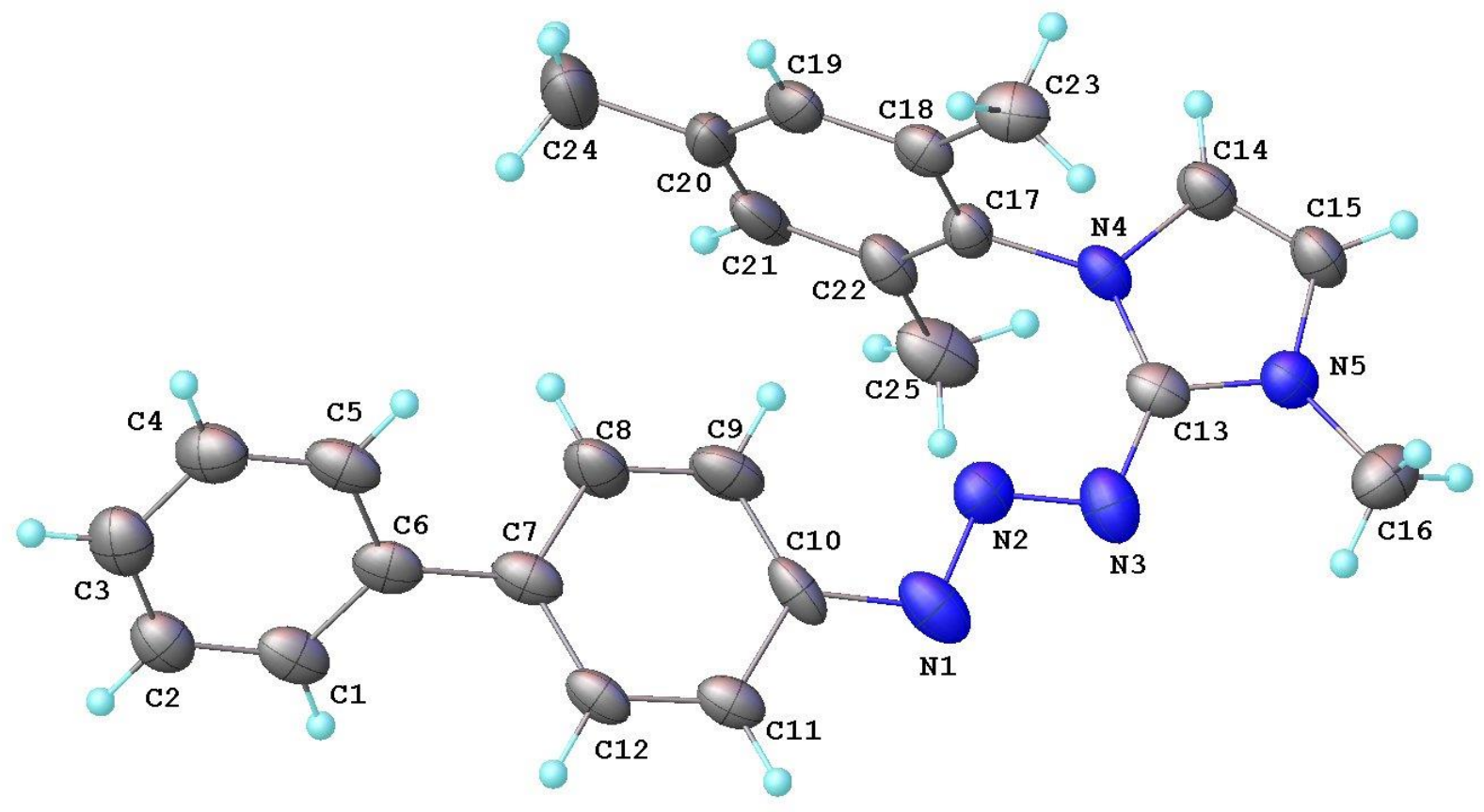

Figure S10. Molecular structure of 7a, highlighting the one molecule per asymmetric unit.

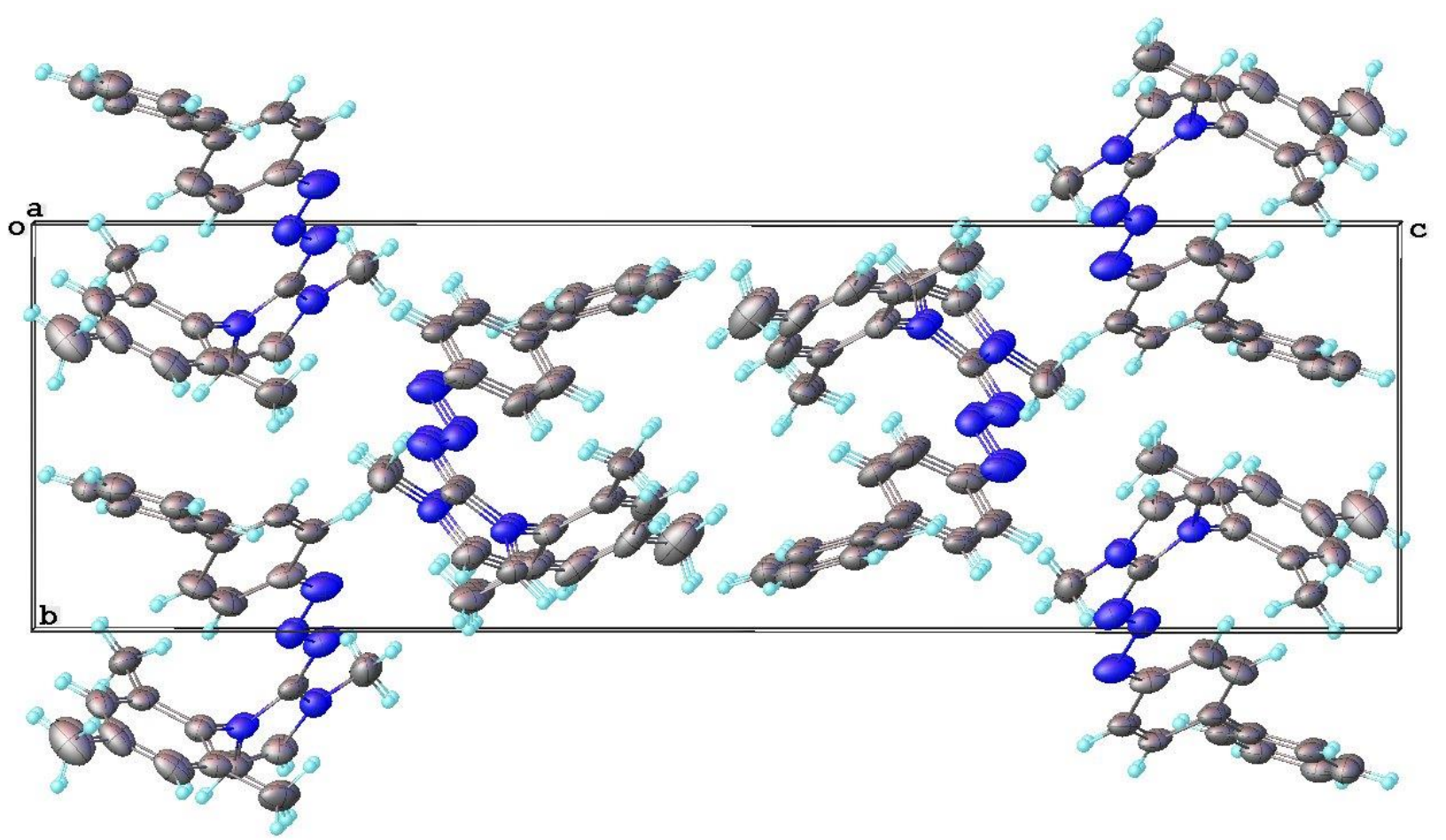

Figure S11. Unit cell of 7a and packing, showing four molecules per unit cell and one molecule per asymmetric unit. The displacement ellipsoids are at 50\% probability level; the hydrogen atoms at carbons are at predicted positions. 


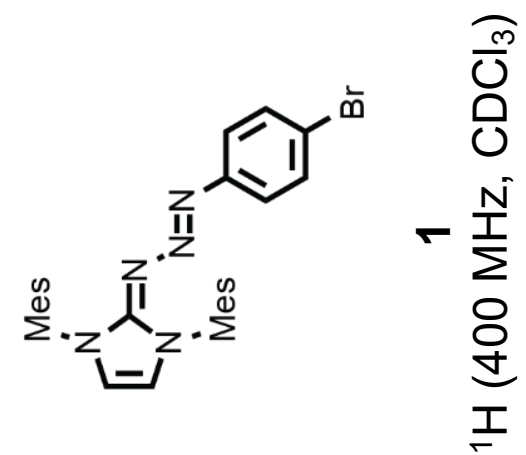

9 $\angle \mathcal{E} Z$

$07^{\circ} 9$ 乙๐ 9 $89^{\circ} 9$ $66^{\circ} 9$

$0{ }^{\circ} L$ OLLF ZL 2 हાつ৫ว 9Z" L

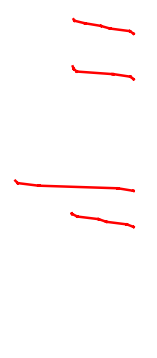


LO'81-

ZZ:Lー

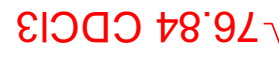

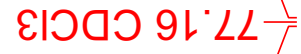

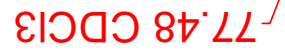

OLடLL

EL'8LL-

L6 ZZL-

St'6ZL

†L'LL

$0{ }^{\circ} \nabla \varepsilon L$

$\varepsilon L^{\circ} \subseteq \varepsilon L^{\prime}$

98.8E ${ }^{-}$

Z9.09L

LLIGL

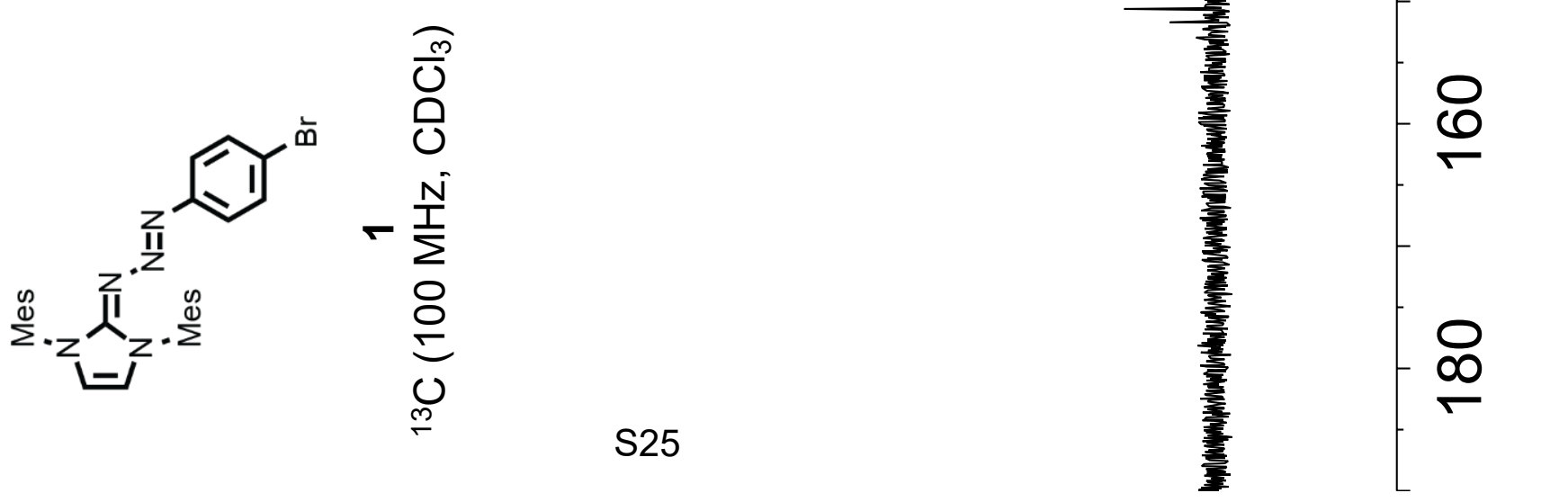




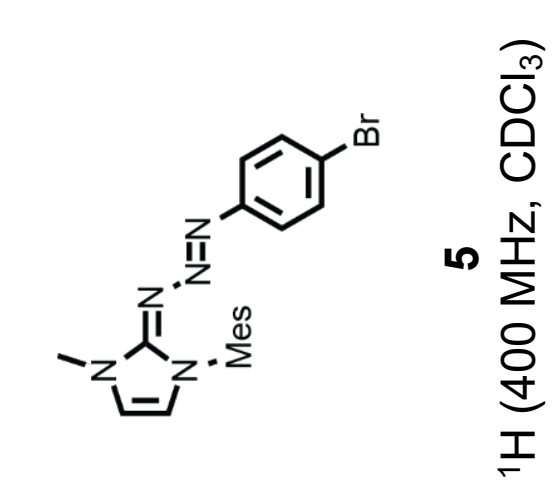

$20 こ-$

$6 \varepsilon^{\prime} 乙-$

$99^{\circ} \varepsilon$

乙ย' 9

$\varepsilon \varepsilon^{\prime} 9$

$8 t^{\circ} 9$

$8 t^{\circ} 9$

$6 \nabla^{\circ} 9$

OS'9-

$69^{\circ} 9$

$69^{\circ} 9^{-}$

$\angle 6^{\circ} 9$

$\varepsilon L^{\circ} L$

$\varepsilon L<J$

GL'L

GL'L

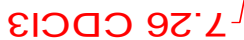

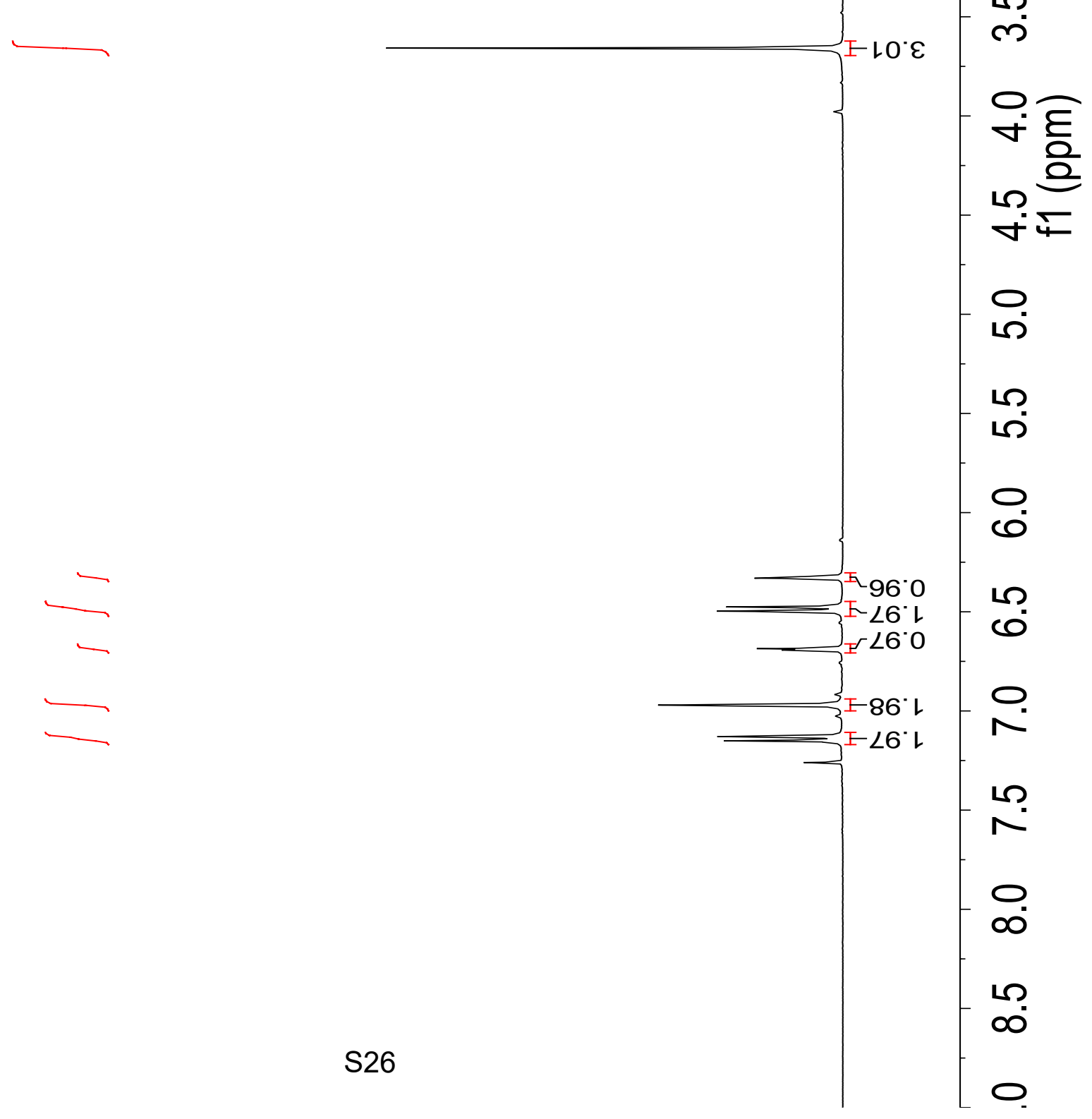


90.8L-

LLLC

०७ $\varepsilon \varepsilon-$

ยІวดว 78.94

हाOดว $9 L^{\circ} L L$

हाวดว 8t $\angle L$

$\angle G \cdot 9$ Lᄂ

OL9LL

0L8LL

८8こてレ

ย古乙 -

เてレにレ-

99' $\nabla \varepsilon L-$

ᄂ6.GEL-

乙ち $8 \varepsilon\llcorner$

G9.0GL

99・ヒレ

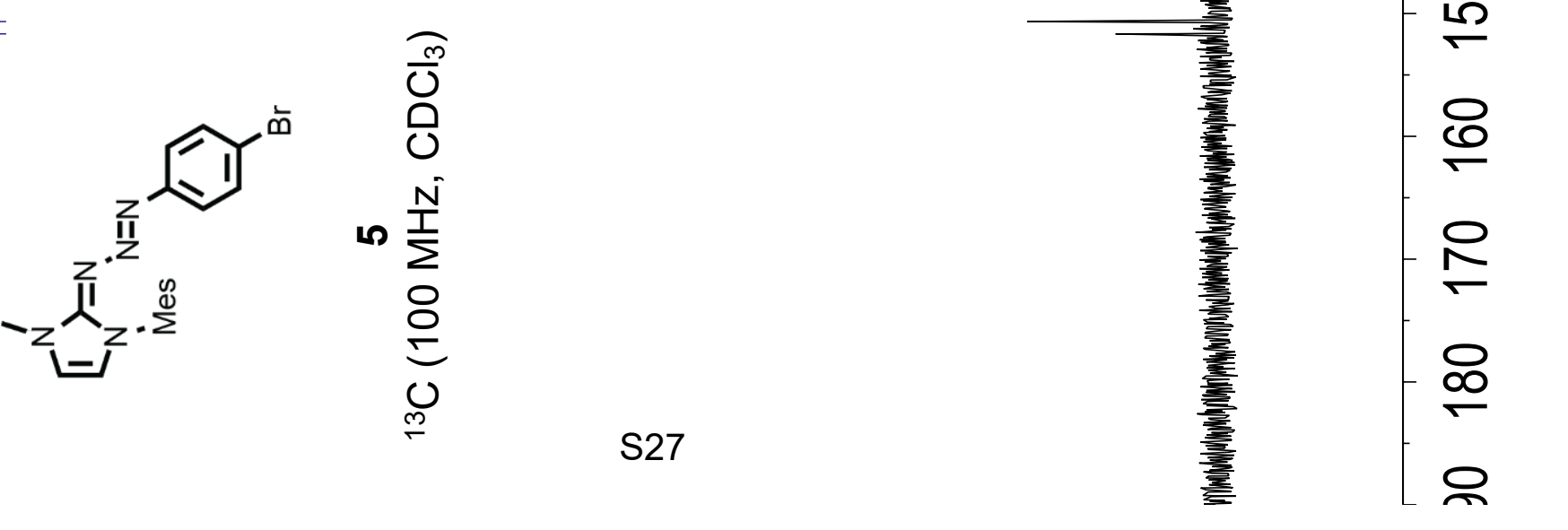



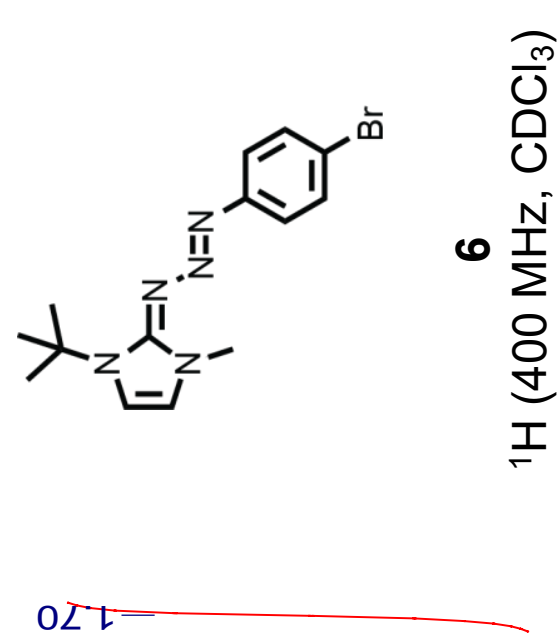

$\angle L E$

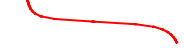

$6 \varepsilon \cdot 9$

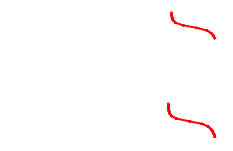

$\varepsilon L 9-$

ยІวดว 9乙"

$6 \varepsilon^{\circ} L$
$0 \nabla^{\circ} L$ 
26.82

$\varepsilon \iota^{\circ} 0 \varepsilon^{-}$

ヤレ $6 \varepsilon$

ยІวดว $\neg 8^{\circ} 9 L$

हIวดว 9L'LL

ยІวดО 8t" $\angle L$

ยとてレレー

เO $\angle L レ$

16 $\angle$ L

Gとててレ

OLレEL-

9L・ルロ

69'乙Gレ

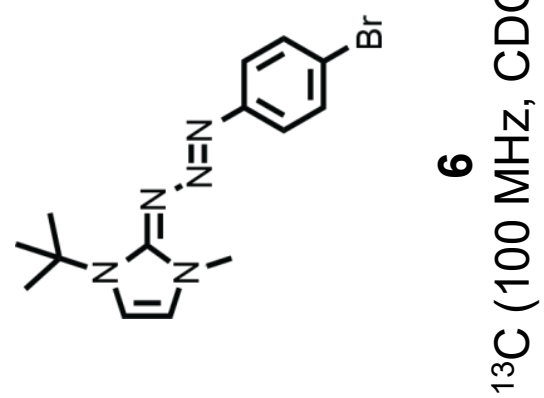

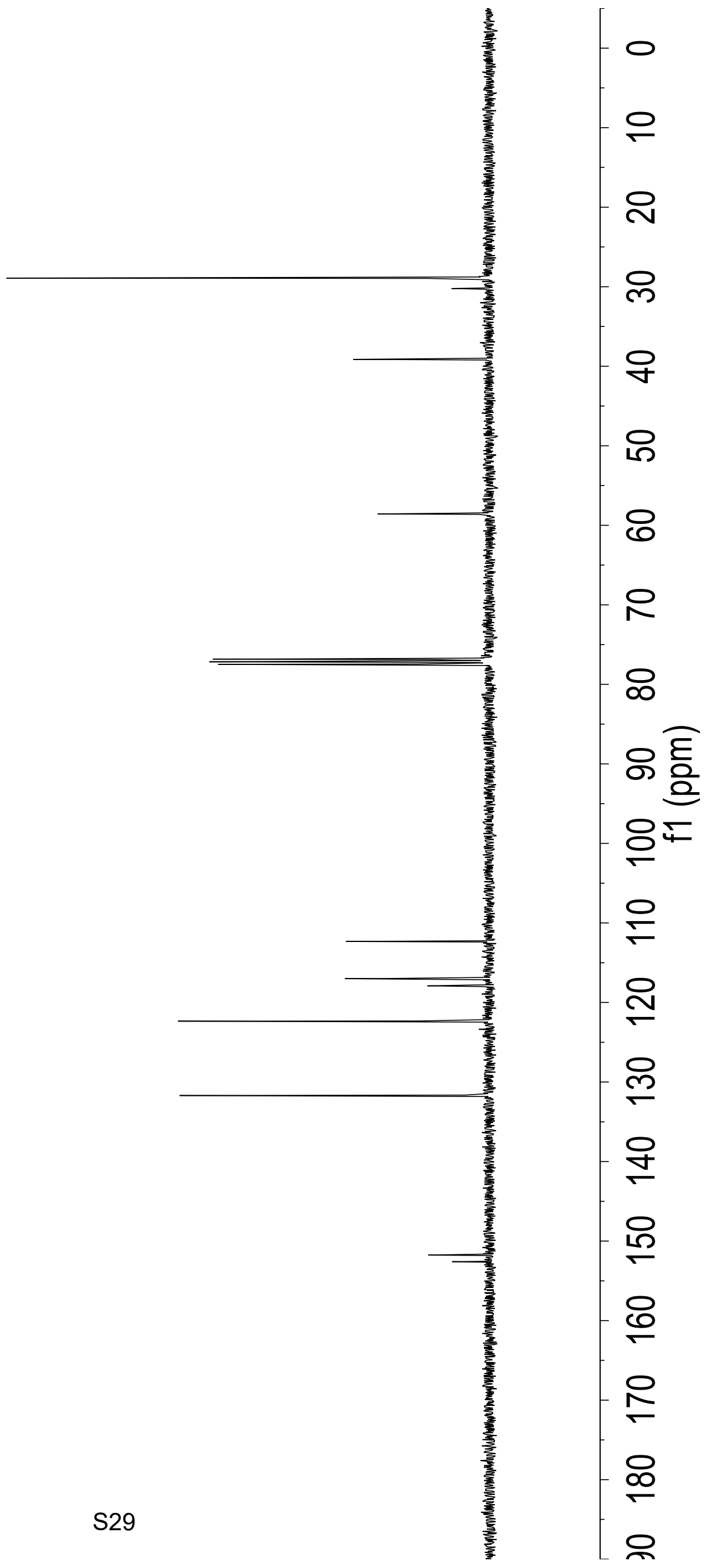




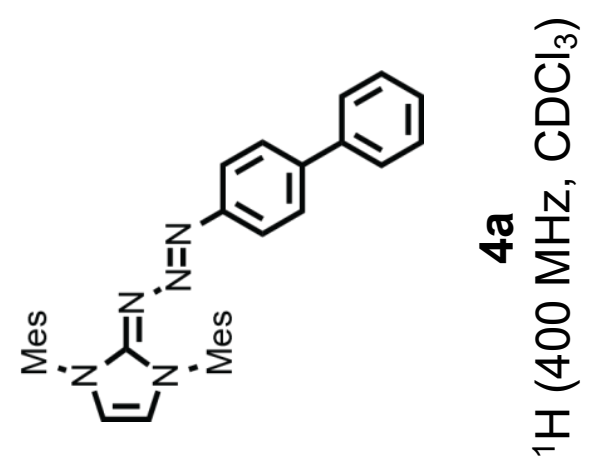

OZ

$6 \varepsilon^{\prime}$ 乙一

$89^{\circ} 9$

$79^{\circ} 9$

99.9

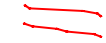

10.2

हાつ०О 92" $\mathrm{L}$

$8 Z^{\circ} \mathrm{L}$

$8 Z^{\prime} \angle$

OE' $L$

$\left\llcorner\varepsilon^{\circ} L\right.$

$8 \varepsilon^{\circ} L$

$0 \nabla^{\circ} \angle$

乙大 L

ZG' $L$

乙G' $L$

$\nabla G^{\circ} L$

$\nabla G^{\circ} L$

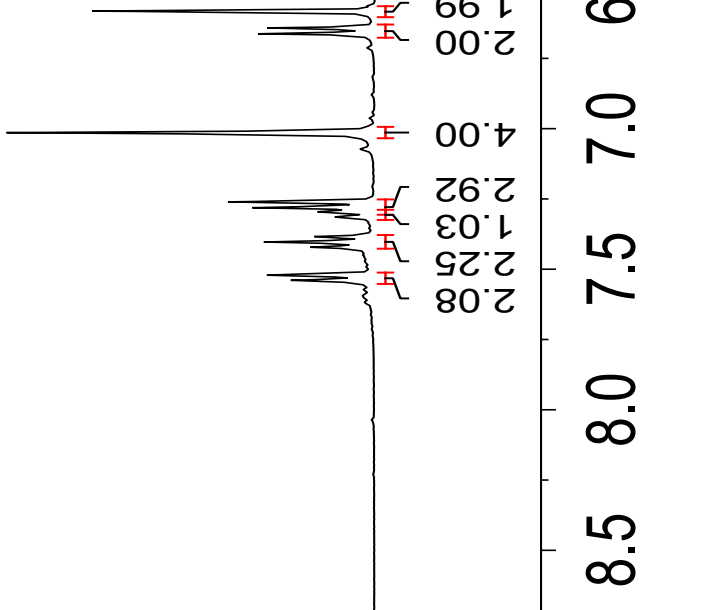


60:8L-

乙てレ乙-

ยІวดว 78.94

हIOดว $9 L^{\circ} L L$

हाวดว 8t $\angle L$

L6'9LL

08 เZL

$\angle 8^{\circ} 9$ Z

68.9ZL

乙L'8ZL

ยヤ 6乙レ -

$6 乙 " \nabla \varepsilon L$

$\angle L G E L-$

$0 乙 \cdot 8 \varepsilon L$

乙L'8EL

Oย・レレ

†8.0GL

ยL・レレー

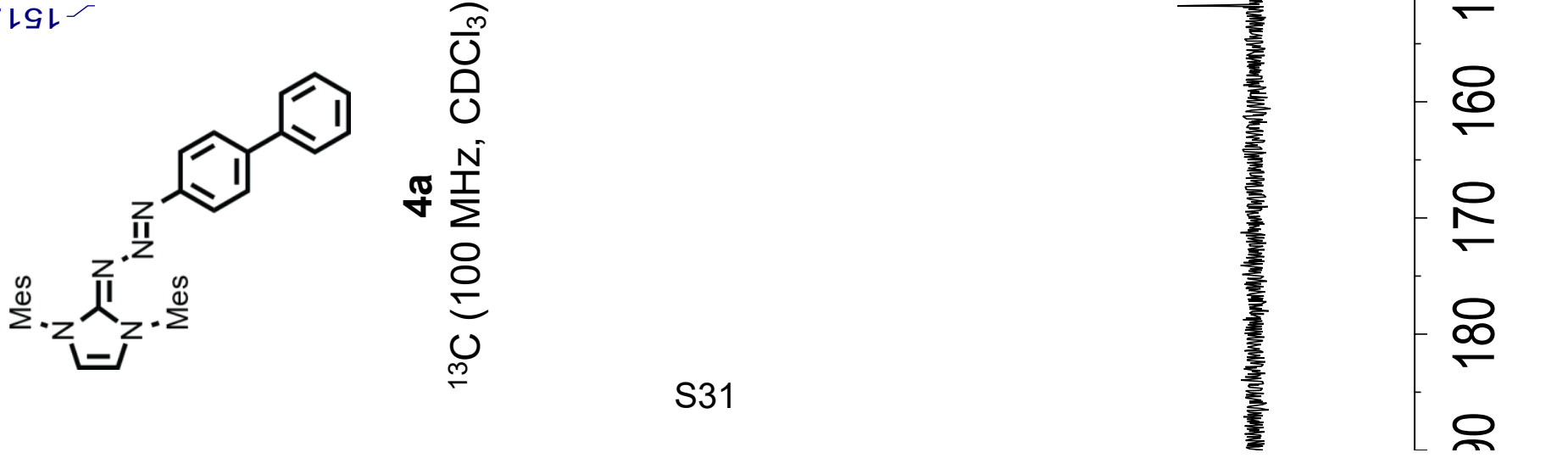




6เ゙

$8 \varepsilon^{\prime} 乙-$

$86^{\circ} \mathrm{G}$

$89^{\circ} 9$

$09^{\circ} 9$

乙9.9

$\succ 8^{\circ} 9$

$98^{\circ} 9$

86.9

$86^{\circ} 9$

$00^{\circ} \angle \mathcal{J}$

$00^{\circ} \mathrm{L}$

$10 \%$

$\angle L^{\circ} L$

$6 L^{\circ} \mathrm{L}$

ยાว $92^{\circ} \mathrm{L}$

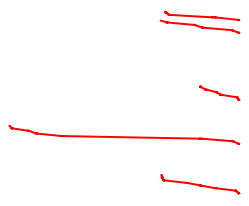


OL'8L-

ย乙゙し-

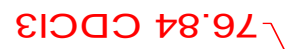

ยレ゙レー

Eャ $\angle O L$

69.80 -

96.9レレ

เE'OZL

LLLZL

19.9ZL

てヤ゙6てレ

6で๋ยレ

8L'GEL

$\angle L G E L-\mathbb{L}$

$76 . \angle \varepsilon L$

ᄂL'BEL

LL'9tL

90.8ヤレ-

†G'OGL-

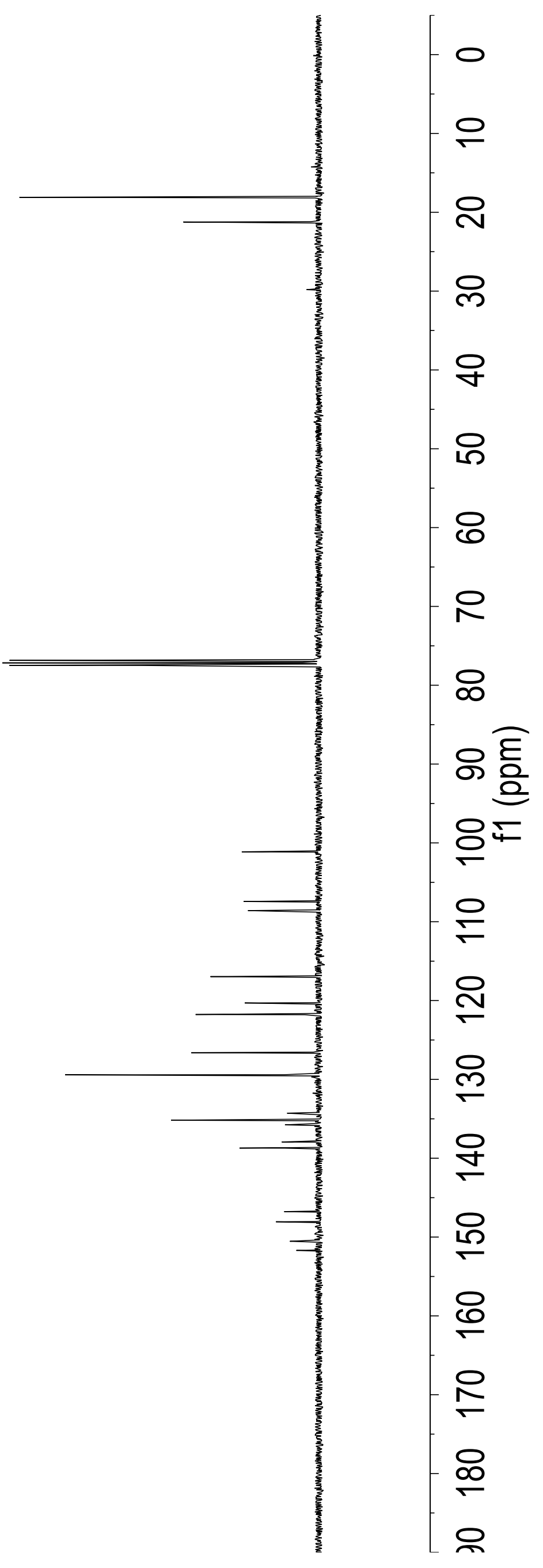




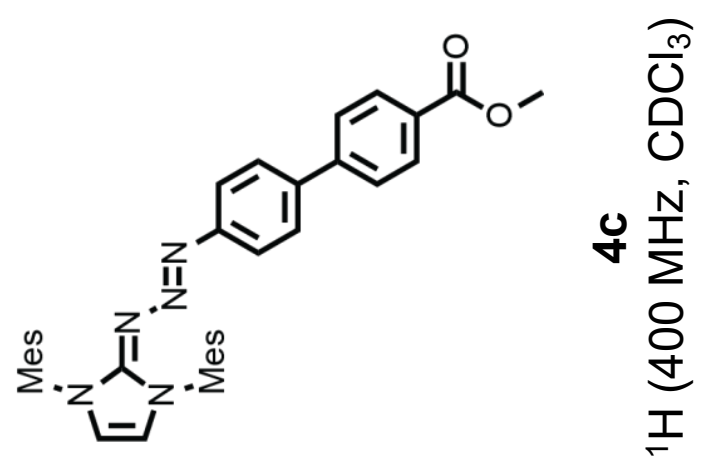

$\varepsilon 6^{\circ} \varepsilon-$

09.9

$\triangleright 9^{\circ} 9$

$\angle 9^{\circ} 9^{-}$

LOL

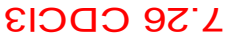

$6 C^{\prime} L$

LE' $L$

$89^{\circ} L$

$69^{\circ} \mathrm{L}$

$00^{\circ} \mathrm{L}$

90.8

90.8

$\angle 0^{\circ} 8^{-}$

$\angle 0.8$ 
60:8L-

ย乙レ乙-

ยІวดว $78^{\circ} 9<\backslash$

हाOดO $9 L^{\circ} L L$

हIวดว 8t" LL

60 ㄴL

เ6.レ2L 乙9.9ZL

$\angle 0^{\circ} \angle Z L$

$\left.\angle \varepsilon^{\cdot} 8 Z L\right]$

Gナ6てL

乙レ'0ع -

乙乙'†हL

GL'GEL

LL'9EL

$6 L 8 \varepsilon$ L

レL'Gカレ -

E9 LGL 69เงレ

$6 L \angle 9 L-$

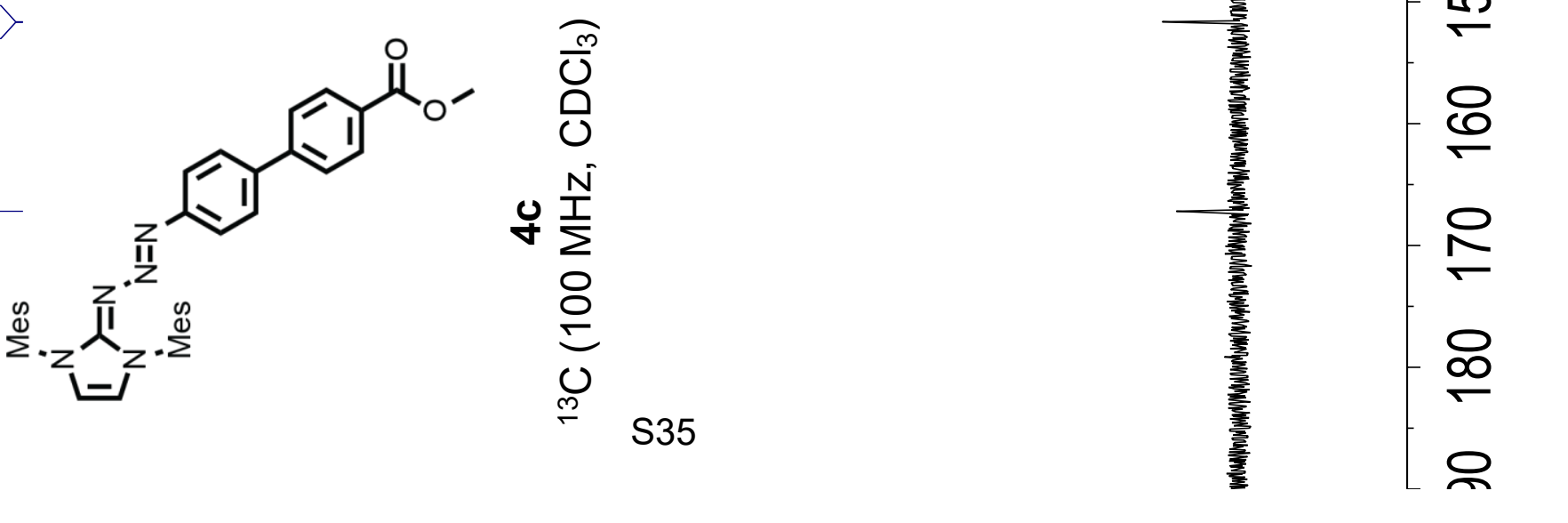



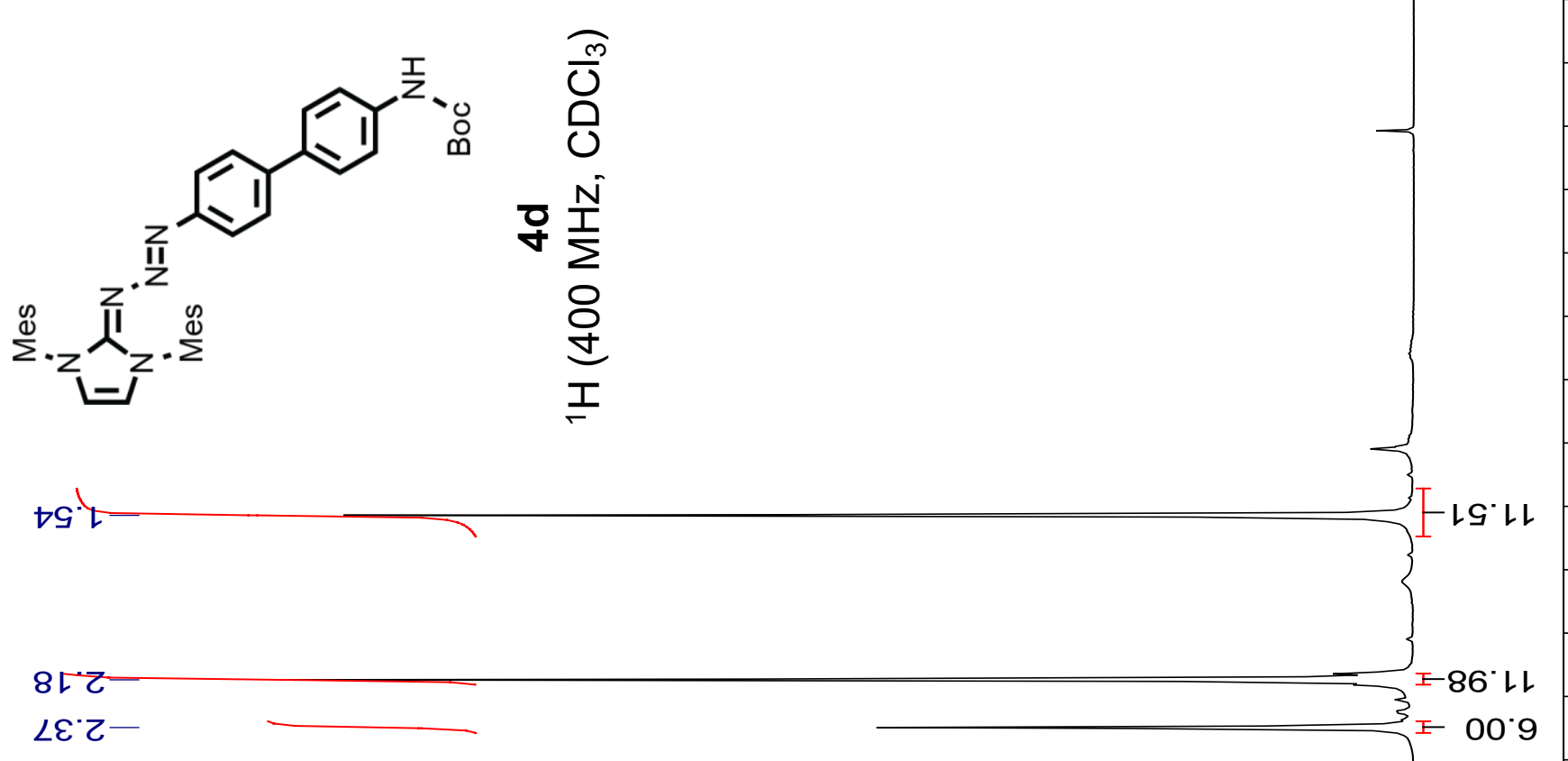

ㄴ?

N م m

누 ल

$\angle G^{\circ} 9$

$19^{\circ} 9$

$19^{\circ} 9$

$\varepsilon 9^{\circ} 9$

$\varepsilon 9^{\circ} 9$

$\varepsilon 9^{\circ} 9$

$00^{\circ} \mathrm{L}$

LC'L

ZC' $\angle$

$\varepsilon \mathcal{C Z}^{\prime}\llcorner$

$\varepsilon Z^{\prime} L$

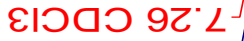

$8 \varepsilon^{\circ} L$

$O \nabla^{\circ} L$

$\nabla \nabla^{\prime} L$

Gt'L

$9 \nabla^{\circ} L$

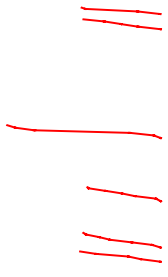


60:8レ-

O乙'レ乙-

งt・8Z-

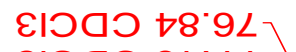

हागดว 91.LLT

हІวดО 8t" LL

ย6.9 L

68.8L ]

เ8เてL

$\angle \nabla^{\circ} 9 Z L$

$6 Z^{\circ} \angle Z L$

乙ヤ゙6てい

$8 \nearrow^{\circ} \nabla \varepsilon\llcorner$

$\angle L G E L$

乙o.9ع ᄂ

$\downarrow \varepsilon^{\circ} \angle \varepsilon L-$

$\angle 9^{\circ} \angle E L$

$0\llcorner 8 \varepsilon\llcorner$

GG'OGL

OLLGL

88.29L

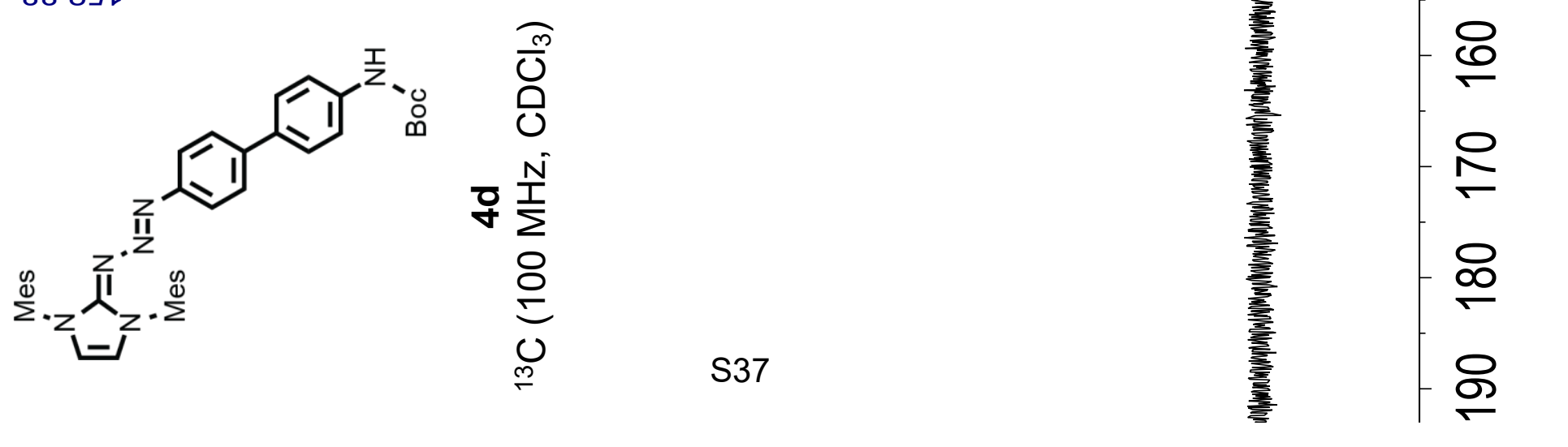




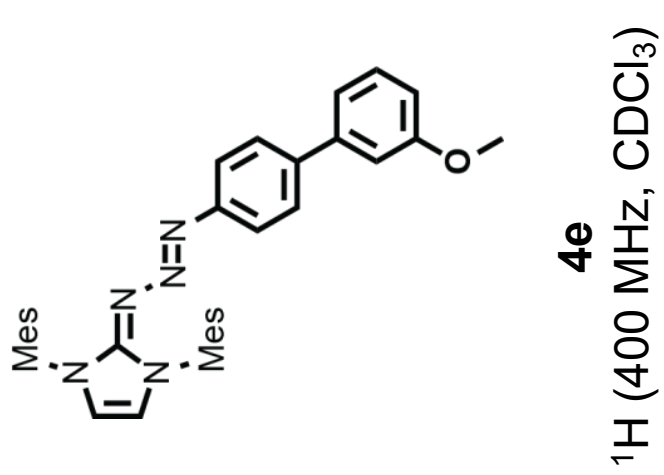

$98^{\circ} \varepsilon-$

$89^{\circ} 9$

ह9.9

99.9

$\downarrow 8^{\circ} 9$

$\downarrow 8^{\circ} 9$

$98^{\circ} 9$

$98^{\circ} 9$

$10 . \mathrm{L}$

$\left.90^{\circ} \angle\right]$

$\angle O \angle$

$\angle O \angle$

UL'

レレL

$\varepsilon L^{\circ} L$

$\varepsilon L L$

$\varepsilon L \cdot L$

ยІつดつ 9乙" L

OE. $L$

乙E. L

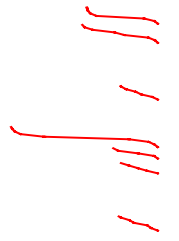


60:8L-

レてレー

SE'GS-

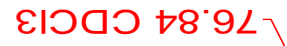

हIग0ว 9L'LL

हІวดО 8t" LL

Gててレン

て9てルレ

L6.9レー

Gオ・6ルー

GLレてL\&6.9Zレ

てヤ゙6てレ

89.6てレ

$\angle 乙 ゙ \nabla \varepsilon L$

9L'GEL-

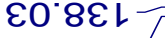

L $\angle 8 L$

ง8てヤレ

86.09L

乙L'LGL

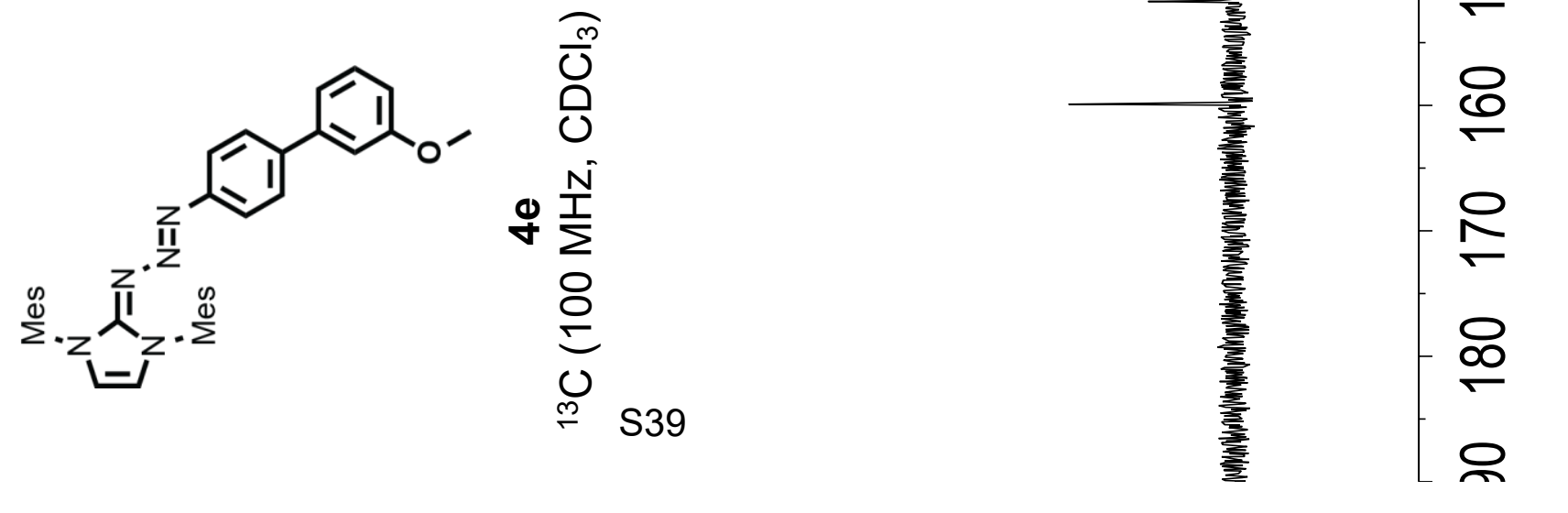

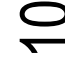

@

ल

$\vartheta$

ᄂ

8

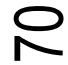

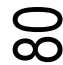

ᄋి $\frac{\bar{\varepsilon}}{\underline{2}}$

$8 \leftarrow$

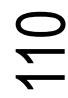

ح

F

ल

เ6.69レ- 


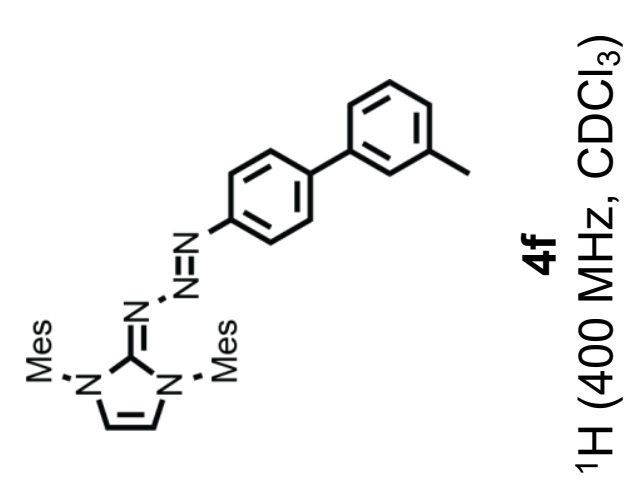

$6 \vdash z$

$8 \varepsilon^{\prime} 乙$
レナこ

$89^{\circ} 9$

ह9.9

๑9.9

S9.9

99.9

$10^{\circ} \mathrm{L}$

レLL】

EL $L$

ยા०ดว

9ट" $\angle$

$6 C^{\circ} L$

$6 C^{\circ} L$

L $\varepsilon^{\circ} L$

乙E' $L$

乙ย' $L$

$\nabla \varepsilon^{\circ} \angle$

$\nabla \varepsilon^{*} L$

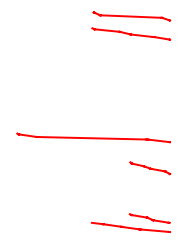

م

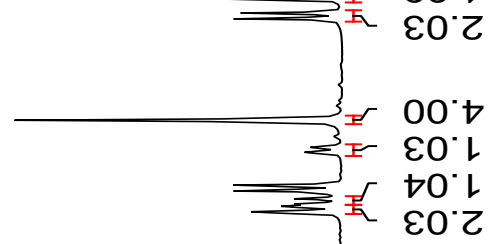

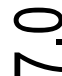


てレ8レ

ยてレ乙

69 เ乙

ยเวดว $\neg 8^{\circ} 9 L$

हाગดО 9L'LL

ยІวดว 8t LL

96.9レL

LL'LL]

$\varepsilon 0^{\circ} \nabla 乙 L$

$\varepsilon 6.9$ 乙

$\left.\varepsilon 9^{\circ} \angle Z L\right]$

$\varepsilon L \angle Z L \mathbb{L}$

ย9.8Zレ

ยヤ゙ 6乙レ

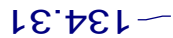

$\downarrow 乙 \cdot 8 \varepsilon\llcorner$

LE'8EL-

乙L'8EL

†ย゙レレレ

8LOGL

9L'LGレ

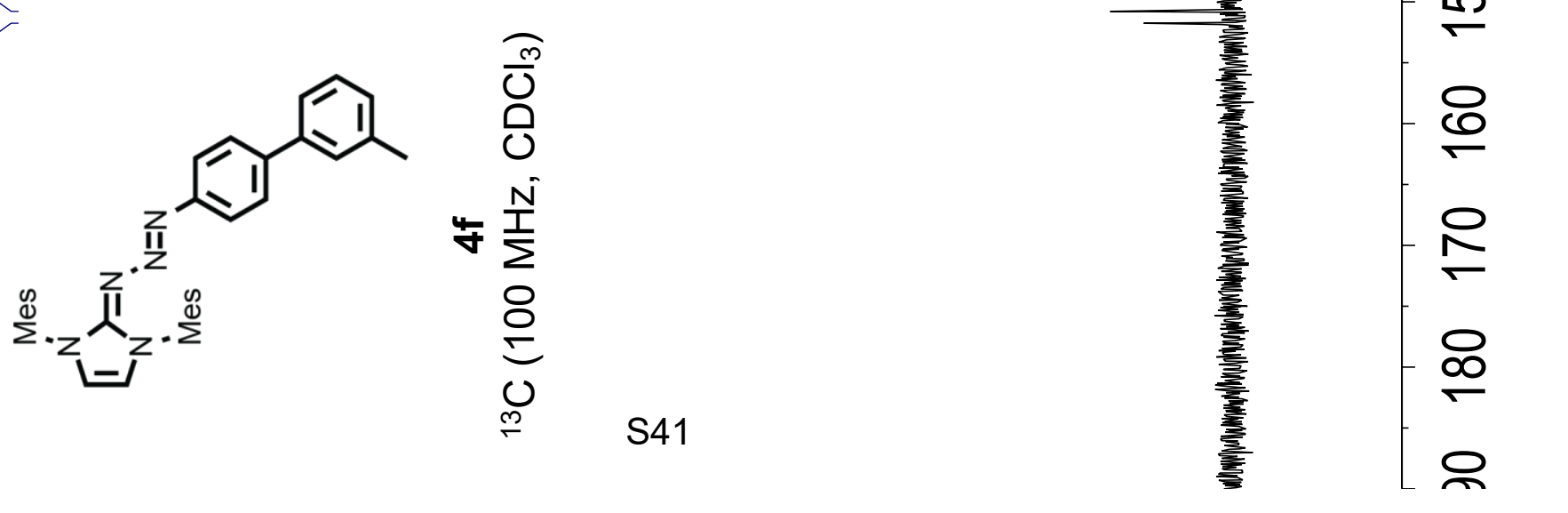




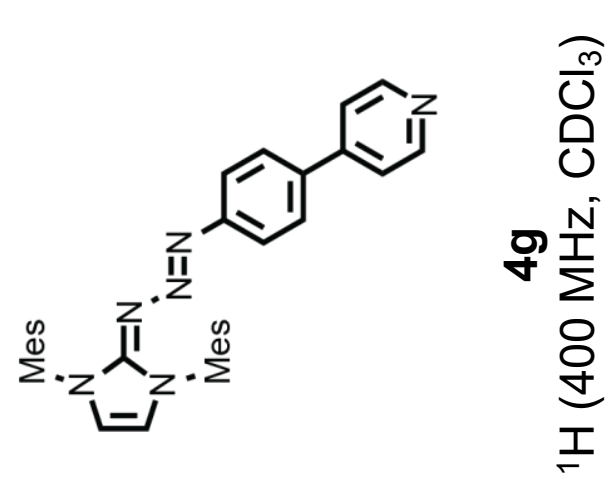

$8 \varepsilon \cdot 2$ 
$\angle 0 \% 8 L-$

ย乙レ乙-

ยІวดつ $78.94 \backslash$ हाOดว $9 L^{\circ} L L$

हागด 8t LL
8L $\angle L L-$ 6レレてレ 00ててレ 08.9Zレ 97・6てレ 9レ'†ยレ $6 G^{\prime} \nabla \varepsilon L$ 乙レ'Gとレー 乙8'8ع -

6己'8ヤレ 8LOGL 99เヒレ-

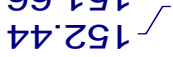

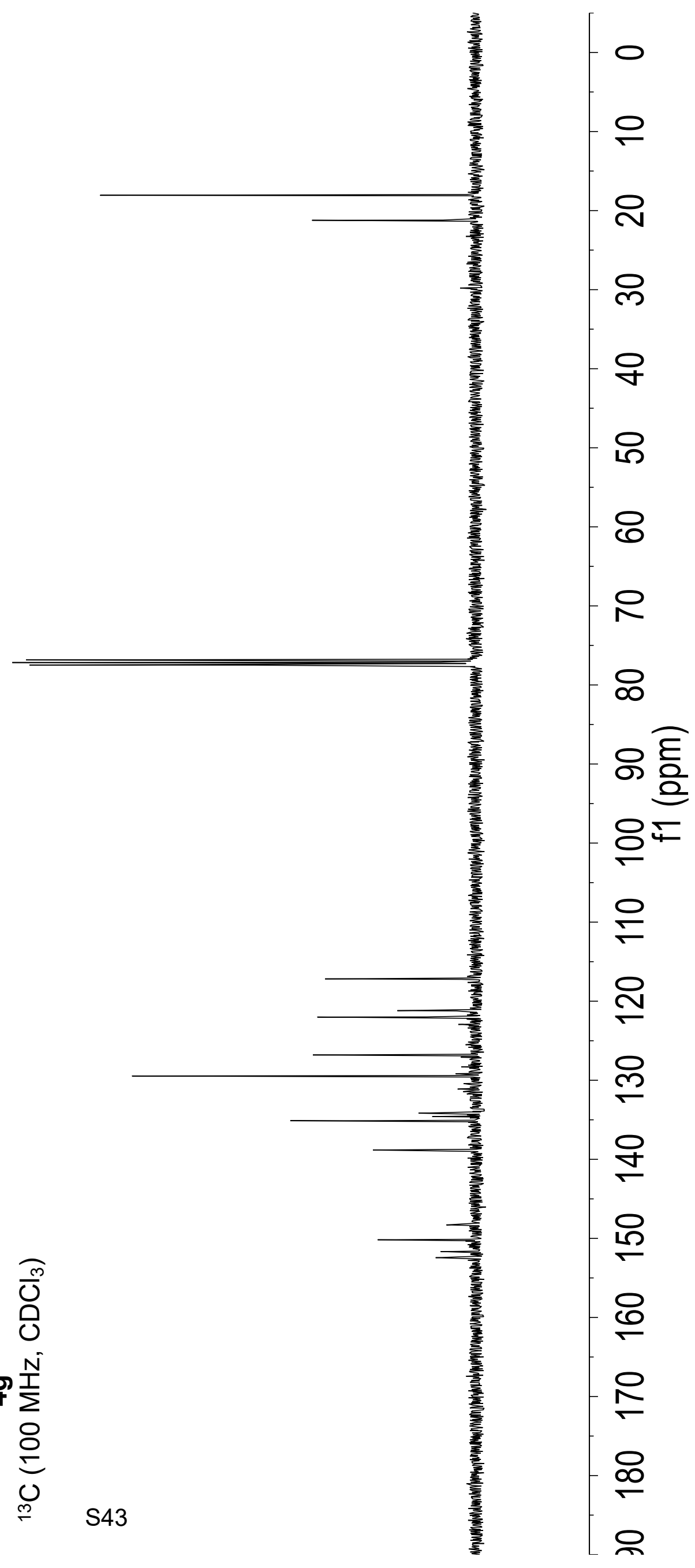




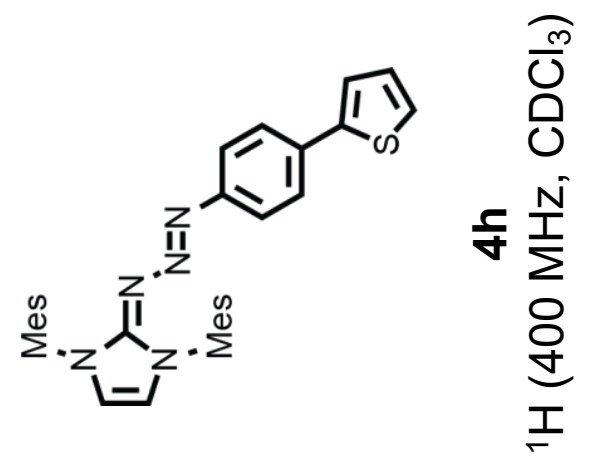

டレ゙】 $8 \varepsilon^{\prime} 乙$ $6 \varepsilon^{\prime} \overbrace{}^{\jmath}$

$69^{\circ} 9$

29.9 $00^{\circ} \mathrm{L}$ ᄂ ยІつดว 9乙" L $\varepsilon \varepsilon^{\prime} L$ $\neg \varepsilon^{\prime}\llcorner J$

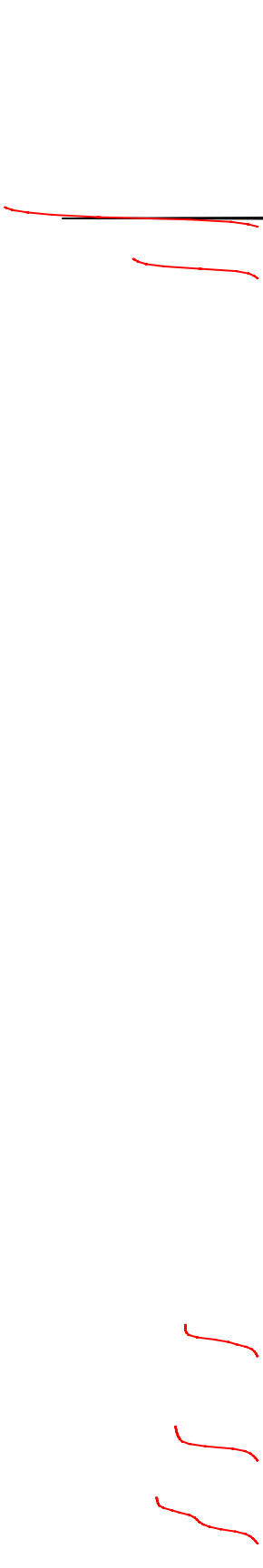

I 
Oレ・8L-

乙でし-

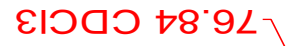

86.9レレ

レナ6レー เ8'レて 00.9ZL

†乙'9Zレ

9と'9乙レ

乙ヤ゙6てレ

乙0.ยとレ

$8 乙^{\circ} \downarrow \varepsilon\llcorner$

8L'GEL

L $\angle E L$

ยG'乙ヤレ

09.0Gレ

69.タレ

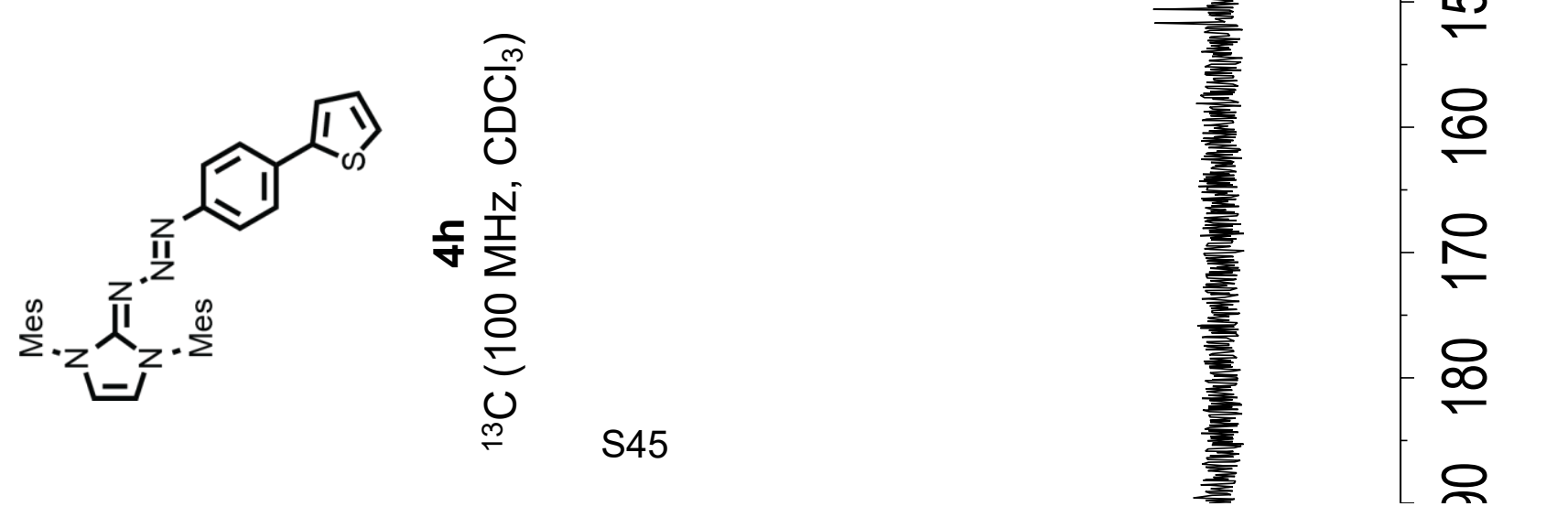




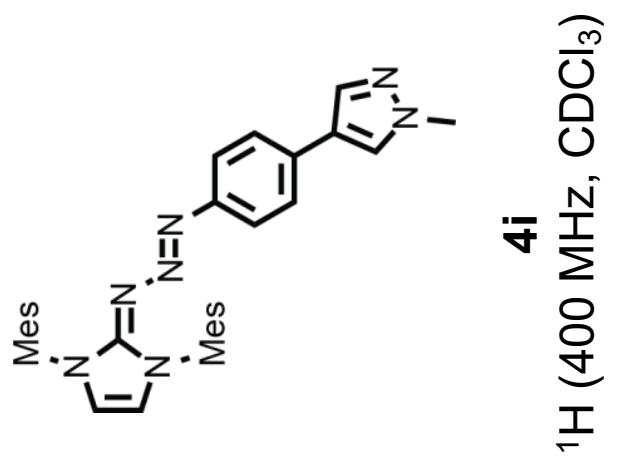

เ6 $\varepsilon-$

99. 9

$\angle G^{\circ} 9$

$89^{\circ} 9$

$89^{\circ} 9$

$86^{\circ} 9$

$00 \angle 1$

OLㄴ

乙L:L

$\varepsilon L \cdot L$

92"L]

$99^{\circ} \mathrm{L}$
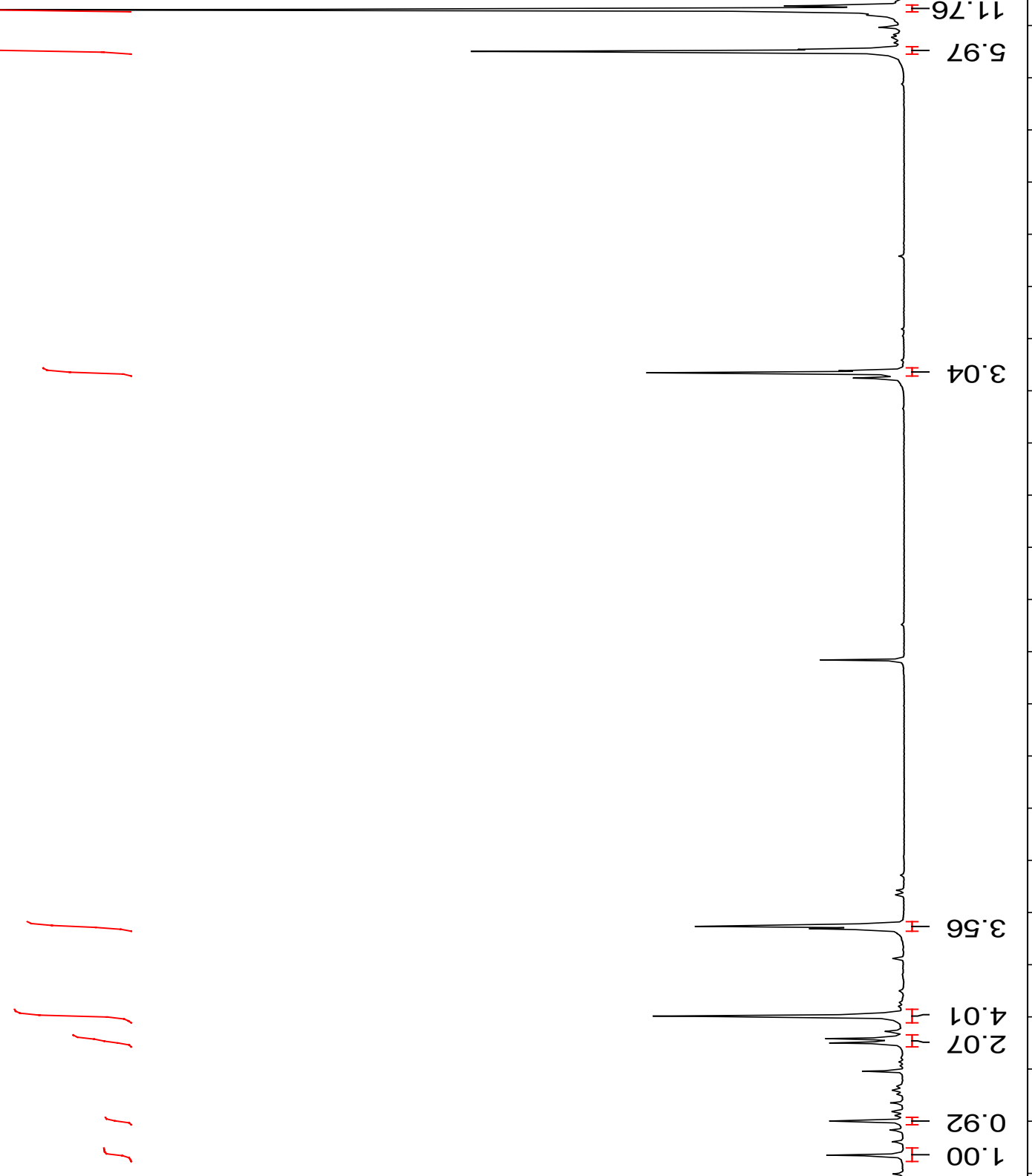

ก

0

น?

ल

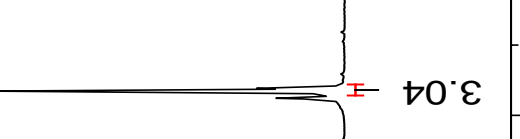

จ 눈

م:

ת

0 
OL8L-

乙でし-

GL $6 \varepsilon-$

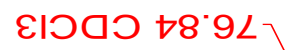

ยІวดว $9 L^{\circ} L L$

हІวดО 8t" LL

Z6.9ルレ

เ6เてL

งナ゙とて

oย'G乙L

†9.9ZL

レナ゙てレ

เ8.6てレ -

レヒ'†とレ

6 'GEL $^{\circ}$

89.9عᄂ

L9.8EL

66・6ヤレー

89.GL-

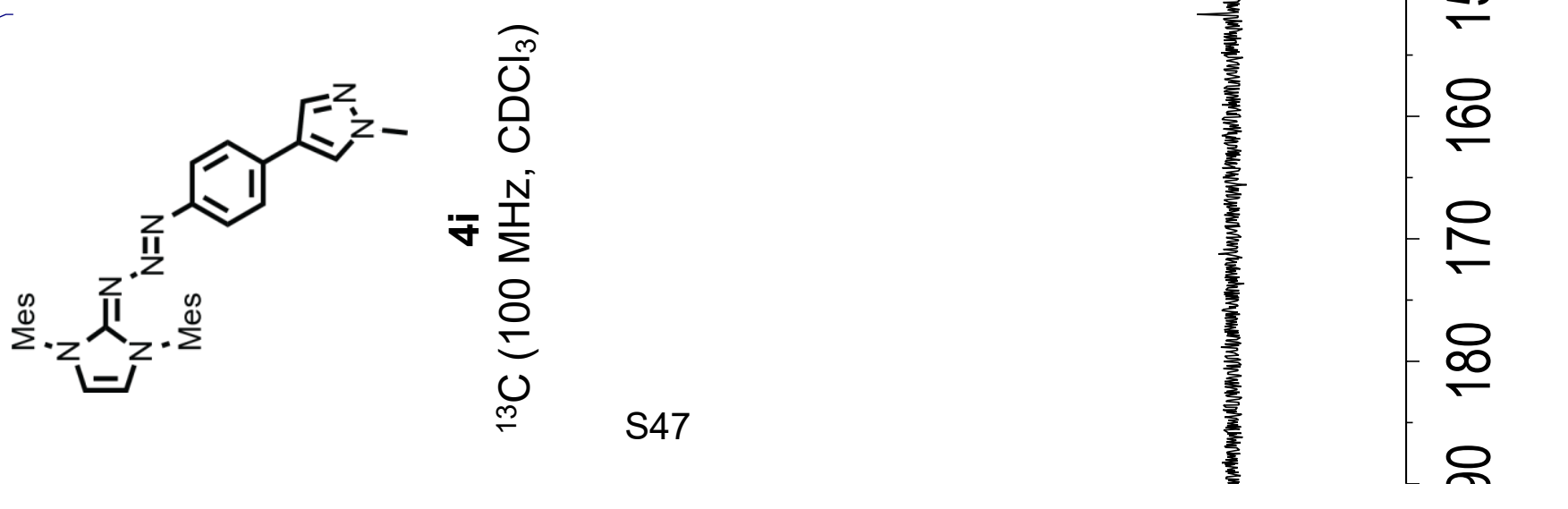




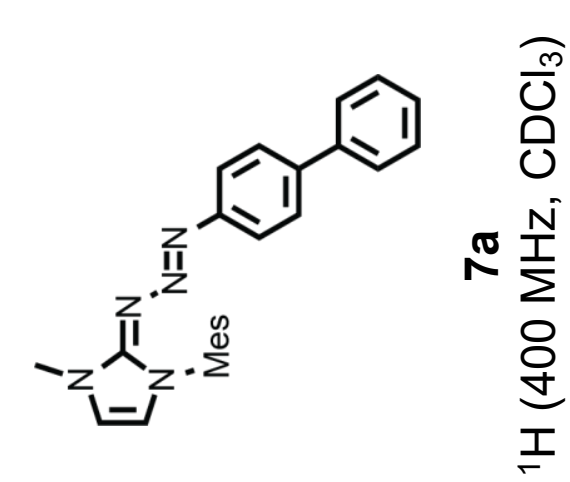

$\angle 0^{\circ} Z$

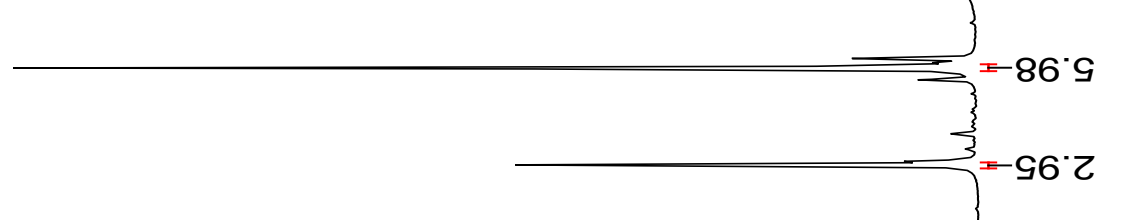

レナてー

$89^{\circ} \varepsilon-$

$\varepsilon \varepsilon \cdot 9$

† ${ }^{\prime}{ }^{-}$

89.9

$69^{\circ} 9$

乙L 9

GL' 9

LO L

ยІ०ดО 9乙" L

6己'LJ

LE: L

$L \varepsilon^{\circ} L$

$8 \varepsilon^{\circ} L$

$0 \nabla^{\circ} L$

乙ヤ" L

ZG' $L$

$\varepsilon G^{\circ} L$

EG'L-

$\nabla G^{\circ} L-$

GS $L$ 
ヤレ・8レー

๕乙レて-

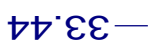

ยІวดว $\downarrow 8^{\circ} 9<>$

Gオ・9レレ]

19.9レレ
9L'レ乙L]

68 ててL

68.9ZL

Z० LZL

GL8ZL

$\angle \varepsilon^{\prime} 6 Z L$

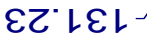

$\angle 9^{\circ} \downarrow \varepsilon\llcorner-1$

$\succ 0.9 \varepsilon L$

$6 \mathrm{C}^{\circ} 8 \varepsilon \mathrm{L}$

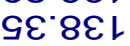

เどレレレ

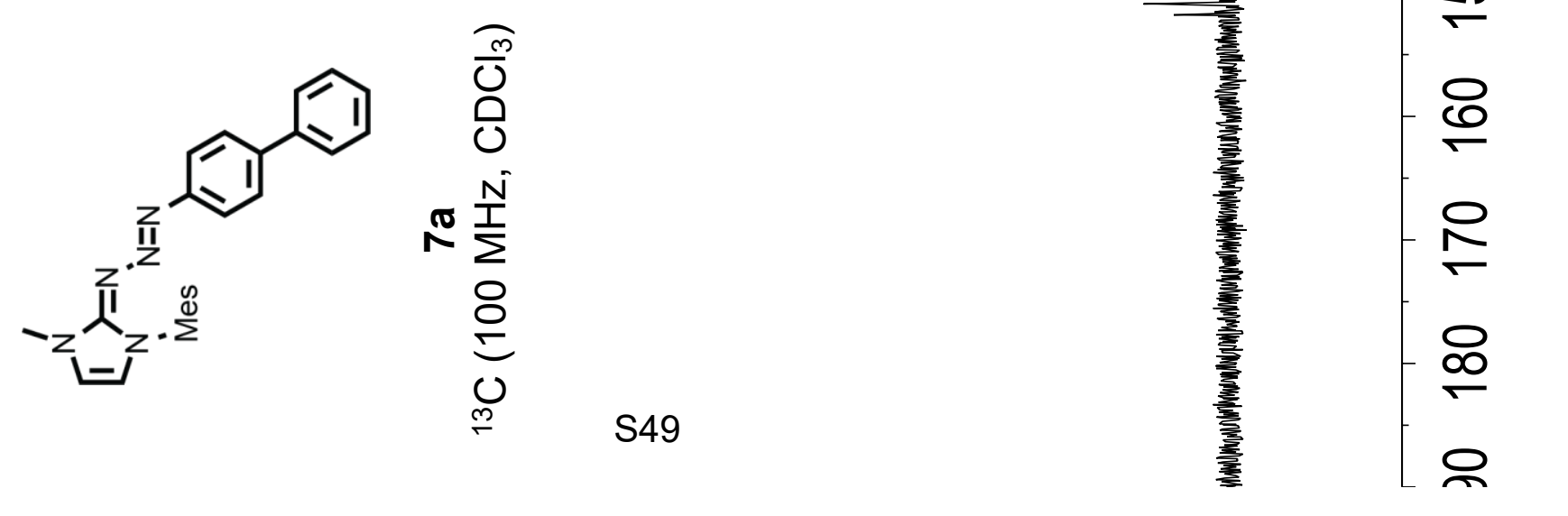




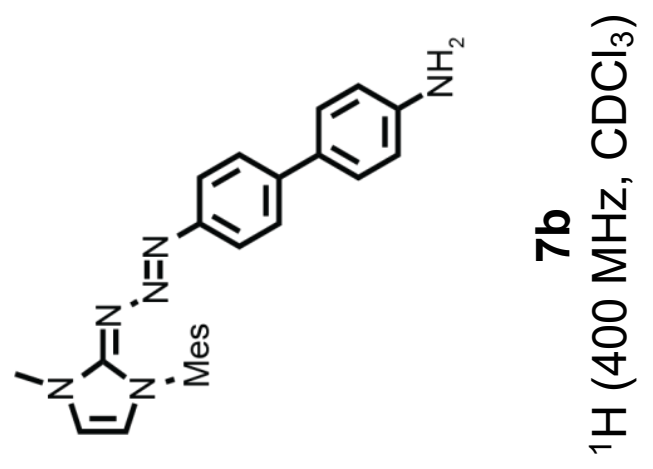

90て

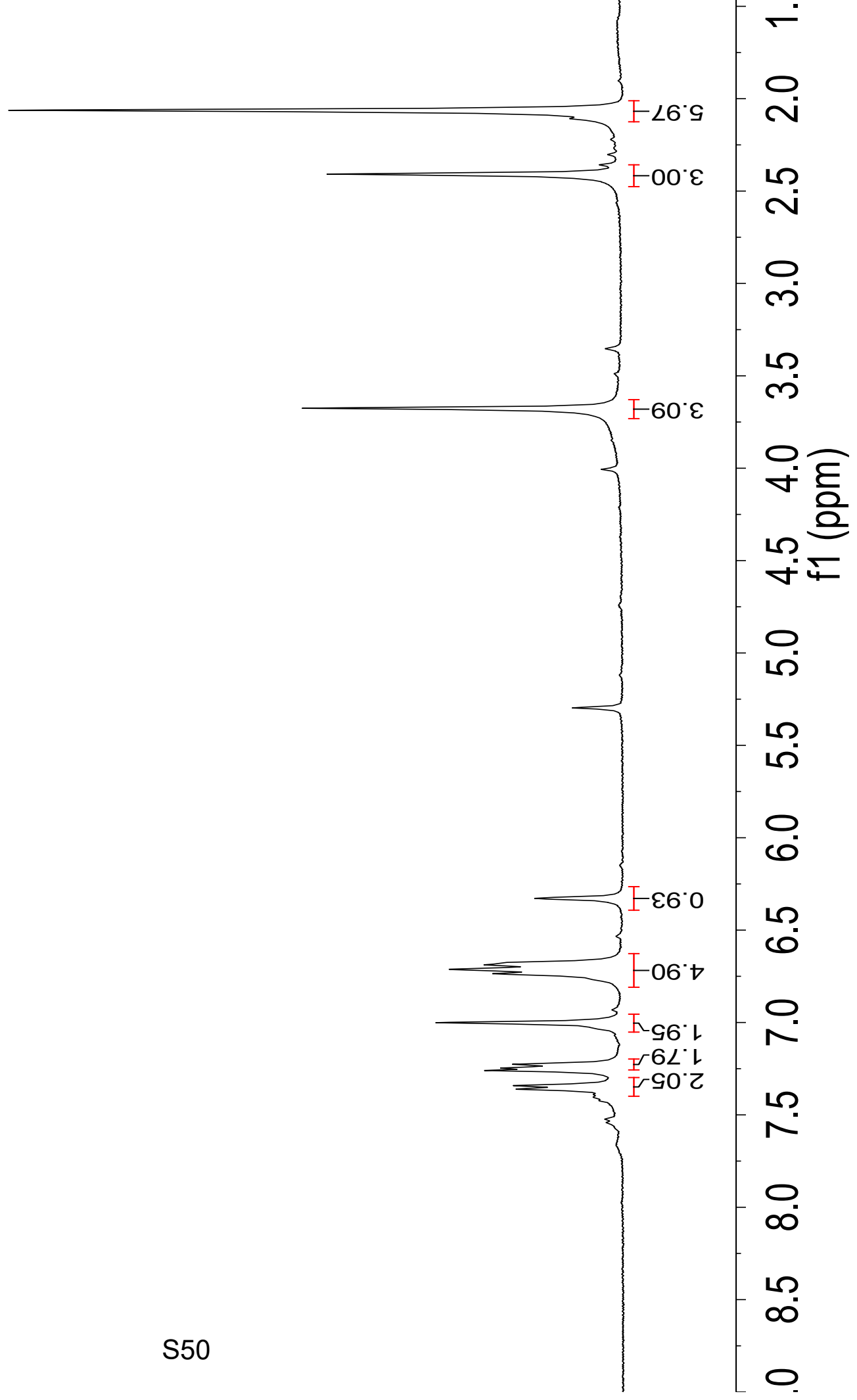

レナてー

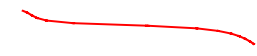

$89^{\circ} \varepsilon$

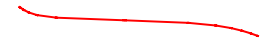

$\varepsilon \varepsilon^{\prime} 9$

89.9

$69^{\circ} 9$

LL'9

$\backslash<\cdot 9$

$00^{\circ} \angle$

$\varepsilon Z</$
Gट $\angle J$

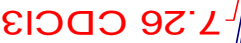

$\nabla \varepsilon^{\prime}\llcorner$

$9 \varepsilon^{\circ} L$ 
てレ・8L-

レ゙レてー

レナとと-

ยІวดว $\nabla 8^{\circ} 9<$

ยІวดว 9L 'LL

ยІつด 8t" $\angle L$

Gே゙ロレ

$8 \varepsilon^{\circ}$ 9 L

99.9レ

89.レL

6レ・9Zレ

$\angle \nabla^{\circ} 9$ Z

GL'LCL

$\angle 0{ }^{\circ} 8 Z L$

$\checkmark L \cdot 8 Z$ L

$\varepsilon \varepsilon \cdot 6 乙\llcorner$

$\angle 9^{\circ}\llcorner\varepsilon\llcorner$

$99^{\circ} \triangleright \varepsilon\llcorner$

$\downarrow 0.9 \varepsilon\llcorner$

$6 乙^{\circ} 8 \varepsilon \mathrm{L}$

0† $8 \varepsilon\llcorner$

09.9ヤレ-

†6'6ヤレ>

ELเルL -

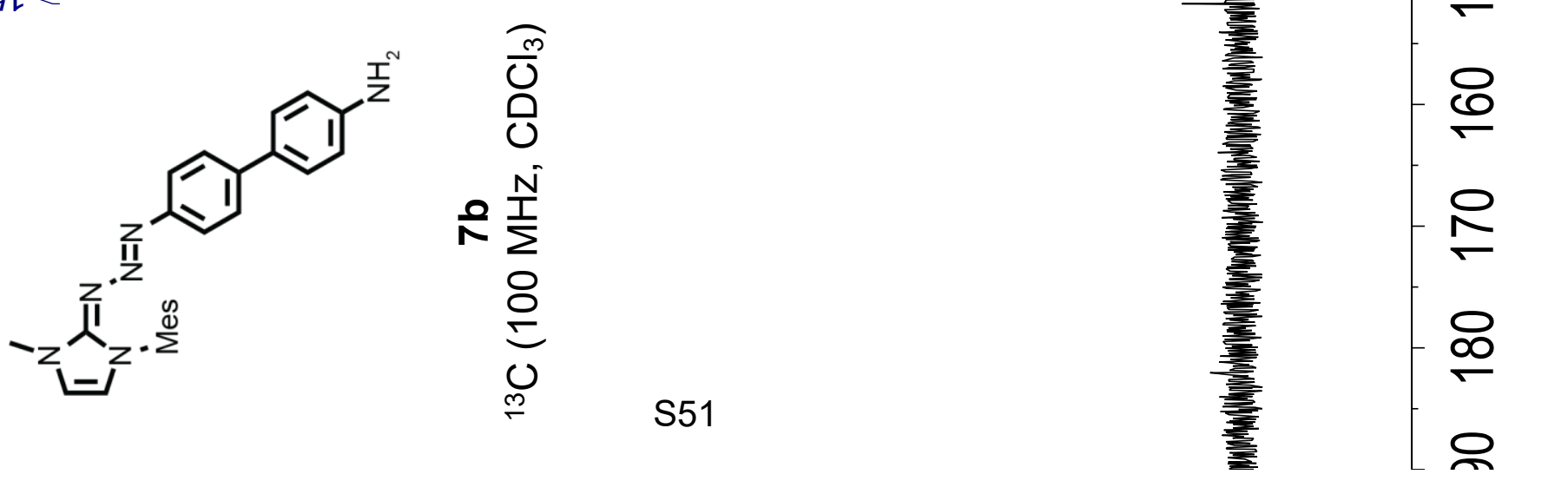



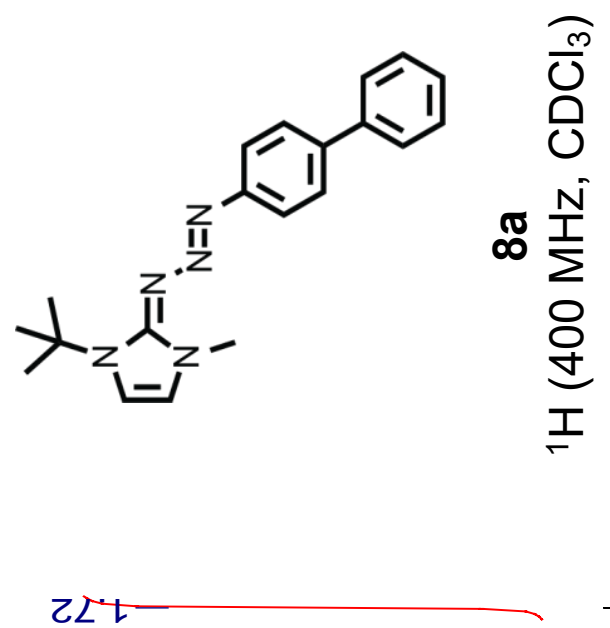

$\varepsilon 8^{*} \varepsilon-$

$6 \varepsilon^{\circ} 9$

Ot 9

乙L'9

$\varepsilon L^{\prime} 9$

ยІつดО $92^{\circ} \mathrm{L}$

$\left.0 \varepsilon^{\circ}<\right]$

乙E $\angle$

乙ち L

E七" L

99. $L$

$89^{\circ} \mathrm{L}$

$69^{\circ} \mathrm{L}$

$09^{\circ} \mathrm{L}$

$29^{\circ} \mathrm{L}$

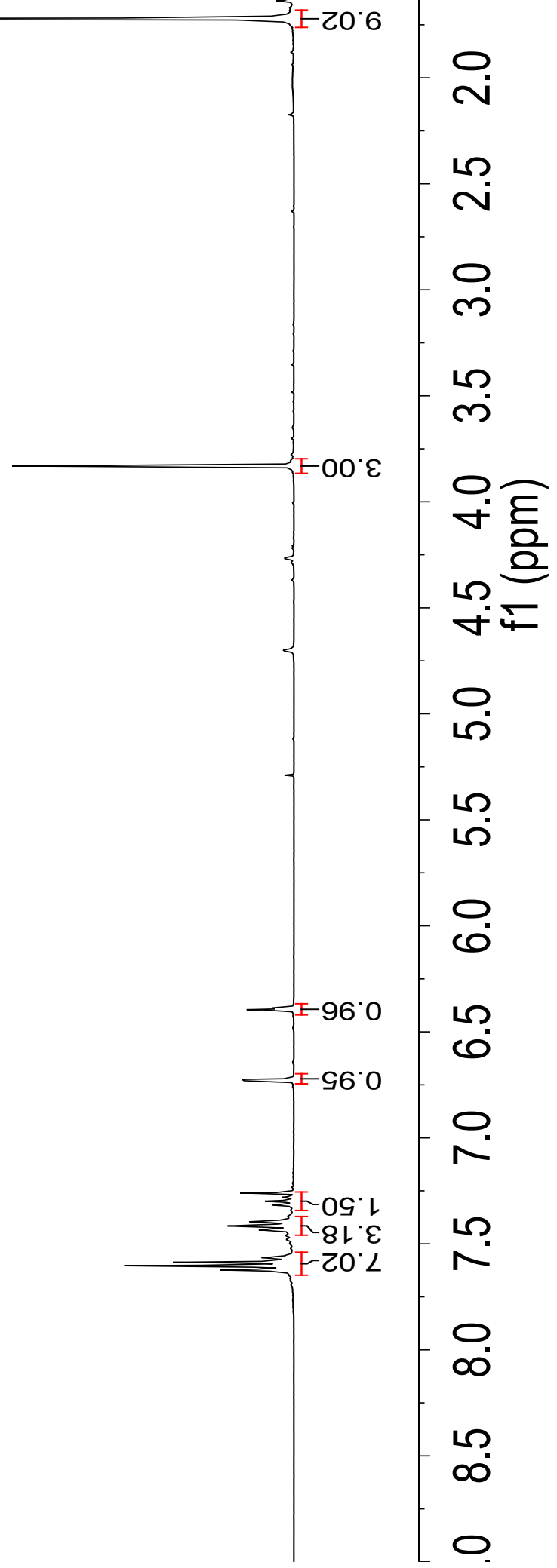


$00 \% 2-$

$82^{\circ} 6 \varepsilon-$

$89 \cdot 89-$

ยเวดว $\neg 8^{\circ} 94 \backslash$

हIग0 91.LL

ยІวดО 8t" LL

9でレケ

96.9レー-

L乙レ乙レ

68.9ZL

LG'LZL

6L'8Zレ

$\angle L \angle E L-$

と乙゙レレー

68.IS

เ8'て9レ

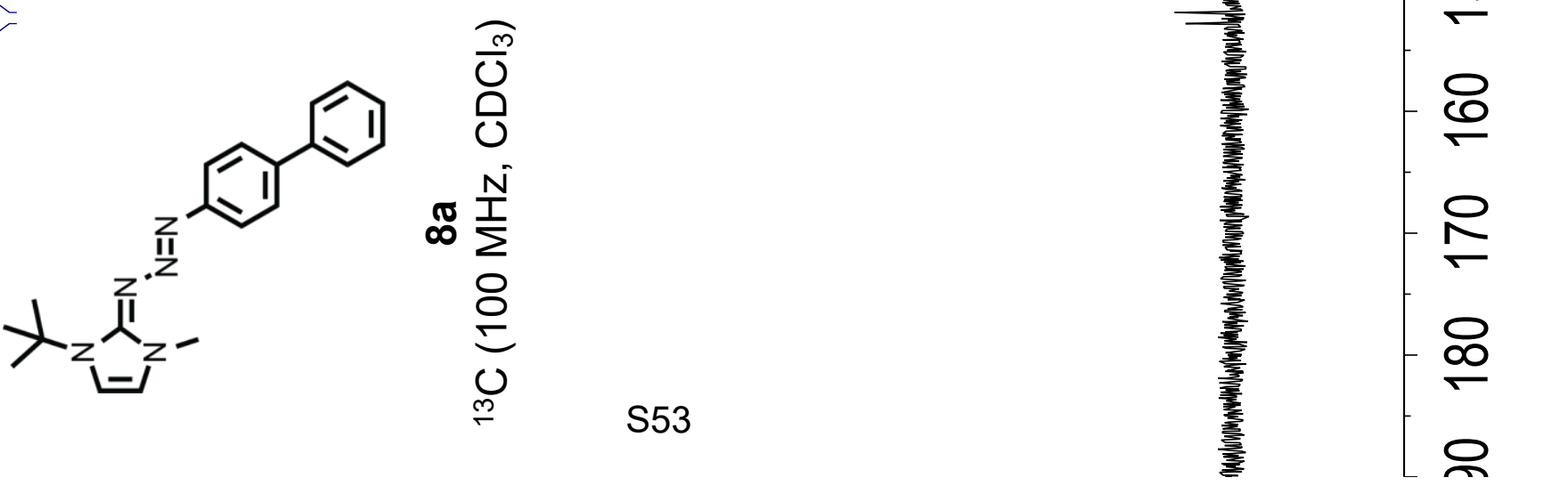




乙L'レ-

$\mathrm{P}_{\text {- }}$

乙8 ${ }^{*} \varepsilon$

$\angle \varepsilon^{\prime} 9$

$8 \varepsilon^{\prime} 9$

ᄂL. 9

乙L' 9

$\varepsilon L^{\prime}{ }^{\prime}$

$\downarrow L \cdot 9$

$G L 9$

$9 \angle 9$

ยાつつ 9ズ

$6 \varepsilon^{\circ}\llcorner$

Ot' $\angle$

乙ぢ L

ヤマ'し

OG' $L$

ZG' $L$

$\nabla G^{\circ} L$

$\angle G^{\circ} \angle-$

69" $\mathrm{L}$

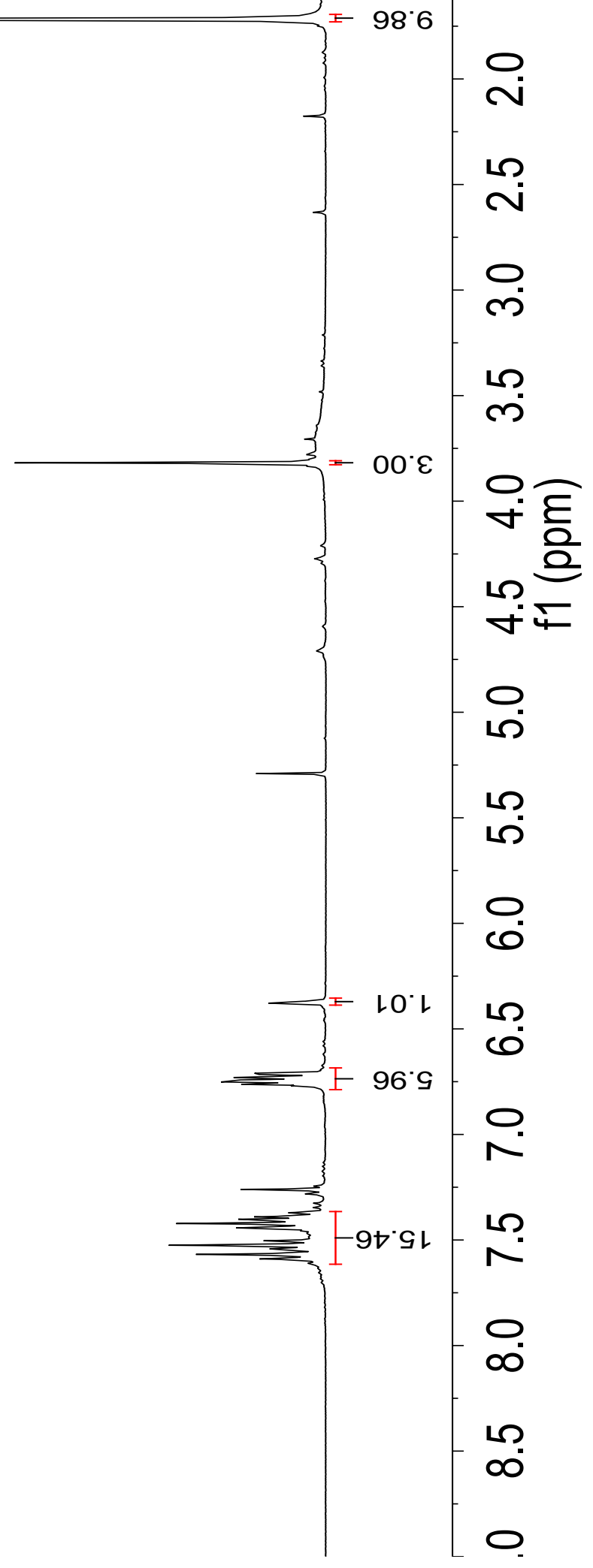


$\angle 6^{\circ} 82-$

$\angle Z^{*} 6 \varepsilon-$

29'89-

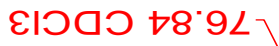
ยІวดО 9L'LLY

हा)ดО 8t $\angle L$
8レてレレ

8t'Gルレ

06.9L

Oでレて

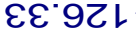

8t.9ZL

89.9ZL

$\checkmark L$ LCL

60.8ZL

GL'8ZL

ย9เยレ

$26^{\circ} \angle \varepsilon L^{\prime}$

9でレレー

69"Gャレ

68.0Gレ-

9LててGレ-

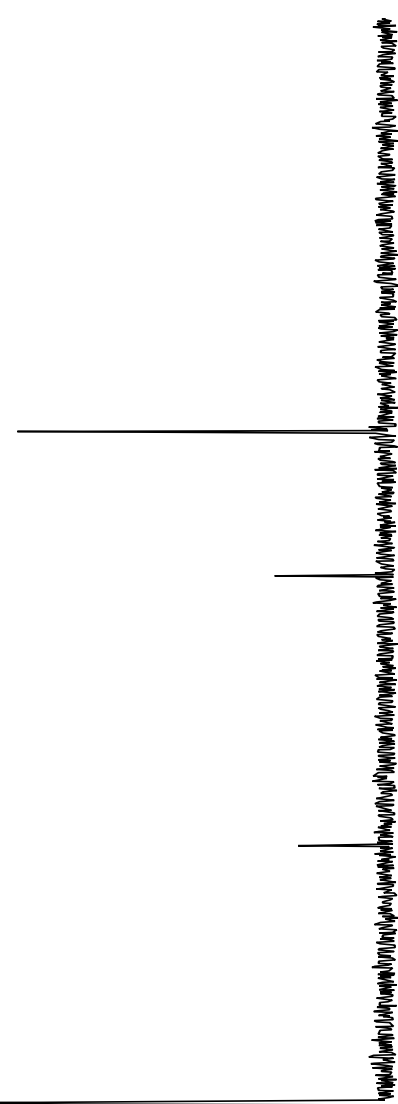

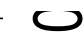

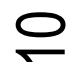

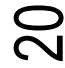

ल

$\vartheta$

ᄂ

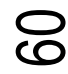

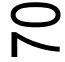

$\infty$

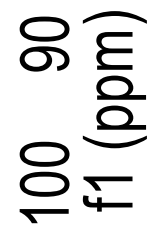

F

$\vartheta$

ल

$\vartheta$

을

ฮ

$\mathcal{N}$

8 


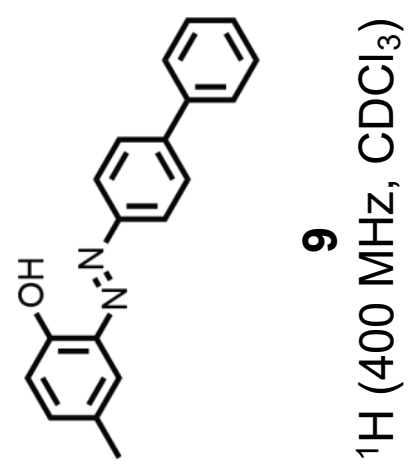

レナてー

$76{ }^{\circ} 9$

$96^{\circ} 9$

$9 \mathrm{~L} L$

$\angle L^{\circ} \angle$

8L L

6レL

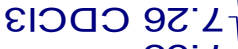

$8 \varepsilon^{\circ} L$

$0 \nabla^{\circ} L$

乙ヤ゙ L

$\angle \nabla^{\circ} \angle$

OG' $L$

$9^{\circ} \angle$

$99 \angle$

$\angle 9^{\circ} \angle$

$89^{\circ} \angle$

$\varepsilon L \cdot L$

$\checkmark L$

$G L L$

9L' $\angle$

$\angle L L$

$\nabla 6^{\circ}<$

$\checkmark 6^{\circ} \mathrm{L}$

$96^{\circ} \mathrm{L}$

$96^{\circ} \angle$
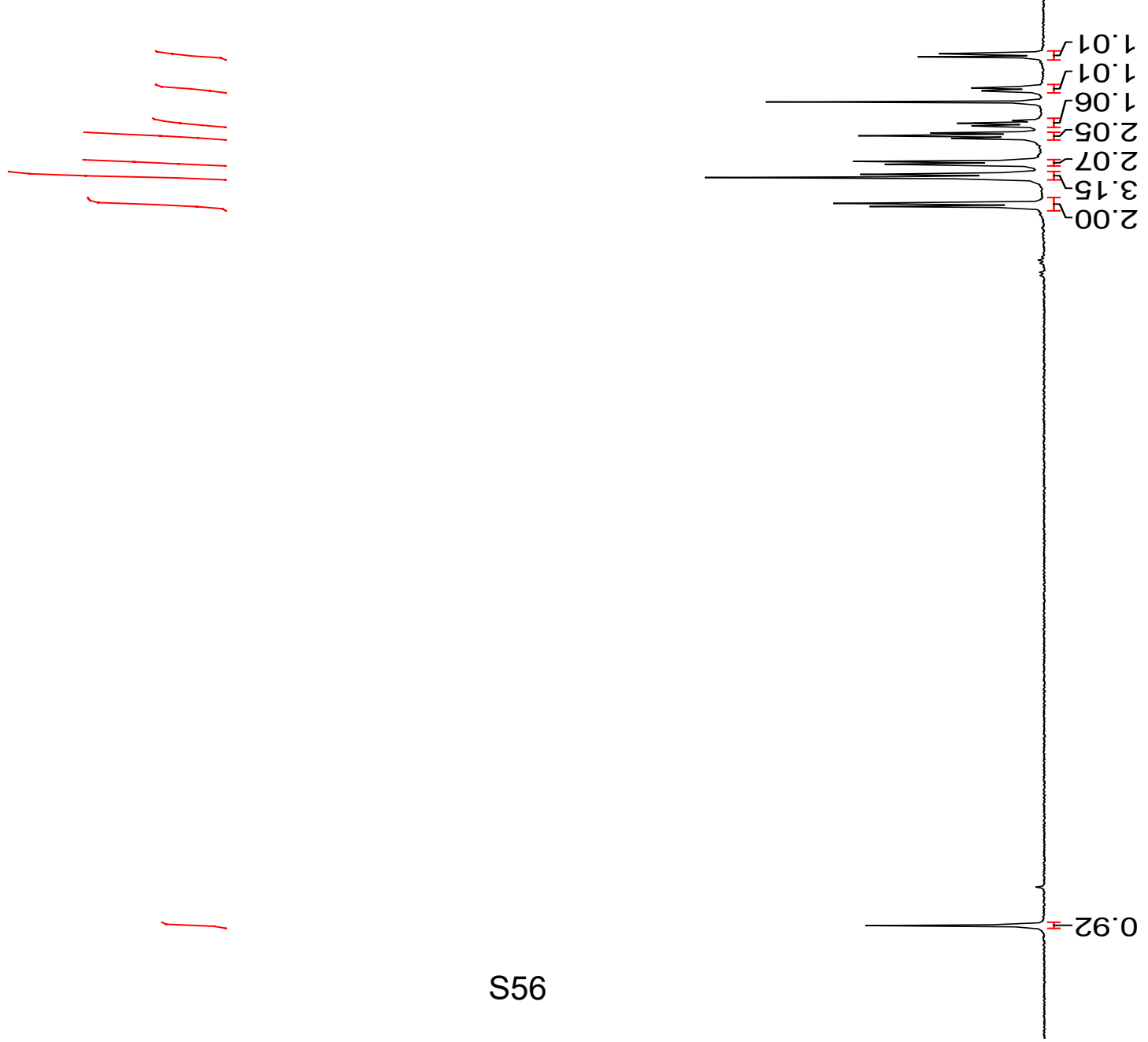

ㄴ?

눈

ก)

눈

ก

(1)

으응

누

N

$\infty$

")

ᄂ

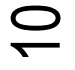

둘

ᄂ

N

늠 
$8 t^{\circ} 02-$

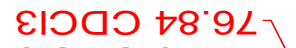

เ08ルー ย8ててレ L $\varepsilon^{\circ} \angle Z L$ $\angle L 8 Z L$ 60.6ZL 8ध'6乙レ $60^{\circ} \varepsilon \varepsilon\llcorner$ Oヤ"७ยレ $\downarrow \varepsilon^{\circ} \angle \varepsilon\llcorner$ 乙レ゚ロレ 96"とヤレ 26.6ヤレ OL'OGレ

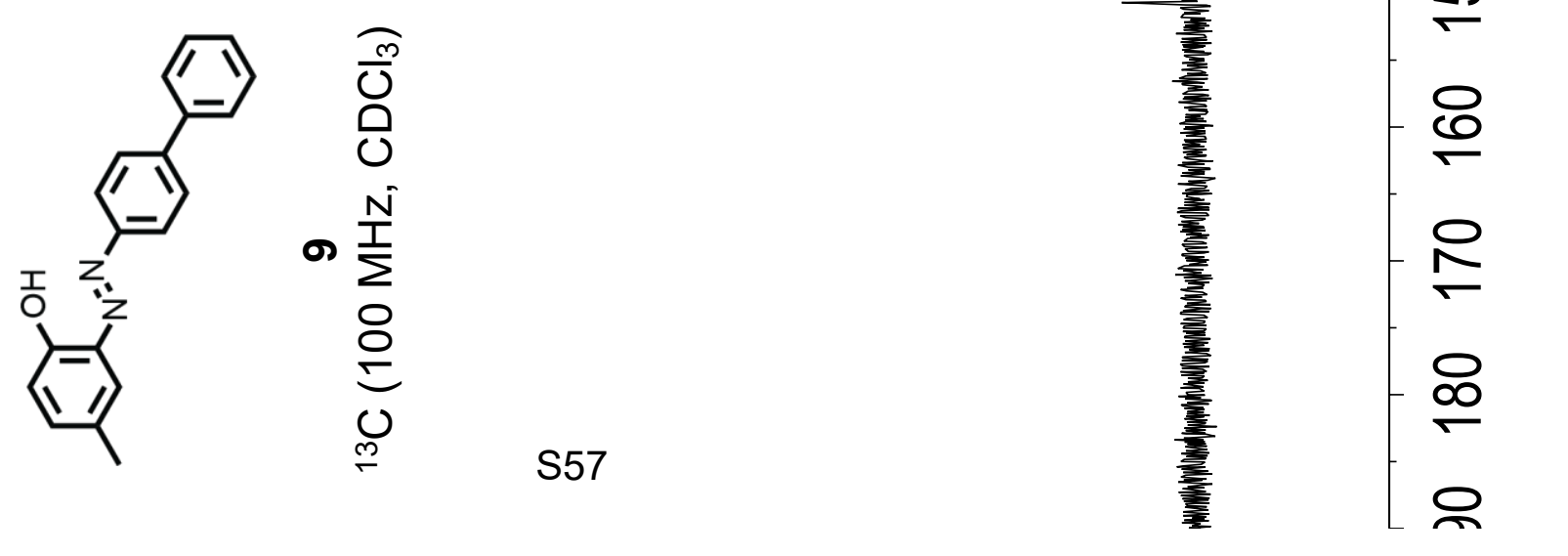

